University of Louisville

ThinkIR: The University of Louisville's Institutional Repository

Electronic Theses and Dissertations

$8-2020$

\title{
Exploring black "saviors": a content analysis of black characters and racial discourses in Obama-era films.
}

Eric A. Jordan

University of Louisiville

Follow this and additional works at: https://ir.library.louisville.edu/etd

Part of the African American Studies Commons, Ethnic Studies Commons, and the Visual Studies Commons

\section{Recommended Citation}

Jordan, Eric A., "Exploring black "saviors": a content analysis of black characters and racial discourses in Obama-era films." (2020). Electronic Theses and Dissertations. Paper 3500.

https://doi.org/10.18297/etd/3500

This Doctoral Dissertation is brought to you for free and open access by ThinkIR: The University of Louisville's Institutional Repository. It has been accepted for inclusion in Electronic Theses and Dissertations by an authorized administrator of ThinkIR: The University of Louisville's Institutional Repository. This title appears here courtesy of the author, who has retained all other copyrights. For more information, please contact thinkir@louisville.edu. 
EXPLORING BLACK "SAVIORS": A CONTENT ANALYSIS OF BLACK

CHARACTERS AND RACIAL DISCOURSES IN OBAMA-ERA FILMS

\author{
By \\ Eric A. Jordan \\ B.A., University of Louisville, 2014 \\ M.A., University of Louisville, 2016 \\ $\mathrm{PhD}$, University of Louisville, 2020

\begin{abstract}
A Dissertation
Submitted to the Faculty of the

College of Arts and Sciences of the University of Louisville in Partial Fulfillment of the Requirements for the Degree of
\end{abstract}

\author{
Doctor of Philosophy \\ in Applied Sociology \\ Department of Sociology \\ University of Louisville \\ Louisville, Kentucky
}

August 2020 

EXPLORING BLACK “SAVIORS”: A CONTENT ANALYSIS OF BLACK

\section{CHARACTERS AND RACIAL DISCOURSES IN OBAMA-ERA FILMS}

By

Eric A. Jordan

B.A., University of Louisville, 2014

M.A., University of Louisville, 2016

PhD, University of Louisville, 2020

A Dissertation Approved on

July 27, 2020

by the following Dissertation Committee:

Melanie Jones Gast

Karen Christopher

Oliver Rollins

Derrick R. Brooms

Siobhan E. Smith-Jones 


\begin{abstract}
EXPLORING BLACK “SAVIORS”: A CONTENT ANALYSIS OF BLACK

CHARACTERS AND RACIAL DISCOURSES IN OBAMA-ERA FILMS
\end{abstract}

Eric A. Jordan

July 27,2020

This dissertation analyzes how black characters across twenty movies released in the years 2006-2018 inspire, coach, "save," or "rescue" other characters. Studies on "savior" characters in film tend to focus on white savior characters who seek to "save" people of color from harm. When comparing black characters and white saviors, I find that black characters use three specific strategies - revolution, vigilantism, and altruism - to help other characters. The characters who use the revolution and vigilantism strategies seem to be what I call "black saviors" who work to fight against institutional and systemic racism to save the black diaspora. Altruistic characters seem the most similar to white saviors. I end by discussing my findings and their connection to past literature on race, class, gender, and colorblindness, and I discuss implications for social change.

Keywords: controlling image, film, intersectionality, Obama, racism, white savior 


\section{TABLE OF CONTENTS}

PAGE

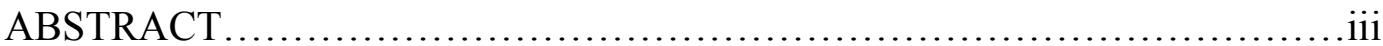

CHAPTER I: INTRODUCTION .........................................

Black Savior Key Elements.......................................4

What the Study Adds to the Literature............................6

Why Film?..................................................... 8

Dissertation Layout...........................................11

CHAPTER II: LITERATURE REVIEW ............................... 13

Paternalism and Power............................................... 15

Paternalistic White Savior Characters................................16

Hegemonic Masculinity and Paternalism.............................19

Messianic Masculinity and Black Paternalism.......................20

The Production of Culture..........................................23

Intersectionality and Controlling Images.............................24

The White Savior Trope: Neoliberalism in Cinema....................26

The White Savior Trope: Whiteness and Post-Racial Theory..............29

The Evolution of the Magical Negro Trope............................. 36

Characteristics of the Traditional Magical Negro.........................39

Activism and Revolution..........................................40 
Vigilantism

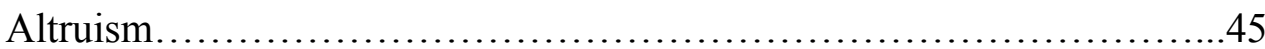

CHAPTER III: METHODOLOGY ......................................48

Sampling Phase ...................................................48

Data Collection Phase................................................55

Coding and Data Analysis Phase....................................57

Qualitative Content Analysis......................................58

Grounded Theory...............................................62

How I Incorporated Grounded Theory and Content Analysis..............65

Methodological Issues.........................................68

CHAPTER IV: THE REVOLUTIONARY .................................70

Revolutionary Messiahs........................................72

Revolutionary Activists...........................................74

Messiahs and Hegemonic Masculinity.................................. 76

Black Male Poverty, Stereotypes, and Re-Appropriation of Violence......83

Women Activists and the Acquisition of Knowledge....................86

The Male Activist and Access to Power...............................98

The Black Revolutionary as a Counter-Narrative to Whiteness............101

CHAPTER V: VIGILANTE HEROES...................................111

Masculine Vigilantism................................................112

Male Vigilantes: Defending the Vulnerable.............................114

Vigilante Males, Superheroism, and Stereotypes of Violence............121

The Female Vigilante: Violence as Liberation.......................... 123 
Mary, the Othermother.......................................... 128

Individualistic Vigilante Heroism......................................135

CHAPTER VI: THE ALTRUIST ......................................... 140

Teachers........................................................... 142

Parents...............................................................

Fathers and Father-Figures............................................ 144

Mothers and Mother-Figures........................................145

Altruistic Characters: Authoritative Male Teachers.....................146

Altruistic Characters: Authoritarian Fathers...........................151

Sons with Emotions, Fathers Without..............................155

Altruistic Teachers: Humanitarian Women.............................157

Altruistic Characters: Humanitarian Mothers, Mammies, and Sapphires164

Mammies, Sapphires, and Magical Negroes..........................170

Filmic Altruism: Benevolence, Colorblindness, and the New Racism...176

CHAPTER VII: DISCUSSION \& CONCLUSION...........................179

Summary of Black Savior Characters................................180

Black Saviors and Malleable Controlling Images.....................182

Black Saviors: Reinforcing Controlling Images and the "New Racism"186

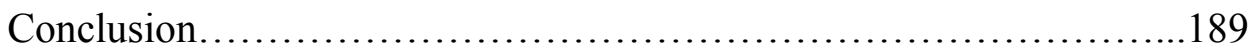

Limitations of the Study............................................192

Recommendations for Future Research.............................194

Final Words...................................................... 196

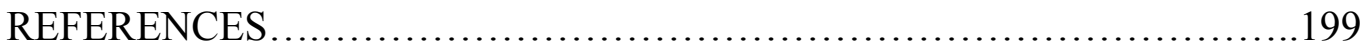


APPENDICES.....................................................216

CURRICULUM VITA................................................221 


\section{CHAPTER I}

\section{INTRODUCTION}

Many films during 2009 to 2017 , when Barack Obama served as the $44^{\text {th }}$

President, addressed issues of race through the post-racial frame of "colorblind individualism," which minimized the effects of systemic racial inequalities on people's lives (Izzo 2015; Rajakumar and Saiyed 2015; Sanchez-Escalonilla and Mateos 2016). Colorblind individualism developed, in part, from the fact that Obama was an upper-class black man whose upward mobility was predicated on his "hard work" that enabled him to embody the American Dream (Hughey et al. 2015; Dovidio et al. 2015; Izzo 2015; Bonilla-Silva 2017; Burke 2017). Due in part to his presidency, several black characters in film were depicted as having power and control over others, emulating Obama's authoritative and charismatic ethos as a leader who knew what was best for America (Izzo 2015; Sanchez-Escalonilla and Mateos 2016). Obama's presidency, and the portrayal of black characters as powerful figures in film, was believed by some to be tangible proof that America had moved beyond its racist past.

Because of the particular brand of colorblindness that developed during the Obama era, and how the dominant theme of "race" was depicted in movies at the time, I argue it is important to look at powerful, heroic, influential, and/or paternalistic black characters in Obama era films. Looking at these characters helps us understand how they have been used in cinema to discuss and/or challenge notions of race and racism. From 
the colonial image of the noble savage to the more modern magical negro trope, black characters have historically been portrayed in embarrassing and dehumanizing ways with very little variety. However, this study advances the research on magical negro characters by showing that black characters can be more than servants and sidekicks - they can be "heroes" and "leaders" as well. Since the number of images of black people as "heroes" and "leaders" supposedly increased during Obama's presidency, I look at black characters in films that were released slightly before, during, and slightly after Obama's presidency to understand the ways in which those black characters acted as "heroes" and "leaders" for others, and the implications of their "heroism" and "leadership."

Many studies of filmic heroism focus on the implicit racism within the "white savior trope," and thus the tenets of a "white savior", are well-known such as the character's paternalistic desire to "help" people of color in need because those people supposedly cannot help themselves. The focus on whiteness, and paternalism exhibited by white people, demonstrates a cultural and academic fixation on whiteness as the source of paternalism in film and "salvation," giving whiteness a lopsided emphasis in media discourse about racial redemption. Unlike past studies, this study explores black male and female main characters in the Obama era, and how those characters add to our knowledge about "salvation" and race in film. Additionally, this study takes a novel approach to studying black main antagonist and protagonist characters in film by using an intersectional approach to explore the similarities and differences between black male and female characters, and the ways masculinity and femininity influence their representations. Therefore, this study advances the discussion of filmic "salvation" by 
looking past white saviors and at black characters in positions of power who might be also play a "savior" role. This study asks three primary research questions:

1. How does a black character's class and gender influence how they rescue, save, inspire, guide, or redeem other characters in Obama-era films from 2006-2018?

2. How are their acts of rescuing, saving, inspiring, or redeeming similar to or different from white saviors?

3. What are the implications of these similarities or differences?

To answer these questions, I employ grounded theory to qualitatively analyze, and theorize, paternalistic black characters across twenty films from 2006 to 2018. I include 2006 and 2018, two years before and after Obama's presidency, because Obama was a known political figure in 2006 and remained so in 2018. Additionally, the years 2006 and 2018 are used to accommodate for the "lag" in production time necessary to make and release a movie. The beginning of the first year of his presidency, may have actually gone into production in 2006 or 2007 when his campaign was just starting. According to the Motion Picture Association (2018), it takes 871 days on average to make a movie, which is about two years. This study accommodates for this amount of time. Movies released in 2008 were probably in production in 2006 and 2007.

By answering the aforementioned research questions, I explain the similarities and differences between white saviors and black characters who may occupy a "savior" role across race, gender, and class lines, and how race and gender combine to influence how black characters "save" or are positioned as a "saviors." The first goal of the study is to provide an analysis of black paternalism in film that analyzes how race, gender, and class influence the manifestation of paternalism. The second goal is to shift academia 
away from understanding whiteness as the only vehicle for "redemption" and "salvation" narratives. The third and final goal is to further Patricia Hill Collins' (2000) discussion of controlling images by showing that controlling images are highly complex and not nearly as one-dimensional and all-encompassing as she originally theorized.

In this study, I argue that, similarly to how films portray paternalistic white savior characters as virtuous redeemers and heroes, black characters in film can also work similarly to white saviors to save or rescue poor, uneducated, low-income, and urbanized black characters from harm, punishment, or oppression. In other words, I argue that black characters in film can occupy a "savior" role similar to their white counterparts. I find that black characters who work to "redeem" or "empower" others utilize three main strategies of revolution, vigilantism, or altruism to achieve their goals of: liberating black people from global systems of racial oppression, saving them from local criminals, or helping them become their "ideal" selves by encouraging them to make "better choices." The characters who use these strategies fall into three specific character archetypes: revolutionaries, vigilantes, and altruists. Each archetype has a different approach to making social change, from addressing systemic racism to helping other characters make "better" social choices, which influences how each character is portrayed. "Black saviors" are all paternalistic, just in different classed and gendered ways compared to white saviors. Additionally, each character represents a different controlling image.

\section{Black Savior Key Elements}

"Black savior" characters work to "save" other characters from some type of harm. How each character "saves" others depends on what "type" of racism they are fighting (interpersonal, institutional, or systemic). How a "black savior" helps a character 
is generally associated with a character's class position and gender. The poorer a "black savior" is portrayed, the more likely he or she is to use tactics meant to help people that address institutional and/or systemic inequalities. For example, revolutionary characters, work to save black populations by eliminating those responsible for large-scale oppression of black people (which correlates with criticizing institutional and systemic racism) either through engaging in terroristic violence (for men) or through protests (for women). Some "black saviors," like vigilantes eliminating specific individuals who harm their communities which indirectly makes social change.

If a character is portrayed as being of a higher class, that character is more likely to use tactics to help people that are meant to address the "faults" of the individual. For example, altruists use their morals and compassion to work at the individual level to "save" others by encouraging them to make different life choices. The "black savior" character is highly complex and nuanced by a character's characteristics and motives. I argue that revolutionary characters in the sample are the archetypal "black saviors" who work to "liberate" all black characters in their respective films from systemic racial oppression by eliminating government and state actors that are complicit in oppression. Vigilantes and, to a much lesser extent (if at all), altruistic characters, also reflect some of the traits of the "black savior" character. The portrayals of each of these character archetypes might bring up the question of whether "black saviors" are just $21^{\text {st }}$ century versions of "magical negroes." However, I argue the "black savior" and magical negro are different characters.

Magical negroes tend to be poor and represent negative stereotypes like: welfare queens, uneducated voodoo priestesses, the mentally challenged, impoverished janitors, 
prisoners, the homeless, mammies, Jezebels, and Uncle Toms (Hughey 2009). Magical negroes are "magical" because they possess some mystical abilities that enable them to help white people. Each of these tropes demonstrate that the main function of black characters is to empower, assist, or please white characters, and some of the black characters in this study reinforce this supposed function. The difference between the "black savior" revolutionary and vigilante, and the magical negro trope, is that magical negroes often lack agency and often are not the focus of their respective movies. I argue that "black savior" characters do have agency and are more-or-less the focus of their films. Therefore, "black saviors" and magical negroes are not similar which will become more apparent as I discuss magical negroes in more depth in upcoming sections.

\section{What the Study Adds to the Literature}

The main contribution of this study, is that this study frames black agency, behaviors, and portrayals in film as evidence of their roles as "saviors." This shifts focus away from black characters as simple "magical negroes" or other stereotypes and controlling images which portray blacks without power and agency. Black characters in film are regularly sublimated in favor of the white savior trope which positions blackness as inferior to whiteness. Thus, white savior narratives tend to erase black perspectives and agency. An analysis of black characters who operate as, or perceive themselves as, "redeemers" and "heroes" in film will provide a more nuanced look at how blackness can be free from depictions of whiteness in the contemporary era, and how black people may act in saving roles without adhering to the tenets of the magical negro trope.

Additionally, I qualitatively assess the presentation of black men and women in twenty "mainstream" movies, released in the years 2006-2018, who are considered 
leaders and/or agents of justice for other people of color. In doing so, I add to, and in some ways contradict, Patricia Hill Collins' discussion of “controlling images” by explaining how the stereotypes assigned to these characters are actually not static, onedimensional, or "tenacious" as Collins (2000) describes them. As I will explain in upcoming chapters, black characters in Obama-era film seem to reject and conform to controlling images due to the nuances and complexities of their characterizations and motives.

By focusing on black characters in roles that allow them to supposedly act in the "best interest" of the people they interact with, this study complicates the portrayal of filmic "heroes" and "saviors" as a uniquely white phenomenon. This study focuses its attention on black main protagonists and antagonist characters who are the focus of their movie narratives, which is something most studies do not do since they tend to focus on the role black characters - who often act as supporting characters - play alongside their white counterparts in the same movie. Thus, another one of this study's contributions to the literature is that it provides a nuanced examination of the aforementioned themes to generate a broader understanding of black heroism's connection to race, gender, and class power dynamics as they are portrayed in films with redemption stories. As mentioned, this study takes a gendered approach to understanding black characters, which is important because women are often left out of the discourse on "salvation" or "paternalism" in film. Black characters, especially female characters, who behave in ways similar to white saviors have only been implied, never explicitly conceptualized or theorized, in the popular film and television literature. 
While there are numerous depictions of white saviors that exist, there are not many depictions of "black saviors" in the culture. As a result, social science has given little attention to non-White "saviors" in modern cinema, and the literature does not expand much beyond its typical whiteness to include a discussion of how, or if, black characters have a place in the conception of a "savior" in film. I am not suggesting that I want more "paternalistic" black characters in film, given what paternalism represents. I am also not saying that being a "savior" is inherently a good thing in film. What I am saying is that I see an opportunity to reframe how we look at black characters in film in general outside of their typical characterizations as sidekicks, comedy relief, black best friends, and magical negro servants.

\section{Why Film?}

This study focuses on films because of their wide reach and growing popularity. The film industry has been one of the largest sources of entertainment and has remained one of the largest, oldest, and most profitable culture industries in the world (Motion Picture Association of America 2018). For example, in 2018 Hollywood film generated 11.9 billion dollars in domestic box office revenue, and sales have steadily increased since 2005. According to the Motion Picture Association of America (2018), "movie theaters drew more than twice as many people as all theme parks and major U.S. sports combined (baseball, basketball, hockey, and football)." This resulted in 1.30 billion dollars in tickets sold (Motion Picture Association of America 2018:16). Three-quarters of the U.S. population aged two and older, or 263 million people, went to a movie at the cinema at least once in 2018, and the typical moviegoer bought 5 tickets per year in 2018 (Motion Picture Association of America 2018:24). In 2018, spending on digital home 
entertainment increased 24 percent compared to 2017, while movie subscription spending increased 28 percent compared to 2017 (Motion Picture Association of America 2018).

The popularity of movies makes it a powerful agent of socialization and an important site of academic inquiry especially as the industry continues to grow. Additionally, films can reflect the culture of the time period in the United States and all over the world. This reflection of the culture makes movies powerful discursive forums in which issues such as race, class, and gender intersect within characters who interact with other characters. These interactions create intersectional "texts" that may mirror our values and morals through the reproduction and distribution of dominant ideologies of racial domination and subordination (Kellner 1995; Glenn and Cunningham 2009; Hughey 2009, 2012; Holtzman and Sharpe 2014).

Film is a powerful agent of socialization that influences how people perceive the world. Films provide guidelines on how to properly behave and think, and they show people the rewards for their behaviors and thoughts (Silverblatt 2004). It is not unreasonable to suggest that the bulk of our interactions with diverse groups are likely to come in the form of vicarious contact via media, substituting for the lack of direct experience (Gunter 1987; Mastro 2015). This is especially plausible when considering the rates of media use in society by young people. Nearly $70 \%$ of infants in the United States spend over two hours per day in front of a screen watching a movie or television show (Rideout, Vandewater, and Wartella 2003). U.S. adults spend nearly twice as much time watching videos and movies as infants do with an average of five to six hours (Nielsen 2012; Motion Picture Association of America 2018). These patterns extend beyond America with consumers in Greece, Serbia, Macedonia, Puerto Rico, Turkey, and Italy 
averaging at four to five hours of video per day (Nielsen 2012; Motion Picture Association of America 2018). People live movie-saturated lives, making it difficult for audiences to recognize the influence of exposure on perceptions of reality. Accordingly, movies have a profound effect on our views on diverse groups. The presentation of racial or racist tropes, narratives, and presentations in movies helps people develop racial identities for others and for one's self (Mastro 2015).

Through their narratives, tropes, and character archetypes, films create and transform how we view gender, class, and race. Films have real consequences on how we navigate understandings of ourselves and others. Films about white saviors are subtle, yet powerful, propaganda tools that help socialize people into dominant racial hierarchies and worldviews. The effects of these kinds of films can be largely attributed to the massive reach they have, which makes them an important way to examine and understand the popular constructions of race relations in the United States. Thus, movie narratives and representations take on unprecedented importance.

However, another question arises from this study's focus: why only film and not television or a similar media source like comic books, novels, video-games, or even music that may contain "savior" narratives and/or themes? Films are one-shot narratives that are easier to systematically code, thus making them less methodologically "problematic" than a television series or other media would be. For example, most television shows contain several seasons with several episodes. Within these episodes, certain characters may evolve into paternalists as the series progresses - this introduces a series of methodological conundrums. As I mentioned, films are a huge media industry and have large reach. Films also allow for character development in a single story, which 
can greatly influence how audiences understand the social rewards or punishments of certain character choices and behaviors. Characters in television shows have greater room for complexities.

\section{Dissertation Layout}

The following sections in this study are laid out as follows: first, Chapter II draws upon sociological literature to provide an in-depth review of paternalism, and how other scholars across disciplines have conceptualized white savior films and their connection to theories of paternalism. Chapter III lays out this study's implementation of qualitative content analysis and grounded theory to answer the aforementioned research questions, and what, and how, data was collected for analysis using these methods. Chapters IV, V, and VI detail the study's most salient findings concerning the archetypal characters (revolutionaries, vigilantes, and altruists respectively) and the strategies these characters use to redeem, rescue, and/or empower others. Finally, Chapter VII synthesizes my findings from the previous three chapters into a theoretical exploration of the potential nuances of a "black savior" trope and its theoretical implications, and how the concept complicates Collins' discussion of controlling images. The following literature review goes into more depth about previous studies on race, racial representation, concepts, and theories on the magical negro and white savior tropes that may speak to the nature or existence of "saviors" in the media and how those concepts are relevant to the study. To study how black characters in film can act as leaders and heroes, it is important to understand paternalism and how the concept relates to white saviors. 


\section{CHAPTER II}

\section{LITERATURE REVIEW}

Paternalism refers to instances in which a person acts on behalf of another person or group of people for their own good or the belief of serving the person's or group's interests (VanDeVeer 1986). Paternalists believe that they know, and can do, what is best for other people in need. In contrast, people in need are perceived as not really knowing what is "good" for them, thus justifying paternalism and creating "paternalistic relationships" in which a paternalistic person — a "paternalist"- — socially engages with a person or group for which he or she is working for. In an effort to help people, paternalists often place limitations on the person's personal freedoms or choices (Mill 1956; Kleinig 1983; Sartorius 1983; Dworkin 1972, 2002, 2005, 2012, 2013). As a result, paternalism involves some degree of power and benevolence, but this benevolence manifests from a sense of obligation to intervene on behalf of people in need. As Blumer (1951) explains, paternalism is,

"[A] sense of responsibility and of obligation for the welfare of the worker is the most outstanding mark of paternalism. It is a tempering influence on the mere proprietary and control relationship and imparts to that relationship a personal and benevolent character" (p.6).

Jackman (1996) explained that paternalism was created by white men as a mechanism of social control rooted in an ideological system, fraught with contradictions, that stemmed from a combination of domination and benevolence. VanDeVeer (1986) defines paternalistic acts as those "in which one person, $A$, interferes with another person, $S$, in 
order to promote $S$ 's own good" (p.12). VanDeVeer ruled out callousness or maliciousness as a motive for paternalistic acts. What makes an act "paternalistic" is the intervening party's "presumptive claim to a superior understanding of the subject's best interests than the subject may possess him- or herself" (Jackman 1996:12). Thus, a paternalist is thought of, or thinks of himself, as superior in some way to his subjects, and this superiority gives the paternalist power and authority.

Paternalism raises several moral questions about freedom and society's obligations to its citizens, and citizens's obligations to each other and society. Any moral arguments for paternalism must offer compelling reasons to justify the restriction of freedom and autonomy. A paternalistic actor is thus defined by (1.) an un-interested, benevolent intent, and (2.) a presumption of greater moral competence than the subject of his or her intervention (Jackman 1986; VanDeVeer 1986; Pogge 2008). These criteria reveal that paternalism is defined by the justifications used to impose it, and the justifications determine the "type" of paternalism that is used (Dworkin 2002).

One type of paternalism is hard paternalism, in which paternalism is "justified" regardless of the subject's autonomy or knowledge. Hard paternalism occurs when a paternalist acts regardless of the condition of his subjects. In contrast to hard paternalism is soft paternalism, in which paternalism is only justified if a subject commits an act voluntarily that demands paternalistic action (Feinberg 1986; Dworkin 2002). Paternalism can be pure, where a person has their liberties taken away to protect them, or rather, the group being protected is the only group losing its liberties. It can also be impure when the people being interfered with is larger in size than the group of people being protected by the paternalist (Dworkin 2002). In other words, paternalistic activity 
causes people outside of the group under protection to also lose their freedoms. Finally, paternalism can be enacted for moral reasons, in which it is justified as promoting people's well-being even if their welfare is not improved. Paternalism can also be justified simply as promoting the general welfare of the person or people being interfered with (Dworkin 2002, 2005, 2013). Regardless of the type of paternalism involved, paternalists power and their subjects do not.

\section{Paternalism and Power}

Power refers to the ability to exercise one's will over others (Weber 1922). Whether power is accepted depends on whether or not the person trying to exercise power has "authority," power that people accept because it comes from a legitimate source and/or is attached to a specific role or institution (Weber 1922). Many paternalistic characters in the study are interesting because they have power, but lack legitimate authority; most of them are not "legitimate" because they operate outside of the bounds of institutions. Most of the characters, specifically the paternalistic black characters in this study's sample who use "revolution" and "vigilantism" as a strategy to help other characters, have "charismatic power" based on their leadership abilities, which is all they have given that they are presented as poor without access to the mechanisms and roles of authority. However, the black characters who uses "altruism" as a strategy, especially characters who are teachers, do tend to have authority because they operate within the institution of schooling and are introduced as experts in their fields. As I will explain in upcoming chapters, how paternalists use their power is influenced by their class, occupation (or lack thereof), and gender intersections. 
In this study, characters portrayed as poor tend to have more charismatic power, while middle-and upper-class characters are more traditionally powerful. In addition to class distinctions, power and authority can also be "intellectual," which is power and/or authority coming from a paternalist's expertise and knowledge, or "social," which is power and/or authority a paternalist has to exert influence over another person. As a result of their interaction with powerful paternalistic figures, subjects in need of "saving" come to internalize the worldview and perspectives of their "savior" which reproduces various forms of racial, class, and gender domination (Fanon 1967; Bourdieu and Wacquant 1992; Desmond and Emirbayer 2009). While I theorize race, class, and gender inform how they act paternalistically as these "savior" characters, white savior characters are also intersectional.

\section{Paternalistic White Savior Characters}

Vera and Gordon (2003) define the White Savior as, "the great leader who saves Blacks from slavery or oppression, rescues people of color from poverty and disease, or leads Indians in battle for their dignity and survival" (p.33). "White savior films" are recognizable through the presence of a white leader who follows Vera's and Gordon's definition. Terms such as "noble savage," "manifest destiny," "White man's burden," and "great White hope" refer to the complex relationship between the white savior and the dark-skinned "other" in need of saving, and demonstrate the use of such tropes (Hughey 2014). The former representation of "nonwhites" as the oppressed, despairing, and needy ethnic group is a common trope in films within white savior films. These narratives are perpetuated in the widespread genre of white savior films. 
Hughey (2009) builds on Vera and Gordon's work by adding a class dynamic, explaining that the white savior narrative features "a group of lower-class,...nonwhites (generally black and Latino/a) who struggle through the social order in general...yet through the sacrifices of a white [protagonist] they are transformed, saved and redeemed" (p.475). The main takeaway here is that a white character is considered a "white savior" if he or she plays a major role in affecting a (lower-class) non-white character's future and goals through education or some other form of transformation when the non-white character cannot, or will not, do so himself or herself. White savior films paint an image of white people as likable, benevolent, sympathetic, helpful, and numinous benefactors who are not like past racists. In these narratives, white characters are portrayed as messianic heroes endowed with a benevolent desire, and/or obligation, to rescue people of color from tragedy, harm, or punishment brought about by oppressive or destructive forces (Hughey 2009, 2012; Glenn and Cunningham 2009).

Benevolent whiteness is juxtaposed with the image of the hopeless, bereaved, and downtrodden people of color who are in desperate need of a (white) hero (Hughey 2009, 2012; Glenn and Cunningham 2009). White savior films highlight the racial boundaries between whites and blacks and help delineate the color-line in a way that reifies race and uplifts the dominant white race (Bernardi 1996; Miller 1998; Hughey 2012, 2014). Thus, films that contain white saviors generally portray them as teachers, lawyers, and coaches — people in positions of power, leadership, and/or authority — who take charge in times of need and act on behalf of people of color to fight against an oppressive individual, institution, or system (Schultz 2014). As white characters challenge the racist individual, 
institution, or system, they indulge in their white privileges in order to lead people of color to safety, salvation, or success.

Some of the most egregious story lines that contain a white savior involve white protagonists venturing into "exotic," "foreign," or "alien” locales such as Jake Scully's expedition into the lush planet Pandora in James Cameron's Avatar (2009), Nathan Algren's travels through $19^{\text {th }}$ Century Japan during the Meiji Restoration in The Last Samurai (2003), and any number of movies in The Mummy franchise (1999). Other white savior narratives involve the white protagonist fighting various forms of racism across different time periods, the most prevalent of which is the Antebellum South during America's Plantation Era. Films set in the Antebellum time period usually involve African captivity and slave narratives. Examples of slave narratives in film include movies such as: Glory (1989), Amistad (1997), and 12 Years a Slave (2013).

In these films, the salvation and liberation of captivated Africans is situated as wholly dependent upon the acts and righteousness of the white protagonist (Hughey 2009, 2012; Glenn and Cunnigham 2009). In all of the aforementioned films, the white character is maximized and heroized while the characters he or she is helping are marginalized. Heroism is thus a key analytic component when seeking to understand white savior tropes and filmic paternalism in general. This frames people of color as less self-reliant than whites - hence the need for a white savior-which rarifies power and agency within people of color and normalizes whiteness (Schultz 2014).

White savior films reflect the ways in which the media represents race relations by racializing positive and universal concepts, like morality and discipline, and linking those concepts to hegemonic whiteness and white ideals. White savior films reveal a 
media myth about whites and their relation to characters of color: white people know what is best, especially if they are middle class (Bulman 2015). This intersectional raceclass myth allows whites in the media to become the faces of intelligence, wisdom, culture, charity, mercy, and benevolence while characters of color become the faces of crime, poverty, drug addiction, mental illness, aggression, and "pathology" that only a white person can fix or save. Ultimately, white savior films provide people "experiences" with people of color through their narratives. In the absence of lived experience, film narratives become synonymous with reality. In white savior films, the cinematic relationships between the white characters and characters of color influence the ways viewers perceive themselves as members of their respective race. In addition, white savior films depict a "utopian" relationship between white people and people of color, leading viewers to believe that these idealized and peaceful relationships depict the current racial milieu. One of the key elements of a white savior film is the depiction of a historically consistent power dynamic between whites and people of color in which whites have more power and authority than people of color which extends into discussions of masculinity.

\section{Hegemonic Masculinity and White Paternalism}

In addition to hegemonic whiteness, the themes of hegemonic masculinity can be applied here as well given that white savior narratives are generally patriarchal narratives that focus on the struggles of men (Hughey 2009). According to Connell and Messerschmidt (2005), hegemonic masculinity legitimizes male dominance in society, the subordination of women, and dismisses marginalized expressions of masculinity. Hegemonic masculinity also acts as a mechanism for policing men's behavior to ensure 
that they conform to a specific kind of "masculinity" that helps to perpetuate male dominion over women and other marginal groups (Donaldson 1993; Connell and Messerschmidt 2005; Jewkes and Morrell 2012). Adding to the aforementioned points, Hughey (2009) explains,

"The overwhelming usage of white men as the counterpart to magical negro characters speaks to the intersectional nature of this phenomenon. That is, the narratives of white loss and redemption in the U.S. context are almost exclusively stories about white men's lives, thus reflecting a dynamic in which quests for masculine dominance motivates these stories" (p.559).

Hughey claims that white savior films are largely masculine narratives that tend to either ignore or marginalize white women. In the case of white savior films, these white characters go on a "quest" to rescue people of color to show that white men know what is "best" (for people of color) which centers whiteness and marginalizes everyone else. This construction of white male saviors creates a hegemonic disposition of white men that generally replaces sentimentality with rationality, reinforcing the sexist adage that (white) men know better than women and people of color hence the need for a paternal figure who will help lead, or be developed into a lead, for others. Hegemonic masculinity is also attributed to famous black men in a concept called "messianic masculinity."

\section{Messianic Masculinity and Black Paternalism}

Ronald Neal (2013) describes messianic masculinity as “an ethical paradigm which is tied principally to the Christian tradition and its cultural history among African Americans" (p.52). Messianic manhood is inseparable from the oral tradition of preaching and singing where Jesus is understood as Lord, savior, and advocate for the oppressed (Neal 2013). This construction of masculinity is derived from W.E.B. Du Bois' "Talented Tenth" in which the black race is supposed to be saved from racial oppression by its exceptional men (Du Bois 1903; West 1993; Neal 2013). These men are 
conceptualized as the leaders of the black race through their education, writing, and involvement in social change (Du Bois 1903; Neal 2013). Messianic masculinity is situated within broader structures of gender domination through the reinforcement of hegemonic masculinity. As a manifestation of hegemonic masculinity, messianic masculinity suggests that only black males can save other people of color and ignores the efficacy of black women.

Messianic masculinity manifests primarily in politics, following the activism, suffering, sacrifice, and martyrdom of Dr. Martin Luther King Jr. (Neal 2013). The form of political messianism that is at the core of Martin Luther King Jr.'s life is tied to Christian messianism (Neal 2013). He was raised as a child of the black elite in the Jim Crow South and thus he was one of the few black people who was raised in, inherited, and lived out a version of messianism that was attached to middle-class notions of salvation (Neal 2013). These notions of messianism and salvation were bourgeois and thus were tied to institutions typically associated with the middle-class such as: churches, colleges, fraternities, sororities, civic associations, and missionary organizations. "Race salvation" became the ultimate goal of masculinity in the black community.

Within the aforementioned institutions, the messianic aristocracy taught black students to serve in their communities through perfectionistic and utopian standards that stressed self-improvement, individualism, and activism with the purpose of rescuing and "uplifting" the black race (Neal 2013). According to Neal, "Through martyrdom, King lived out the ultimate virtue and outcome of messianic masculinity...” (p.53). Dr. Martin Luther King Jr. and Barack Obama represent the impossible moral standards that no African American man could ever be able to meet because King and Obama are viewed, 
in the abstract, to represent a savior role for African Americans. According to the tenets of messianic masculinity, black men who do not measure up to what King or Obama are conceived to be are marginalized (Neal 2013).

Connecting black male agency to messianic masculinity reveals how paternalistic black males reinforce sexism and middle-class ideologies in black communities. This creates a better understanding of the implications of black male characters in film by placing them in a larger context of racist and patriarchal movie propaganda that continues to use stereotypical black masculinity to frame blacks as saviors who can only save in "masculine" and "middle-class" ways. According to Hughey $(2009,2012)$, this portrayal of black men reinforces hegemonic, middle-class masculinity and, theoretically, makes films featuring black men who act as "saviors" masculinist productions that center on the experiences of black men. These films center their narratives on paternalism and redemption as an extension of masculine dominance and the marginalization of women which constantly empowers "elite" black men. This is reminiscent of how "neoliberalism" influences the construction of white masculinity.

Given how notions of neoliberalism, post-racialism, and post-feminism continue to influence the production of white savior, magical negro, and the theoretical "black savior" films, these forces are producing cultural depictions of white and black agency in the media. Therefore, it is critical to analyze the representations of racial and ethnic minorities on screen from the production of culture perspective, as championed by Peterson and Anand (1976, 1979, 2000, 2001, 2004). Previous research has looked at the liberal nature of magical negroes and the roles these "benign" representations of blacks play in the modern racial system (Appiah 1993; Miller 1998; Bogle 2001; Entman and 
Rojecki 2001; Glenn and Cunningham 2009; Hughey 2009, 2012, 2014). The production of culture approach helps us make sense of these representations and why they matter to the broader culture.

\section{The Production of Culture}

The production of culture perspective focuses on how symbolic elements of a given culture are manipulated and shaped by the systems they originate and exist in. When applying this perspective to film tropes, it is helpful to analyze them as cultural objects (Griswold 1986, 1992; Schudson 1989, 2002; Monk-Turner et al 2010; Hughey 2012) in American culture. Cultural objects are influenced by the racial systems in which they were "created, distributed, evaluated, taught, and preserved" (Peterson and Anand 2004:547). Films as cultural objects can be understood as artifacts that are mass-marketed and (re)produced in reference to cultural, technological, and social factors necessary for navigation in the everyday world (Hughey 2009).

This perspective helps us consider the impact of the ways in which words and images shape our understanding of interactive expectations and how films seek to appeal to a wide range of audiences in their attempts to tell a story and make a profit (Gamson et al. 1992; Hughey 2012). "Culture" and "structure" mirror one another, and reflect dominate group and elite class interests (Gamson et al. 1992; Bristor, Lee, and Hunt 1995; Peterson and Anand 2004:312; Hughey 2012). Thus, analyzing films — as reflections of socio-cultural patterns - is an important enterprise in the social sciences when considering hegemonic race, class, or gender relations, and other forms of dominance that may be presented in them (Gamson et al. 1992:381). Films resonate with audiences's notions of race, and racism, and reflects racialized narratives of America, 
making them consequential and meaningful tools of racial socialization for audiences (Hughey, 2009).

Because of the troubled racial history of the United States, and how deeply embedded in U.S. institutions race is, the U.S. culture industry is racialized and reflects racial differences that help socialize audiences and shape racial realities for audiences who consume racialized media (Aldoni and Mane 1984; Berry 1998; Miller 1998; Van den Bulck 1999; Silverblatt 2004; Hughey 2012, 2014; Francis 2014:148). As mentioned in previous sections, the characterization of paternalistic black characters might be constructed around messianic, and hegemonic, masculinity, necessitating an intersectional analysis to more thoroughly address the study's research questions.

\section{Intersectionality and Controlling Images}

Kimberle Crenshaw coined the term "intersectionality" in 1989 to discuss how the experiences of women of color were ignored in court cases and how they were wrongfully made to choose between their identities, as either women or people of color, in order to make sense of their lives, ignoring the fact that the two identities overlap. She noted how courts often failed to "think intersectionally" (Crenshaw 1993; Carbado et al. 2013; Collins 2000, 2015). Since the creation of the term, there have been numerous studies and conceptualizations of the term intersectionality from the concept as a black feminist thought project, a black feminist paradigm, or even as an intersectional and/or systemic process that structures, influences, and constrains behavior (Crenshaw 1993; Collins 2000, 2015; McCall 2005; Ken 2008; Carbado et al. 2013; Choo and Ferree 2010). Given the multitude of critiques, conceptualizations, and metaphors surrounding the concept, it is impossible to exhaustively explain the depth of this approach. 
Intersectionality is the way in which race, class, gender, and sexual orientationand other social group memberships-impact lived experiences and social relations (Crenshaw 1993; Collins 2000, 2015; McCall 2005; Carbado et al. 2013). Intersectionality enables us to look at multiple forms of power and oppression simultaneously to help make sense of their lived experiences (Crenshaw 1993; Collins 2000, 2015). Through intersectionality, we can begin to see that a person's race, class, and gender cannot be separated from each other and we can see how one's identities and social positions infinitely influence each other. Intersectionality is important to consider when we look at savior narratives in the media because we can see how concepts of class, masculinity, and colorblind racism shapes these narratives. I compare instances of paternalism between black men and women since white saviors can be male or female, and I theorize black "savior" characters can be as well.

Another concept within intersectionality that is important to help frame black paternalism is Collins's (2000) concept of "controlling images." Controlling images are stereotypes that guide society's perception and presentation of black people, and they are "designed to make racism, sexism, poverty, and other forms of social injustice appear to be natural, normal, and inevitable parts of everyday life" (p.69). Controlling images are repeated over time and across institutions to denigrate mock, humiliate, and black people, and this study analyzes these controlling images. Specifically, I analyze how black characters may simultaneously reject and conform to controlling images through their actions, language, character and narrative presentation. The controlling images that I find are the most prominent are the mammy, angry black woman, and Sapphire. I go into more depth on these, and other, controlling images in other chapters, but the mammy image is 
important because three characters, Big Momma, Minny, and Madea, represent the servile, motherly "mammy" figure who works to "save" white families, which is different from most other characters in the sample. The angry black woman and Sapphire images stand out because of how they are used to portray the black women in the sample as constantly "angry" at the injustice in the world, which inspires women like Starr Carter, Sam White, and Lysistrata to fight for systemic changes. Almost every woman in the sample represents some aspect of the angry black woman trope.

Given that savior narratives tend to be more "masculine" and patriarchal in nature, black womanhood tends to be depicted using a patriarchal lens, indicating that an analysis of paternalistic male and female characters, who might occupy a "savior" role, needs to incorporate an intersectional approach. However, regardless of the savior's gender, there is a tendency for filmic paternalists to reinforce hegemonic discourses. In addition to this, it is important to analyze how these black characters may be empowered and disempowered within the organization(s) they operate in due to the controlling images and stereotypes that attempt to negate black agency and power.

\section{The White Savior Trope: Neoliberalism in Cinema}

The focus on masculine, middle-class dominance in films starring a paternalist fuels post-racial colorblind rhetoric. According to Wilson (2013), the white savior narrative exists in cultural moments of "racialized, gendered, and classed instability" that develops within neoliberal discourses (Wilson 2013:25). Harvey (2005) explains that neoliberalism is "a theory of political economic practices that proposes that human wellbeing can be best advanced by liberating individual entrepreneurial freedoms and skills within an institutional framework characterized by strong private property rights, free 
markets, and free trade" (p. 2). Neoliberal discourses are necessary for examining race, gender, and class in post-racial and post-feminist theorizing. Specifically, these theories work with neoliberalism to marginalize race and gender by claiming the constructs are unimportant concepts in the soci0-political world while using the perceived irrelevance of race and gender to subtly promote white male privilege (Mukherjee 2006; Wilson 2013). Thus, neoliberalism operates within post-racial and post-feminist theories to perpetuate both race and gender inequalities that bestow power to white male elites. Neoliberalism's deferment to the free market for the solution to various social problems-like racism, sexism, and other forms of discrimination and inequality—places the onus of reconciling social problems on individuals without the intervention of the government (Harvey 2005; Wilson 2013). This reductionism generates a new social contract that replaces issues of race and gender discrimination with issues of class and capitalism.

Joseph (2013) argues that post-racial and post-feminist theories function similarly for black people and white women within neoliberal discourse by claiming that race and gender no longer factor into the lives of black people and white women because the Civil Rights and Second Wave Feminist movements supposedly eliminated racism and sexism. Joseph (2013) claims, "Just as race and gender intersect...the gambits of post-race and post-feminism inform each other" (p.27). One exception to this is Patricia Hill Collins' (2005) discussion of the "new racism" that "supports the social order while seemingly challenging the racial inequality constitutive of that order" (Hughey 2009:3). In terms of cinematic representations of white and black characters, new racism reinforces the positive images of white characters as "moral" and "pure" while simultaneously describing how "powerful," "divine," or "magical" black characters may interact with 
whites and mainstream white culture (Collins 2005). Collins (2005) argues that gender and sexual stereotypes of black women are used to reinforce a type of racism that is predicated on the increased presence of black women in media. This reinforcement is perpetuated by post-race and post-feminist theories that inform each other to help create white savior narratives that commodify race, gender, and class identities (Wilson 2013).

Post-racial theories are situated within the history of race theory in the United States that has suggested that race and racial disparities are the byproduct of biological and genetic differences between blacks and whites. These biological essentialist theories of race suggest that racial inequalities are the result of cultural differences between the two groups (Omi and Winant 2015). Scholars who discuss and investigate post-racial theory have also described "enlightened racism" (Jhally and Lewis 1992) and "colorblind racism" (Bonilla-Silva 2017).

Colorblind racism (also called "colorblindness") is rooted in the fallacy that race is not an important consideration when considering institutional, structural, or interpersonal inequalities, discrimination, or mistreatment (Hughey 2015; Bonilla-Silva 2017). People who claim that they "do not see race" and "treat people equally" ignore centuries of ingrained racial ideologies, animus, antagonisms, and sociopolitical and historical struggles that have come to shape their very desire to believe that they do not see color. Colorblindness is a problematic racial ideology that allows people to say and believe racist things and maintain systemic racial inequalities while distancing themselves from racism. Colorblindness is an extension of post-racial theory and neoliberalism. 
Despite the academic debate over the characteristics, boundaries, and terminology used, the focus of post-racial theories is the neoliberal construct of race-neutral meritocracy (Jhally and Lewis 1992; Collins 2005; Wilson 2013; Bonilla-Silva 2017). The post-racial focus on meritocracy is important to the examination of white savior narratives because it minimizes the influence race has on the social and economic mobility of black people. Furthermore, post-racial theories, which are grounded in colorblind race rhetoric, attribute black/white racial race relations to "market dynamics, natural occurring phenomena, and blacks' imputed cultural limitations" (Gallagher 2003:2). Colorblind post-racial ideology legitimize the current racial order by allowing whites to believe they are socially, politically, and racially progressive and tolerant while at the same time supporting political and economic policies that privilege whiteness (Gallagher 2003; Bonilla-Silva 2017). Post-racial theory reinforces a white middle-class subjectivity that erases racialized, classed, and sexualized differences (Projansky 2001; Wilson 2013). Post-racial theories align with post-feminist theories and the interaction of post-race and post-feminism is important to the examination of the commodification of the white savior narratives, especially those narratives about race and gender empowerment without referencing issues of race and gender (Wilson 2013).

\section{The White Savior Trope: Whiteness and Post-Racial Theory}

As previously mentioned, neoliberalism utilizes post-racial and post-feminist theories to normalize a middle-class white male subjectivity by commodifying race and gender differences and inequalities. Given how neoliberalism, post-racial, and postfeminist ideologies construct whiteness as normative, this section examines the discourse of whiteness and how it assists with the construction of white savior narratives. An 
explanation of white savior narratives helps contextualize some of the hallmarks of a "savior," which I argue some "black savior" characters exhibit. Like I mentioned previously, "black savior" characters seek to help "rescue" people from some form of misfortune which is exactly what white saviors do. Therefore, understanding how white saviors behave helps us understand how "black saviors" work to "rescue" others and why that matters. It is important to note that movie studios do not market their films as "white savior” films, nor do audiences specifically look for these narratives (Wilson 2013). White savior narratives are instead made up of implicit tropes that reinforce whiteness, many of those tropes are post-racial.

Whiteness is a social construct that designates a racial category and/or racialized social position in the United States (Jordan 1968; Frankenburg 1993; Jacobson 1998; Roediger 1998; Lewis 2004; Nayak 2007; Hancock 2008; Baldwin 2011). Because whiteness is assumed to be the default racial position in the United States, it is an invisible marker of identity loaded with social privileges (Frankenburg 1993; Dyer 1997; Lewis 2004; Hancock 2008; Hughey 2010). According to Foucault (2008), the desire for racial purity in political empires constructs whiteness and allows for white people to view themselves as "good" and "pure" in relation to "bad" and "impure" people of color. The need for racial purity adds race and gender to the construction of whiteness by focusing on the reproduction of the white race (Wilson 2013). Post-racial and post-feminist theories are needed to stabilize the hegemony of white masculinity by reinforcing racial and gender inequalities (Mukherkjee 2006; Wilson 2013). White masculinity is now positioned as the opposite of blackness and womanhood in order to challenge the political discrimination protections provided to white women and black people (Wilson 2013). 
Media representation helps to construct and normalize the white masculine ethos as the default racial and gendered power in the United States. According to Vera and Gordon (2003:15), “deliberately constructed images" create a "sincere fiction" of whiteness that represents the white self as a natural leader above the guilt of racism. These sincere fictions assume that "humans are constantly producing and consuming stories — some fantasized, others based on real events — about themselves and the world in which they live" (p.15). According to Shohat and Stam (1994), "spectators are invested in realism because they are invested in the idea of the truth (they) reserve the right to confront a film with their own personal and cultural knowledge" (p.178). Shohat and Stam make the point that audiences bring their worldview, including their ideas about race and gender, to media texts. This means that the discourse of whiteness is a mitigating influence in how audiences read and make meaning out of the media they consume. Therefore, as Vera and Gordon (2003) argue, movies are an appropriate venue to address the representation of whiteness because of the dominant racial notions and discourse present in movie production and consumption. When whiteness is discussed in film, it is often in the context of white saviors.

The white savior trope is a white supremacist movie cliché that presents altruistic white characters as paternalistic messiahs who enter disadvantaged communities and inspire, assist, or "rescue" people of color from injustice (Hughey 2009, 2012). White saviors generally act on behalf of people of color based on the idea that people of color tend to lack the faculties to help or protect themselves in their time of need, creating a paternalistic relationship between whites and people of color in which whites are considered "allies" fighting against oppressive individuals and/or institutions on behalf of 
people of color. White savior narratives are extensions of "the white man's burden" and build on the belief that whites are endowed with a special responsibility to assimilate and civilize people of color (Shohat and Stam 1994; Glenn and Cunnigham 2009; Hughey 2009, 2012). These narratives are examples of imperialist nostalgia.

In white savior narratives, transformation of the white savior takes precedent over that of the redeemed, even though both are required to change by the story's end (Shohat and Stam 1994; Hughey 2012; Wilson 2013). Since white savior films are about reinforcing mythology and "sincere fictions" of whiteness, audiences who consume these movies get a simplistic, if any, understanding of the black perspective (Shohat and Stam 1994; Vera and Gordon 2003; Mukherjee 2006; Glenn and Cunningham 2009; Hughey 2009, 2012; Wilson 2013). Race is hardly ever highlighted in these films because they seek to be post-racial, to ignore the influence race has on black people's life chances in an effort to reinforce the fundamental goodness of whiteness (Vera and Gordon 2003).

White savior narratives fall along a spectrum of Hollywood social problem films that often combine "dialectic social analysis and interpersonal conflict (while) dramatiz[ing] the relationship between an individual and society, taking a highly cynical attitude toward social institutions" (Mukherjee 2006:88). According to Mukherjee (2006), social problem films fall into three categories: assimilation, affirmative action, and nostalgia. Assimilation film emphasizes immigration and the immigrant's endeavors to achieve the American dream through assimilation into U.S. culture. Affirmative action films problematize "liberal intentions of the sixties and take contemporary anxieties over racial and gender integration as their central problematic" (Mukherjee 2006:87). Finally, nostalgia films focus on historical moments in the United States' racial and gendered past 
in order to criticize the racial and gendered transformation that occurred in the Civil Rights movement by shifting the story away from “the marginalized group's history to the salvation of the central white (fe)male character" (Mukherjee 2006:155). White savior narratives extend the concept of social problem film by centralizing a race-neutral meritocracy that marginalizes the influence race has on the lives of people of color (Glenn and Cunningham 2009; Hughey 2009, 2012; Wilson 2013). In other words, white savior films are neoliberal texts that suggest that the "savior" for people of color is a charismatic male who legitimizes his position as a leader to a group of dark-skinned people in need of redemption (Hughey 2009, 2012; Wilson 2013).

It is important to note that women rarely get to be white saviors given how patriarchal white savior narratives are (Vera and Gordon 2003). However, post-feminism enables white women to assume the role of white saviors. Projansky (2001) argues that post-feminism claims that women are now equal to men, therefore, feminism is no longer necessary and, thus, white women can save people of color as well. The presence of a female white savior challenges the need for governmental intervention to deal with gender discrimination because women are assuming a position once reserved for men (Projansky 2001; Mukherjee 2006; Wilson 2013).

The post-feminism of savior narratives establishes the filmic "savior" as distinctly white, patriarchal, masculine, and anti-black, demonstrating the intersectionality of the trope. Following the concept of hegemonic masculinity and symbolic violence, white savior films may then reinforce dominant modes of thought about the essence of white men. People who see these films may come away believing that there is some natural 
quality to white males that enables them to "lead" people of color further, which, in effect, reinforces domination.

As a result of the savior character's presentation, the main tenet of the white savior trope is that he or she is a do-gooder, an altruist who is often featured, and centered, in films "based on a true story." In movies "based on a true story," the white savior tends to be a coach or a teacher, and characters of color are represented with a variety of racial stereotypes: out-of wedlock, teenage mothers; Latino gangsters and their hand-wringing girlfriends; black drug-dealers. The white savior tries to transform and inspire people of color, but they will initially fail at their task. The white savior finds a way to motivate their students, for example, and gives them agency to improve their lives. The people of color who have come into contact with the white savior prove themselves to be exceptions to dysfunctional non-whites around them (Hughey 2012). People of color take the lessons they learned from white saviors and attempt to escape their impoverished neighborhoods and improve their lives, demonstrating that if people of color would just "act right" (i.e. be white), then racial and class inequality would be a thing of the past (Glenn and Cunnigham 2009; Hughey 2009, 2012). Movies like Freedom Writers and Dangerous Minds fit into this category of white savior narrative. Another facet of white saviors concern the white interloper entering a non-white culture that is under assault. The white interloper learns to respect the value of the native or indigenous culture and then teaches the people in that culture rationality, logic, and modern techniques for how to defend themselves from the "bad" white people of which the savior was formally a part (Hughey 2012). These films rely on racial and xenophobic narratives to propel the exoticism of the foreign and dark "others" for US audiences. 
White saviors also intrude on domestic areas as long those settings are a priori understood as dangerous and backward like urban ghettos or the rural Deep South (Hughey 2012). These films make extensive use of sentimental dialogue that emphasizes the point that "a true and authentic inter-racial and inter-cultural friendship has been established, which obscures the larger pattern that the white intruder qua savior instructs the 'primitive' peoples on how to live" (Hughey 2012:762). In other words, white saviors enter into black spaces and attempt to "civilize" black people by trying to make them like "civilized" white people. Many of these films, such as The Last Samurai, claim to be "based on a true story" as well which is supposed to let audiences believe in the virtues of white paternalism and that people of color should be grateful for white assistance. This also demonstrates Hollywood's greater interest in narratives of "heroic" whites saving people of color than in the stories about people of color helping their own communities or resisting racism (Hughey 2012). Thus, the white savior motif is used to retell stories in ways that are palatable for "mainstream" consumption. This allows for negative stereotyping of non-white characters or cultures while white people emerge as possessive of messianic characteristics that can fix hopeless people of color.

The media tends to represent the white savior figure as a character deserving of worship that he receives from people of color because he is willing to sacrifice himself for their salvation, like a Christ figure, sent to act as a fatherly de facto savior of the dysfunctional racial "others" (Hughey 2012). The "others" are redeemable so long as they assimilate into white society via "their obedience to their white benefactors of class, capital, and compassion" (Hughey 2012:761). "Compassionate" white people tend to be teachers, coaches, and lawyers because they can intervene in a racist system in an effort 
to "improve" the lives of people of color by assimilating them into some form of whiteness (Schultz 2014).

The variety of research on the white savior narrative is indicative of its cultural reach, importance, and implications for people of color worldwide. Hence, conceptualizing white savior narratives as the progenitors of other types of "savior narratives" is an important starting point for this investigation. We can begin defining "saviors" as those who use their resources and skills to help, rescue, or bring justice for people in need and/or people who are threatened by danger or forms of systemic or institutional oppression. In his blog post, The Whiteness of Oscar Night, Hughey (2015) describes the narrative structure of the white savior sub-genre,

"A White Savior film is often based on some supposedly true story. Second, it features a nonwhite group or person who experiences conflict and struggle with others that is particularly dangerous or threatening to their life and livelihood. Third, a White person (the savior) enters the milieu and through their sacrifices, as a teacher, mentor, lawyer, military hero, aspiring writer, or wannabe Native American warrior, is able to physically save — or at least morally redeem - the person or community of folks of color, by the film's end..."

White savior films follow a predictable narrative structure that makes them easy to find and follow, and the aforementioned story formula is ever-present across movies in a variety of genres and time periods. In addition to Hughey's description of the white savior trope (as noted in the blog post cited above), if we look at black characters historically, we can see that black characterization has evolved from the noble savage and magical negro literary tropes and has always had a historical connection to white paternalism described above.

The Evolution of the Magical Negro Trope

The phrase "noble savage" was first used in 1672 in John Dryden's play The Conquest of Grenada (Ellingson 2001; Gyrus 2009). Dryden described noble savages as 
"guiltless men" who came to represent the first stages of innocence; these men were primitive, nascent, and close to nature (Lovejoy 1923; Hughey 2009, 2012). These men were stereotyped as violent and brutish, and those traits encompassed the noble savage stock character. The character was conceived as a Native American or African male which combined race and gender identities into a single stereotypical image of people who needed to be cultured and "rescued" from their uncivilized, barbaric, and violent lifestyles. The noble savage served to marginalize men of color, helped establish the discourse and representations of men of color as low-class and inferior, and linked virtue and wisdom to the "inferior" races and classes as a literary motif (Ellingson 2001). This was the beginning of race and masculinity becoming the centerpiece of redemption narratives, highlighting the importance of messianic masculinity as a concept to help make sense of these stories and characters.

Native men of color became foils who highlighted the cultural and white racial “superiority" of Europe which justified European imperial expansion (Ellingson 2001). The noble savage concept led to racist and pseudo-scientific colonial discourse about the nobility of dark-skinned "savages." This discourse was influenced by the paternalistic, Christian doctrine that "The white man brings civilization and Christianity to the savages..." (Ellingson 2001:11). The discourse created myths about how "savagery" manifested, what needed to be done to people determined to be "savages," and who was considered to be a savage (Ellingson 2001; Gyrus 2009). The hallmarks of the noble savage remained largely unchanged until the mid-twentieth century and the rise of more "positive" black stereotypes in film and television. The famous black actor, Sidney Poitier, was the face of the assimilationist black male caricatures that were popular in the 
50 s and 60s, referred to as "ebony saints," which came to represent an entirely new portrayal of Black, working-class males in film (Manchel 1990; Hughey 2009, 2012).

The "ebony saint" roles were "sterile paragons of virtue completely devoid of mature characterization or of any political or social reality" (Eberwein 2004:93). Sidney Poitier's debut in the film No Way Out (1950) was a prime example of the ebony saint character that "carried with it an obvious accommodation to white middle-class fears about sexual and social mores" (Eberwein 2004:93). The ebony saint rose above past racial injustices and got along with whites despite his own frustrations with their racism (Manchel 1990). Ebony saints were "hopeful" characters who showed that racial progress was possible through interracial relationships in which the problem of race and racism was ignored or quietly reconciled through "positive" interactions between whites and blacks (Manchel 1990; Eberwein 2004). This aspect of the ebony saint is an implicit theme of magical negro narratives.

The ebony saint retained the noble savage's supposed inferiority by being represented solely as a black male, but he had partially assimilated into, and capitulated to, mainstream white culture. The ebony saint stock character resurged in the 80 s postblaxploitation era of film and television (Hughey 2012). Through the 80s and 90s, black representations were not only more frequent but they were also more diverse. Instead of being presented as entertainers and sidekicks to their white counterparts, blacks were portrayed as middle-class with professions typically associated with that class (Hughey 2012).

The ebony saint evolved into, and cemented the hallmarks of, the magical negro during the 1990s, the so-called "Neo-Minstrel Era" (Hughey 2012). Spike Lee coined the 
phrase "magical negro" in 2001 when he criticized the overuse of traditions, characteristics, and narrative clichés that reinforced black inferiority via subservience to whites (Okorafor-Mbachu 2004). Because of his capitulation to whiteness, the ebony saint occupied a working-class or middle-class status position compared to noble savages who were divorced from civilization and were viewed as subhuman. Thus, the noble savage's assimilation into whiteness and "civilization" as an ebony saint added class distinction to his black male status that helped create the foundation for the magical negro trope. In order to fully understand the magical negro trope, we need to look at how it extends hegemonic masculinity and reinforces ideologies of class, which racial groups belong in which class, and how different racialized classes should interact.

\section{Characteristics of the Traditional Magical Negro}

The magical negro is a black stock character in film, television, and literature who often appears to be impoverished, lower class and uneducated. The character tends to possess some supernatural magical abilities or otherworldly folkloric wisdom used to save and uplift broken, uncultured, and lost whites (Appiah 1993; Glenn and Cunningham 2009; Hughey 2009). Kwame Appiah (1993) describes these Black characters as saints who are the moral equivalent to their "normal" White counterparts (p. 82). This equivalence offsets the usual stereotypes attributed to Blacks, and draws from the superior moral nature that is often associated with the oppressed (Glenn and Cunnigham 2009).

Magical negro films are situated within broader racial discourse and ideology where blacks are regularly characterized as simple-minded and uneducated people who desire an uncomplicated life of helpfulness, convenience, and service to whites (Hughey 
2009). Once whites have been served, the magical negro character dies or disappears (Hughey 2009). The magical negro's disappearance is a narrative imperative, as Hughey claims (2012), because the endurance of any interracial friendships in these films "would unsettle the racial status quo of the movie world in which the characters live" (p.759). If the character does not die or disappear then a slew of unresolved questions and problems would arise from the interracial relationships these films establish which creates a problem that the film's plot cannot solve without becoming politicized (Hughey 2012).

In modern media, black actors are afforded more range, generating more diverse black representations. Despite the increased visibility and diversity of black characters, the magical negro is a positive, progressive, yet racist Hollywood trope that falls within the category of "new racism" (Hughey 2009). The only way magical negroes can interact with white culture is through deference and subservience to white people and the supposed "racial order" supported by racist institutions and systems. Theoretically, the racial dynamic changes when the black character occupies a higher class and education level. Theoretically, when black characters use the privileges of their higher class, education level, or skills to combat interpersonal, institutional, or systemic racism, they may begin to act as paternalists and engage in either revolution, vigilantism, or altruism as strategies to "save" others. In the next section I discuss the concepts that underpin each of these strategies and how they might work to turn paternalistic black characters into "saviors."

\section{Activism and Revolution}

Black revolutionaries in the study are engaged in constant struggle for justice, much like messianic characters. The visage of the black revolutionary is multifaceted and 
layered with history and figureheads from Dr. Martin Luther King Jr., to Malcolm X, to Stokely Carmichael and many more. Throughout history, black activists have demanded freedom from oppression, usually without getting much in return (Johnson 2007). However, the Black Power movement represented a key turning point in American politics and black power. Disenchanted by the superficial and hollow progress of federal desegregation during the 1960s, many black citizens and leaders across the United States demanded meaningful self-determination, and they fought for black power through art, militant political action, and ideological debate (Johnson 2007). The black struggle for equality and emancipation was eventually converted into what we might call "civil rights cinema" that incorporated the civil rights struggle into a variety of legal narratives, comedies, and some action films (Monteith 2003).

Over time, a small but distinct body of films developed that chronicled, or referenced, civil rights successes. These movies presented a liberal reformist vision of racial struggle, retribution, and/or reconciliation that operated as narratives in which "they function in a postmodern imaginary as socially symbolic texts in which racial tensions that remain unresolved in life and temporary resolution in narrative" (Monteith 2003:121). Civil rights cinema reduce larger historical events to personal histories, domesticating the memory of the Civil Rights Movement.

Many movies about civil rights and revolution revolve around the stories of specific individuals fighting for justice when other people do not. The main characters in these films are presented as paternalists who gained their subjects' goodwill, or at least a modicum of it, usually through acts of charity and negotiation when other actors and groups would not attempt to gain their respect (Herman 2012). In turn, subjects are 
willing to accept the paternalist's version of the status quo so long as they receive the benefits of the paternalist's work, and this acceptance leads to resistance and, theoretically, some social change. Revolutionaries in "civil rights cinema," or movies that emulate the themes of such cinema, work similarly to civil rights leaders of yesteryear (as I explain in Chapter IV). Ultimately, because these movies tend to reduce the fight for black power and civil rights to a personal, instead of a broader political, struggle, the characters might come across as messiahs or strong black women tropes. The usage of these tropes is not necessarily intentional or overt, but it may be the byproduct of storytelling that relies on symbols and signifiers of boycott and revolution that come to be embodied by specific actors, and their actions, in specific situations (Monteith 2003). Moreover, the characters that engage in the civil rights struggle often frames those characters as "exceptional" as compared to other (black) characters.

"Exceptionalism" refers generally to the innate sense of ambition that carries the acknowledgment that to be black and successful in America, you must be "twice as good" as everyone else. Thus, black people often fare more poorly compared to other groups in the U.S. (Butler 2013). Essentially, exceptionalism is the idea that strong, educated, and competent black people are extraordinary presumably because they are required to be "twice as good" as other people, which is thought to be improbable for black people given the disadvantage they face (Marco 2018). Exceptionalism justifies the characters' role as paternalistic activists. These "exceptional" actors are akin to the "Talented Tenth" Neal (2013) mentions who were designated as the saviors of the black race. The reason the Talented Tenth is able to save the black race is because of how much "better" than other blacks they are, or are perceived to be. The function of exceptionalism in 
paternalism, and activism by extension, is to designate those who are able to, and should, focus their attention and resources toward "saving" black people. The elements of paternalism and exceptionalism can also be found in movies about vigilantes.

\section{Vigilantism}

As a concept, vigilantism is enigmatic and often only discussed in sensationalist media or in academic discourse as a type of "security fetishism," or a movement that uses (the threat of) force by citizens to maintain community security (Johnston 1996). The concept of vigilantism is rooted in criminological literatures, and it is often thought of as a sub-category of political violence (Rosenbaum and Sedeberg 1976; Johnston 1996; Jacobs et al 2007). The existence of vigilantism is thought to be proof of the existence of some societal flaw since the vigilante is a symptom and a victim of society and the collapse of social order. According to Johnston (1996), vigilantism has at least six elements: (1) minimal planning, premeditation, and organization of activity; (2) private, voluntary agency in which the vigilante engages in some private enterprise; (3) autonomous citizenship in which a voluntary activity is engaged in by private voluntary citizens without state authority; (4) use or threatened use of force; (5) reaction to crime and social deviance; (6) personal and collective security. These six elements combine to mean that vigilantism is a strategy born from a desire to "do something" when formal systems of control are ineffective. Thus, vigilantism is a reaction to social deviance whether real, threatened, or imputed. The aim of vigilantism is to offer people the assurance that the established order will prevail and will remain intact, especially at the local level (Johnston 1996). Vigilantes seek to control crime and offer assurances of 
security (Rosenberg 1956; Rosenbaum and Sedeberg 1976; Johnston 1996; Jacobs et al 2007; Tyree 2014; Cunningham 2018).

When looking at vigilantism in this study's films, vigilante characters meet most of the aforementioned elements. Vigilantes characters pursue local criminals who have harmed the vigilante's loved ones or community members, and the criminals are dealt with through extreme physical violence such as through beatings or shootings. These characters also tend to rescue women and children usually as a way to enhance their heroism. Often, this violence is a response to a social failure, such as corrupt police officers and/or departments, or the emergence of large, local criminal organizations. To counteract the breakdown of society, the vigilante plans and premeditates ways to track down and eliminate the criminals at large. Thus, the hallmark of the vigilante is his or her heroism in the face of social ills, and his or her willingness to provide people with the assurance that the ills will be eliminated. This heroism is on full display in movies primarily about men with military and police backgrounds, a great sense of justice, a connection the local community, and subtle superhuman skill; characters who might give in to "security fetishism" and the maintenance of social norms.

The themes of revenge and retribution are commonly found in neo-blaxploitation film, a subgenre that often relies upon and showcases interpersonal black violence as an allegory for black power and the subversion of white racial rule (Cunningham 2018). Neo-blaxploitation refers to the ways in which contemporary texts featuring "black protagonists negotiate with the archetypes, iconography, and themes of blaxploitation" (Cunningham 2018:98). Usually, the appropriation of blaxploitation themes happens in parodies or pastiche films. More contemporarily, the term "neo-blaxploitation" has been 
used to discuss movies that tend to use revenge narratives and the subversion of racial motifs (Cunningham 2018).

In many contemporary neo-blaxploitation films whites are portrayed as evil, corrupt, and decadent — a clear subversion of the ways mainstream films portray white characters — while black characters are concerned with getting revenge through vigilantism (Hughey 2012; Cunningham 2018). Because of its over-reliance on violent solutions to various problems, vigilantism can be said to be a sub-category of paternalism since both revolutionaries and paternalists seek the same thing: security through some sort of social change. While vigilantism is similar to paternalism, it is anathema to altruism which employs more subtle forms of assistance.

Altruism

Altruism, in sociological terms, is defined simply as behavior intended to benefit another person or group regardless of the risk or necessary sacrifices (Monroe 1994; Konstan 2000; Japtok 2004). Altruism entails specific actions, not just good intentions or kind thoughts, and it is always about furthering the welfare of another. If another person's welfare is treated as an unintended or secondary byproduct of specific behaviors, then those behaviors are not altruistic. Additionally, intentions count more than consequences, when deciding whether an action is altruistic or not, and altruism may carry with it a possibility of diminution of the altruist's welfare (Monroe 1994). In sociological literature, altruism is often contrasted with self-interested behavior. Since most people exhibit subtle varieties of self-interested and altruistic behavior, altruism has to exist on a spectrum. 
If we begin to treat altruism as continuous, then it becomes less about behavior and more about the interpretation and framing of behavior (Konstan 2000). In movies, altruistic black characters are often framed as the "good guys," and are thus supposed to be interpreted as such even when their actions can, and often do, possess elements of selfinterest. The aforementioned "strategies" that I theorize black characters employ vary within movies featuring parents, leaders, coaches, and lawyers. In the next section, I explain my theoretical perspectives that I utilize for this study that will help analyze movies for the elements of black characters to see if my initial theories accurately describe these characters.

To sum up the literature review, the theme of paternalism is particularly important to this study because it provides a context for the actions black characters take to "save" or "redeem" others. The way a character chooses to be paternalistic gives us a glimpse into how that character chooses to wield his or her power in his or her interactions with others. White savior characters have been the characters in film most likely to display their power by intervening in people of color's lives to "save" them, which has helped define "savior" tropes as distinctly white. However, the concept of "messianic masculinity" is useful to help provide an understanding of how black males in film can be paternalistic. Messianic masculinity highlights the ways in which black men can use their power to "save" or "redeem" others, which is the opposite of how traditional magical negroes are portrayed. Tying the concepts explored so far back into my research questions, the discussion of black males and females as having the potential to be "paternalistic" means that class and gender definitely have some influence over whether a character is a paternalist or not, and how that paternalism is expressed. I go into these 
expressions of paternalism in upcoming chapters. The next chapter details specifically how both content analysis and grounded theory were used in the various stages of the data collection and analysis process. 


\section{CHAPTER III}

\section{METHODOLOGY}

The study proceeded across several stages that built upon each other to form the backbone of the analysis of the presentation and purpose of black characters and their connection, if any, to white saviors. To proceed with the analysis of the black savior trope, I started first with a non-random sampling method that followed a set of rules and criteria to ensure that the study was conducted systematically and consistently. Second, I watched each movie alongside their respective script (once to gain an understanding of the plot, and then watching specific scenes of interest to the research questions in subsequent viewings), and I transcribed the notes I took while watching each movie into Microsoft Word documents for the coding process. Third, I coded data for each film to summarize each piece of data from my notes so that the data could then be separated and sorted for an analysis. Finally, I took the codes and developed them into cogent categories and themes that form the backbone of the analysis. The following sections detail each of the study's major "stages" from sampling to categorization.

\section{Sampling Stage}

To analyze and theorize black paternalism in film, this study's sample was drawn using relevance, or purposive, sampling of movies released in the years 2006-2018. The reason why this study implemented relevance sampling was because relevance sampling 
aims to select all texts that contribute to answering given research questions. When using relevance sampling, this study proceeded by examining the texts to be analyzed in a multistage process. Relevance sampling is not a random sampling method (Krippendorff 2004). As Krippendorff (2004) explains,

"It is important to remember that the use of random samples always entails the admission that one does not have a clue regarding what the population of interest looks like or where to find the needed information. In content analysis, this is rarely the case. Cluster sampling already acknowledges that the universe of texts is partitioned onto large clusters and makes use of this knowledge. Snowball sampling presumes knowledge of the network-like organization of this universe of texts" (p.119).

It is important to mention that relevance sampling is not probabilistic and is not random. A random sample could be drawn from all of the movies that, for example, contain black main protagonist (and some antagonist) characters that may help answer this study's research questions, but the task of sorting through the mostly irrelevant sources while ensuring each movie selected met my criteria proved to be convoluted and unwieldy. I used the search function in the Internet Movie Database (IMDb) to sort through thousands of movies automatically.

In IMDb, I used synopses, plot summaries, and character summaries (available through IMDb and wiki pages) to determine whether the films were relevant to the study's research questions. Specifically, the movies most relevant to the study were those that featured black characters portrayed as: teachers, coaches, politicians, activists, parents, and superheroes - roles that are typically more "paternalistic" given the social, cultural, and/or intellectual power people in these roles tend to have. I used IMDb and searched the database using keywords that already exist within it. However, IMDb's search function was often difficult to navigate since the site's search functions were 
unorganized, and specific keywords like "Black Teacher," "Black U.S Presidents in Film," "Black Superhero," and "Black Activist/Politician" almost always yield very few results. It was hard to know what keywords to use to find a nice sample given all of IMDb's flaws. However, the aforementioned keywords yielded a total of $35(\mathrm{n}=35)$ movies with black characters in them who might have been useful to the study (See Appendix A).The sample of 35 was, however, chosen based on the fact that they came up in keyword searches instead of an overarching logic for their inclusion, and they also did not fit into my 2006-2018 timeline. Only fourteen movies from this sample of 35 fit the timeline I kept those fourteen movies and I restarted the search process using a broader keyword, "African American" and the 2006-2018 release year. These keyword searches yielded a population of 2,266 movies. To select movies from this population, I added new keywords to "African American" and "Black American" such as "Police," "Lawyer," "Mother Son Relationship" and more keywords to make finding movies that fit the study's criteria more manageable. For example:

- Adding the keyword "Police" to the "African American" keyword yields a sample of 153 movies.

- Adding the keyword "Lawyer" yielded 46 movies.

- Adding the keyword "Black American" yielded a sample of 314 movies.

- Adding the keywords "Father Son Relationship" yielded 274 movies.

- Adding the keywords "Father Daughter Relationship" yielded 235 movies.

- Adding the keywords "Mother Son Relationship" yielded 234 movies.

- Adding the keywords "Mother Daughter Relationship" yielded 264 movies. 
- Adding the keyword "Violence" yielded 250 movies.

- Adding the keyword "Racism" yielded 150 movies.

- Adding the keyword "Doctor" yielded 46 movies.

IMDb's search function shows any movie with any character that fits the keyword searches, so many movies in these smaller samples were irrelevant to the study because many of the characters were supporting characters. Additionally, many of the same movies in this series of searches fit into multiple categories. For example, Black Panther fits into the "Violence" search and "Racism" search. Choosing movies from this population of over 2,000 movies was difficult. Thus, I developed three criteria to determine whether a movie was "relevant" to the study.

First, each movie on the list had to be a feature-length film (approximately 90 minutes or more). The film could not be animated or biographical. I avoided animated films, even though many of them have savior narratives, because they often deal with racially ambiguous alien races or cartoon and computer-generated imagery (CGI) creatures that may not be totally analogous to the characters I am studying. Characters in animated films can also have exaggerated mannerisms and behaviors that are unlike the mannerisms and behaviors in movies that are not animated, which makes coding animated films different from coding live-action films. I chose not to observe biographies because I wanted to study fictional characters in fictional worlds. I was more interested in how writers chose to write their characters in fictional worlds in order to analyze how class and gender affected power between fictional characters. Biographies, however, do often contain paternalistic characters, and biographies may be useful for future studies. 
The second criteria was that each movie had to have a black protagonist and/or antagonist character in a position of power or leadership. Most moviegoers are not looking at this info when they go see a movie, nor is the lead actor's race explicitly advertised for the films, which may be a symptom of a mostly colorblind film industry. The film industry's colorblindness highlights the fact that women and people of color are significantly underrepresented as protagonists and antagonists in films, with white characters taking up anywhere from $70-80 \%$ of all film and television character roles in any given year and males taking up 52-60\% of all roles (Hollywood Diversity Report 2019).

Third, because this study focuses on character gender, I picked films that had black female characters in addition to movies with black male characters. I aimed to have a sample that had a relatively equal number of male and female characters I selected films that allowed me to compare if and how black men and black women characters interact with other characters. For example, if I selected a movie featuring a black male teacher, I made sure to select a movie featuring a prominent black female teacher as well. This did not necessarily produce a perfectly even and equal sample that matches characters' positions of power and authority across gender and social class, but I matched them as much as possible given the 2006-2018 timeline and previous restrictions. To determine which female characters I selected for the study, I focused on IMDb's description of the movies that showed up in the searches in order to determine which women were "main" characters. 
With these three criteria, I dropped nine of the fourteen films I initially kept from the specific keyword search. This left me with five movies from the initial 35 that fit the criteria and timeline from the original sample that fit the criteria. I then added fifteen other films from the second round of IMDb searches using the broad "African American" keyword that fit the study's search criteria. As I previously mentioned, IMDb's database, when winnowed down using keywords, shows movies (and television shows) that merely feature a black character and/or a character that matches the keyword. So, I chose the additional fifteen movies based on the fact that they were the only movies I could find through the database searches that met all of the criteria at the same time based on the plot summaries IMDb offered.

Most movies were easy to disqualify from the study since the movies with black characters that came up in the study were supporting characters as indicated by the cast and credits as indicated on IMDb - the movie's "main" characters are listed at the beginning of the cast list. In addition to the cast, I chose movies based on the characters on a movie's poster on IMDb, which typically shows at least some of the most relevant characters. In addition to looking at the poster, I did more research on the film, looking at IMDb's information and looking at Wiki pages on movies I suspected were usable. Wiki pages provide summaries of characters and movie plots, and these pages proved to be very useful in helping me decide if a movie and/or character was worth analyzing, especially if the characters met my three criteria.

So, I did research on all of the movies of interest and I read their synopses to see what the movies were about. Whether or not a movie ultimately was added to the sample 
was left up to my interpretation of the movies I did research on. If I believed a movie did not neatly fit my search criteria, or helped me answer my research questions as a result of meeting my criteria, the movie was not included. It is worth noting that it is entirely possible, given my methods, that there were movies I may have missed that would have worked well in the sample-I attribute that to the human error that comes with having one researcher hand-picking (instead of randomly selecting) movies.

Given the aforementioned methods, I identified a sample of $20(n=20)$ films that neatly fit each of my criteria (See Appendix B). I figured I would start the study with twenty movies, see what theory I could develop from these twenty and, if I needed more clarification on any theories or categories I develop from the data, I would add more movies. I ended up not needing additional movies because I reached a point where I was not finding anything new from my data from the original twenty. So, I stayed with twenty and developed a theory from that sample.

I ultimately ended up with a sample of texts that are not meant to be representative of a population of texts; rather, they are the population of relevant texts, excluding irrelevant sources. This means I ultimately sampled for relevance, range, and uniqueness to a certain degree based on my interests (Small 2009). In other words, I identified a specific "type" of character I wanted to study and I ensured I had a number of films that would allow me to gain some understanding of the depth of that character. I found sampling for relevance, range, and uniqueness to be effective because random sampling ultimately would not have yielded a sample made up characters I wanted to 
analyze. As I have explained previously, this "sampling for range" method increased the study's bias and reduced its representativeness.

\section{Data Collection Phase}

To collect data on the films, I first watched each film in their entirety, noting the date of when I watched them. I also noted the timestamps for scenes of interest, and I was sure to describe the scene(s) in detail in my notes. I noted recurring themes such as: How are characters interacting in the films? What are the motives behind the interactions? Do characters exercise power, authority, and agency? As I watched each film, I paid special attention to the characters of interest for each film, which I decided upon using some preliminary plot summaries and research in each film. My notes were ultimately focused on: the character's occupation; who was being "saved" (based on that character's social environment, socioeconomic status, or personal problems); what methods the character used to save, how paternalism was expressed in the film; how the paternalistic character asserted power, authority, and agency, etc.

I also took notes on the character(s) of interest's actions in certain scenes of interest—-scenes in which the character expressed signs of paternalistic behavior-and how other characters react to them. This aspect of the note-taking in some ways resembled taking "field notes" on the characters themselves. Due to the issues I had with the scripts, I decided not to focus on taking notes from each movie and coding them by relying on captions and subtitles in order to capture dialogue along with the scenes in which they were spoken. To make sure I was hearing the lines correctly, I had the script for the films open alongside the film and followed the script while watching the movie at 
the same time. I used the script as a way to know which page the lines of dialogue were on so that I could refer back to them for future reference.

The movies I watched first were those revolving around "heroic" male characters. I focused on "heroic" black males because the discussion of paternalistic white characters, like white savior characters for example, was usually centered around men and their "heroism." I decided that looking first at movies that explicitly center their black males as respectable heroes and vigilantes who go out of their way to rescue and save others. After watching each film, I organized my notes using a Microsoft Word template that contained the same set of questions for each film I watched.

Using Word might seem like an unorthodox choice for a content analysis given the amount of data that this study engages with and the seemingly low-functionality of the platform. However, I used Microsoft Word to archive, and organize my notes because Word allowed me to more easily highlight and tag specific lines and passages (using the comments feature) so that I could refer back to them for deeper analysis. Word also allowed me to write larger notes and/or memos of the codes that I then turned into larger thematic categories. Additionally, Word allowed me to create descriptive tables to help me visualize and organize my data. My familiarity with the platform made using Word preferable to other platforms. Ultimately, I generated over 200 pages of notes and findings data using Microsoft Word. Finally, I compared to compared those findings both within and between movies - using constant comparative analysis - in order to detect patterns in order to theorize if and how paternalistic black characters could act as "saviors." 


\section{Coding and Data Analysis Phase}

To code the data I collected, I utilized media content analysis — also called "textual analysis"- to collect data. In this section I will first explain the content analysis and grounded theory methods and then explain how I used them. Content analysis can be summed up as an analysis of "who says what, through which channel, to whom, and with what effect" (Shoemaker and Reese 1996:12; Macnamura 2005). Essentially, content analysis focuses on the meanings, interpretations, and impact of various forms of media (Macnamura 2005:1). Content analysis is primarily used to study "texts" from transcripts of interviews and discussions in social research of the narrative and form of films, TV programs and the editorial and advertising content of newspapers and magazines (Macnamura 2005). A "text" in this case is any object that can be "read" as a coherent set of signs that transmit a message. Texts include: written text, oral text, image text, audiovisual text, and internet hypertext. Content analysis is a systematic research method for examining any combination of these symbolical texts by recording or transcribing their messages into categories (Berelson 2000; Stemler 2001). This study focuses on both audio-visual (film) and written text (dialogue in film scripts) in order to answer the initial research questions. Using the scripts was initially supposed to help me catch anything I missed in my initial viewing of the films, reducing the need for me to constantly re-watch the films for information. However, there were some methodological issues with using the scripts available to me, which I explain more in the Methodological Issues section. Janis (2009) classified the content analysis method into three categories: pragmatical content analysis, semantical content analysis, and sign-vehicle analysis. 
Pragmatical content analysis is the procedure in which messages are categorized by their possible causes or effects. Semantical content analysis is the procedure that classifies messages based on their meanings. Sign-vehicle analysis measures how often a word appears in the media source, and analyzes the psychological properties of the "signs" being observed. This study focuses more on semantic analyses of Obama-era films.

Researchers using content analysis as a method often lack control of extraneous factors that might affect the production, dissemination, and interpretation of symbols. In this case, there are extraneous factors in the film industry such as pre-production, postproduction, editing, distribution, etc that this study cannot account for in the creation of certain types of movies or narratives. Additionally, content analysis is only categorically descriptive of symbols (Holsti 1969; Kolbe and Burnett 1991). Kassarjian (1977) discussed the problems of using content analysis methodology in early consumer studies. Kassarjian suggested that objectivity, systematization, and quantification were the most significant and distinguishing attributes of content analysis. Content analysis comes in two forms: qualitative content analysis and quantitative content analysis and the next section will explain these forms and why this study will take advantage of the principles of qualitative content analysis.

\section{Qualitative Content Analysis}

Qualitative content analysis emphasizes an integrated view of speech/texts and their specific contexts (Zhang and Wildemuth 2005). It goes beyond simply counting words or extracting objective content from texts to examine meanings, themes, and patterns that may occur within a text. It allows researchers to understand social reality in 
a more subjective, yet scientific, manner. Qualitative content analysis is mainly inductive, with its examinations, and inferences drawn from those examinations, of topics and themes grounded in the data. This type of content analysis attempts to generate theory, in some cases, from carefully selected texts which help inform the research questions being investigated. This means that a qualitative method is more appropriate for a grounded theory approach.

Thus, the results of the qualitative approach usually produces descriptions or typologies, along with expressions from subjects reflecting how they view the social world (Zhang and Wildemuth 2005:2). Zhang and Wildemuth (2005) draw upon Berg's work (2001) to explain that the "perspectives of the producers of the text can be better understood by the investigator as well as the readers of the study's results." This approach is focused on the unique themes that invoke a range of meanings rather than the statistical significance of the occurrence of particular texts or concepts.

In contrast, quantitative content analysis is focused on deductive reasoning and objective measures that are designed to test hypotheses or address questions generated from theories or previous empirical research. As suggested by Smith (1975), "qualitative analysis deals with the forms and the antecedent-consequent patterns of form, while quantitative analysis deals with duration frequency of form" (p.218). Weber (1990) points out that the best content-analytic studies use both approaches to some degree to get a breadth and depth of data. All readings of texts are qualitative in nature even when characteristics of the text are converted to numbers (Krippendorff 2004). Despite how the two approaches can be combined and how they complement each other, this study will 
focus on applying the principles of qualitative content analysis because the study aims to look at the themes and patterns present within the selected films in regards to black heroes and redeemers.

By analyzing these films for their themes and patterns, this study also aims to understand their implicit meanings and implications, which is something that quantitative analysis cannot account for. A stronger focus on qualitative analyses can help reveal implicit meanings of the media, and help re-articulate a given source into a new narrative based on theory. Quantitative approaches may not necessarily accomplish this study's goal of interpretation and re-articulation of media narratives because the method is concerned more with counts and probability.

One of the main issues with qualitative content analysis is research bias and a lack of reliability. A "rigorous" approach to media content analysis to gain maximum reliability requires that two or more coders are used — at least for a sample of the content being studied (Macnamara 2005). While a primary researcher conducts most of the research in content analysis, a reliability sub-sample coded by a second or third coder is important to ensure that the results, ratings, and categories of analysis are not the result of a researcher's subjective judgement or bias (Tinsley and Weiss 1975; Macnamara 2005). Neuendorf (2002) says, "There is growing acknowledgement in the research literature that the establishment of intercoder reliability is essential, a necessary criterion for valid and useful research when human coding is employed," highlighting the importance of having intercoder reliability in a content analysis study (p. 142). However, Riffe and Freitag (1997) found that only $56 \%$ of 486 content analysis studies, published in 
Journalism and Mass Communication Quarterly from 1971 through 1995, reported intercoder reliability and that most failed to report reliability variable-by-variable, which is recommended. Lombard, Synder-Duch and Bracken (2003) found that only 69\% discussed intercoder reliability and only $41 \%$ reported reliability for specific variables.

Despite the critical importance of intercoder reliability to content analyses, it is not possible for this study to have a measure of intercoder reliability because there is only one researcher coding and analyzing data. Therefore, this study is purely qualitative, but it is worth noting, for the sake of transparency, that there is another type of content analysis that could have been used for this study under different circumstances. Because this study is qualitative, the study is meticulous, thorough, and systematic about the rationale for the decisions that are made in each stage of the study process. Therefore this study is not, and does not aim to be, generalizable to all films featuring a paternalistic black character, nor do I aim to make any causal claims or inferences based on my data.

This study aims instead to be transferable, adhering to the conventions of qualitative transferability. In other words, the study aims for its inferences and analyses to be detailed enough so that the reader can decide whether the analyses contained herein are similar to other films and characters the reader is familiar with and whether the findings can be applied to other concepts so that comparisons can be made across concepts (Marshall and Rossman 1989; Davis 1992; Gomm, Hammersley and Foster 2000; Hughey 2009). I aimed to be systematic in my discovery of nuances in the analysis of the culturally significant themes, ideologies, racial representations, and the racial and 
gender ideologies in these films. To study these nuances, I first used a qualitative method called "coding."

According to Charmaz (2006), "Coding is the pivotal link between collecting data and developing an emergent theory to explain these data" (p.46). I followed the conventions of grounded theory coding following Charmaz's (2006) model. I followed Charmaz's (2006) guidelines for grounded theory coding in two phases: 1.) an initial phase involving naming each word, line, or segment of data followed by 2.) a focused, more selective phase that used the most relevant, significant, and/or frequent initial codes to sort, synthesize, integrate, and organize large amounts of data. In the first phase, I remained open to all possible theoretical directions indicated by my interpretations of the data. Developing codes for the analysis of the data post-content analysis required extensive use of grounded theory.

\section{Grounded Theory}

According to Glaser and Strauss (1967), grounded theory is "the discovery of theory from data—systematically obtained and analyzed in social research" (p.1). In other words, grounded theory sets out to create new theories as this study does with its discussion of "black savior" characters. Instead of verifying theories, Glaser and Strauss introduced a method to arrive at a "theory suited to its supposed uses" contrasting with a "theory generated by its logical deduction from a priori assumptions" (Glaser and Strauss 1967:3). Grounded theory involves the use of an open-ended, and iterative process, that involves data collection, coding (data analysis), and memo-writing (theory-building) 
(Groat and Wang 2002:181; Charmaz 2006). This study utilizes each of the aforementioned processes.

According to Glaser and Strauss (1967) grounded theory has two unique characteristics: constant comparative analysis and theoretical sampling. Comparative analysis involves iterative data collection and analytical processes that involve "the systematic choice and study of several comparison groups" (Glaser and Strauss 1967:9). It is unnecessary for the researcher to wait until data are completely collected to being data analysis. Instead, data collection and analysis happen at the same time so that the analyzed data guides subsequent data collection. In the process of data analysis, an incident should be compared and contrasted with other incidents (Corbin and Strauss 1990). Researchers need to make comparisons between empirical data and concept, between concept and categories, among data, among categories, and among "different 'slices of data' in order to reach higher levels of abstraction and advance with the conceptualization" (Gregory 2010:7). Comparative analysis serves to obtain accuracy of evidence in the conceptual category and to establish the generality of a fact (Glaser and Strauss 1967).

I used grounded theory in this study in conjunction with content analysis because the two methods mesh well together and there were no prior theories or literature that helped explain how black characters behaved in film. Thus, I believed I would need to begin building an understanding of such characters from the bottom up using an inductive, analytical method. According to Elo and Kyngas (2008) and Cho and Lee (2014), an inductive approach to content analysis is appropriate when prior knowledge 
regarding the phenomenon under investigation is limited or fragmented, as is the case with the black heroes and redeemers. According to Glaser (2013), grounded theory is an inductive methodology as explained in the following statement,

"Grounded theory is an inductive methodology. Although many call Grounded theory a qualitative method, it is not. It is a general method. It is the systematic generation of theory from systematic research. It is a set of rigorous research procedures leading to the emergence of conceptual categories...Grounded theory can be used with either qualitative or quantitative data" (Grounded Theory Institute 2013).

Given Glaser's statement, it makes sense to combine qualitative content analysis and grounded theory methods in which one method influences the other and vice-versa. Using this inductive approach to conceptualizing black "saviors," their codes, categories, and/or themes are directly drawn from the data to pinpoint the hallmarks of these characters (content analysis) in an effort to develop a substantive hypothesis or theory that will help explain the implications of the characters and their supposed use (grounded theory).

Goldkuhl and Cronholm (2010) challenge conventional, inductive grounded theory methods and argue for multi-grounded theory (MGT). MGT goes beyond pure inductivist approaches and adds explicit use of external theories. They say that, "We claim that theory development should aim at knowledge integration and synthesis. This means that extant theories can be used actively, aiming at a knowledge synthesis of such extant theories and new abstractions arrived from the coding of new data" (p.188). I synthesized existing theory with new data from the coding process to answer my research questions. To ensure that the study was systematic throughout its various phases of data collection, coding, and analysis, I employed definite rules and procedures throughout the 
content analysis process in order to only examine movies that were relevant to the research questions at hand as I explain in the next section.

According to Charmaz (2006), grounded theory involves studying early data and beginning to separate, sort, and synthesize data using qualitative coding. This means that I attach labels to segments of data that describe or depict what the segments of data are about in order to sort the data and make comparisons to help define concepts that best fit and interpret the data (Charmaz 2006). I coded the data gathered from content analysis of audiovisual film content and the content of the scripts for each of those films for themes, patterns, and concepts corresponding to the theoretical rudiments of the savior trope in film as outlined in the earlier sections. Film scripts were necessary for analysis because language was important in the coding process since words, either written on a page or spoken aloud, reflected character views and values (Charmaz 2006).

\section{How I Incorporated Grounded Theory and Content Analysis}

Using line-by-line coding, I took the notes I recorded from watching each film and I transcribed those notes into Microsoft Word first. However, instead of doing lineby-line coding of the script, I used "line-by-line" coding of the captions in the movie (when necessary) since I was still capturing the dialogue on screen. After transcribing the notes, I looked at lines of dialogue for indicators of paternalism such as any hints at a character's motive for "helping" others, threats of violence, presentation of these characters as "saviors" of a race or group of people, any signs of hegemonic masculinity, how characters offer to help solve problems, and more. I tagged each of the 
aforementioned phenomena with a specific "code" to briefly describe what I read. The codes I found across each film are in the table below.

TABLE 1. CODES FOR EACH MOVIE

\begin{tabular}{|ll|l|}
\hline Abstract Liberalism & Guidance & Obligation \\
Activism & Hegemonic Masculinity & Strict \\
Aggression & Humanitarian & Supportive \\
Angry Black Woman & Individualism & Tough Love \\
Stereotype & Inspiration & Vigilantism \\
Authoritarian parenting & Intimidation & Violence \\
Awareness of inequality & Leadership & Women as Victim \\
Compassion & Messianic Masculinity & \\
Disadvantage & Moral Superiority & \\
Exceptionalism & & \\
\hline
\end{tabular}

These were the codes that I recorded across each film using line-by-line coding of my notes which included lines of dialogue and character actions. I did not line-by-line code each line of the script because not every line proved useful to the analysis as many lines of dialogue did not have any relevance to the themes of paternalism, nor did analyzing every line help me answer my research questions. The aforementioned coding method, moved the study toward data "fit" and "relevance," two of the most important criteria in grounded theory (Charmaz 2006).

As part of the coding and analysis process, I wrote analytic memos incorporating the codes from each film in order to keep from having to rewatch the movies more times than necessary and to ensure that I had enough data about each movie to from which to create analytic categories. I created these memos by reading through my coded notes and noted specific initial "archetypes" that seemed to encompass male and female characters as shown in the table below. 
TABLE 2. INITIAL CHARACTER ARCHETYPES

\begin{tabular}{|c|c|}
\hline Male Savior & Female Savior \\
\hline The father figure & The mother figure \\
\hline The guide & The guide \\
\hline The macho vigilante & Strong/Angry Black Woman \\
\hline The messianic hero & The social justice activist \\
\hline
\end{tabular}

After I developed these initial archetypes, I wrote memos detailing the extent to which I saw how these archetypes did or did not play out across all of the movies. I unpacked and detailed the specific components of each archetype in more memos. These analytic memos focused on a specific "theme" or category that was the most salient in my analysis of the characters behaviors, language, and motivations. For example, I created over a dozen different analytic memos (spanning 100 pages in total) that covered abstract topics such "power," "violence," "exceptionalism," and "masculinity." I recorded all of the instances and codes across all of the films that corresponded to these concepts. Likewise, I had memos for more specific roles like "mother," "father," vigilante," and "activist," and I recorded all of the instances and codes across all of the films that corresponded to these concepts. Creating these memos helped me analyze "trends" and patterns across multiple films. I adjusted my understanding of the initial archetypes based on my new memos. Once that content was analyzed, I relied on grounded theory to use the memos gathered from the content analysis to create conceptual categories about the potential functions and roles of the black paternalistic character.

After creating memos, I turned them into conceptual categories that eventually became the "strategies" each of the black characters in the sample used to "save" others. I 
created these categories by looking at what codes certain characters had in common in an “active coding” phase. As Charmaz (2006) explains, "Through this active coding, you interact your data again and again and ask many different questions of them. As a result, coding may take you into unforeseen areas and new research questions" (p.46). Three of my memos: "Revolutionary," "Vigilante," and "Altruist" were developed into broader categories for analysis since they were the memos under which each character fit under given their behaviors and dialogue. Thus, the codes for each of those character's words and behaviors also fell under at least one of these categories. This process allowed for a more robust theory of paternalism in film.

\section{Methodological Issues}

While coding the scripts was originally part of the coding process, it proved to be unreliable. Upon looking for specific scripts, I found many of them in easily accessible online databases such as Scripts.com, Springfield! Springfield!, and other similar sites. Upon downloading the scripts for analysis, I noticed many of the scripts were missing key pieces of information in the script that would have allowed me to accurately code them. For example, some scripts such as the script for Akeelah and the Bee, parts of the Black Panther, After Earth, and The Equalizer contained the dialogue used in the film but did not accurately or fully detail who was saying which lines, and did not contain a good depiction of the events of the plot.

I had to rely on watching each film to collect meaningful and coherent data. Another issue that arose was that some scripts, like the script for Django Unchained, contained detailed dialogue and descriptions, but were actually different from the final 
version of the film that was released in theaters. This change to Django Unchained was most likely the result of re-shoots, changes during the production of the film, and postproduction edits - all of which are extremely common in the film industry. Django Unchained specifically has scenes that were either edited out or un-filmed, but were left in the available script I could find. The film's deviance from the script I had access to made it difficult to code it and compare it to the final version of the movie used for analysis.

Essentially, this deviation from the script meant that I abandoned the study's original plan to code the scripts separately from the film and I instead looked at them in tandem. With the aforementioned changes, I coded the film while using the script as a reference to orient me to specific lines of dialogue if I needed to go back them. Utilizing the aforementioned coding methods, I could ask: which theoretical categories might these segments indicate? The coding processes outlined above helped specific codes emerge of specific from the data that helped me to analyze my findings from these films, which I detail in the following chapters. 


\section{CHAPTER IV}

\section{THE REVOLUTIONARY}

I find that revolutionary characters seek to make large systemic changes to address racial oppression. What is immediately apparent with these characters, that I call "revolutionaries," is how different they are from white savior characters. Revolutionaries seek revenge and systemic change to address racism. The specific ways in which revolutionary characters seek to make systemic change is usually through terroristic violence or non-violent peaceful protest. In addition to their focus on systemic change, these movies ultimately resemble civil rights films in that they reduce social movements to eliminate racism and sexism down to the violent or activistic actions of one individual, one "leader" who knows what is best for others. In other words, movies with these revolutionary characters are ultimately individualistic narratives.

Both violence and protest manifest as "revolution" in these films because revolutionaries use violence (if they are men) and protest (if they are women) as tactics to influence others around them to make specific social changes that drastically improve black people's lives. The ways these characters seek to make change reinforce specific controlling images such as the violent black male or the common "bad black girl" images that have race and gender dynamics as Collins (2005) describes them. The type of 
controlling image a character is associated with affords different characters intellectual and social power depending on their gender.

In this chapter, I will discuss how black men and women revolutionary characters in my film sample seek to address and eliminate global systems of racial oppression, in gendered ways, in an effort to achieve systemic changes in the films. First, I lay out how the revolutionary category breaks down into its two archetypes, messiah and activist, and their characteristics (See Appendix C). Second, I provide evidence of my claims for movies featuring "messiahs" and then movies featuring "activists." Finally, I synthesize my findings to provide a discussion of these characters and their implications in regards to my intersectional theoretical framework.

While black male and female revolutionaries often experience and understand oppression, they channel their understanding into specific actions for addressing the oppression they see around them. Both men and women revolutionaries seek to address and eliminate racial oppression and, in doing so, they seek to liberate themselves and other black people through direct violence. The ways in which these revolutionary characters "liberate" others is gendered since men tend to possess more social, political, and intellectual power to enact change which affords them more agency and efficacy in a movie's plot. Revolutionary men are much more violent and extreme than women, thus men reinforce the controlling image of violent black males. Violence, in the context of this study, refers to the use of physical force to inflict pain on another individual. Violence can be expressed symbolically through threats or displays of physical force, and is framed as a "masculine" tool of resistance and retribution for being mistreated that is 
often used to directly affect the people around the men who appear to rely on violence to succeed.

Women revolutionaries tend to lack social, political, and intellectual power and initially lack agency until someone else, usually a teacher or mentor, gives them the resources, education, confidence to advocate for change. Another aspect of the revolutionary character is the strategy of protest, a tool of resistance associated with women in these movies that admonishes race, class, and gender oppression using rhetoric and the spectacle of civil rights mobilization. When women do become conscious of racism, they seem to transform into "angry black woman," and "bad black girl" controlling images. The ways in which race, class, and gender intersect within these characters influences how they seek to liberate others. Given the aforementioned gender differences, I find that there are two specific character archetypes that fall within this chapter's broader theme of "revolution:" the messiah, who engages in war against his own, or other, governments to bring large revolutionary change; and the activist, characters that work to make broad systemic change. Both of these archetypes fall within gender lines.

\section{Revolutionary Messiahs}

In the context of this study, messianic characters generally conform to notions of messianic masculinity and hegemonic masculinity (Connell and Messerschmidt 2005; Neal 2013). Messianic characters work to save the world or entire groups of people at once because they appear to be the only people who can act as saviors. They tend to be very aware of institutional and systemic racial oppression, and they use their resources 
and violence against governments and government leaders, usually in an effort to coerce those governments (or officials), to bring about broader institutional changes. Messianic violence is usually political or terroristic in nature. Messianic characters rarely achieve change organically—change has to be brought about by force. Messianic characters are portrayed as military heroes — or people with a military backgrounds—who are charismatic enough to command a large mass of people like a military general.

These characters tend to be shown as vastly "superior" and exceptional men. The expressions and variations of hegemonic masculinity in the films are paired with men who think of themselves as messiahs who promise revolution and salvation from white supremacy. This messianic bent creates characters who believe themselves to be the only ones who can save humanity, which justifies their paternalistic behavior. Thus, masculinity makes these men seem "heroic," while simultaneously reinforcing patriarchal ideologies of masculine domination and primacy over women and men who do not meet certain impossible standards (Neal 2013).

All of the traits of the messianic character are coded as masculine, and messianic black men are defined, in part, by their physicality and direct implied use of physical force. Violence is a controlling image of poor black males that is used to demonize them as lacking civility and middle-class sensibilities. Because these men are portrayed as preternaturally violent, they are thought to be upsetting to the social order. However, I find that while violent black males is a stereotype, the messianic black men in my sample reclaim and use violence as a tool for liberation. Instead of allowing white "oppressors" 
or "The Man" to use violence to violate them, black men use violence to violate the oppressor.

\section{Revolutionary Activists}

While messiahs are portrayed as black males who are prone to violence, activists are portrayed as black women who avoid violence by engaging in protests, policy proposals, and reforms to bring awareness to racial and gender oppression in their communities and all over the world. Movies with these women show them protesting against systemic racism and sexism in an effort which results in the elimination of racism and sexism in their communities. However, there is an example of one male activist, which seems to be an outlier in the sample. Like the messianic males, both activist women and men seek to end systemic racism (and/or sexism). However, since they do not try to bring change by force or threat of violence, activists tend to fight oppression academically, intellectually and, for women like Lysistrata in Chi-Raq, through their sexuality.

Activists focus their efforts on raising people's consciousness around racism and, in doing so, they inspire others to make change as the moral thing to do. Like black male messiahs, black female activists are also associated with controlling images involving their physicality. However, instead of being framed as violent, some black women activists use sex, and forms of traditional protest, to make change. By relying on sexuality, and the use of sex to manipulate men, black women fall into Collins' (2005) concept of the common "bad black girl" stereotype that sums up characters like Lysistrata in Chi-Raq. In addition to the "bad black girl" stereotype, non-sexual black female 
activists tend to reinforce the "angry black woman" and "educated bad black girl" controlling images that are commonly used to denigrate poor, educated black women as uncivil (Collins 2005). Activists embody those controlling images, adding an intersectional focus to how activists behave. Like men, black activist's use of sex, or anger, is a way for them to reclaim those tactics to resist their oppression. Subversion reframes the aforementioned controlling images into "counter-narratives" of black female empowerment.

The main difference between the messiah and activist is that messiahs (men) use violence as a liberation strategy because violence is coded as "masculine" in media, while activists (women) use sex because it is coded as "feminine" in media. Thus, "revolution" is carried out in ways that are gendered and classed. Poor black men are masculine, violent, terrorists; poor black women are feminine, sexual, "bad black girls." Despite the difference in their methods and presentations, both activists and messiahs want to achieve the same goal: liberate black people from racial oppression via (gendered forms of) political action.

The two character archetypes are not mutually exclusive, since messiahs can exhibit traits of activists and vice versa. Despite the possibility of overlap, they are largely separate characters. In the upcoming sections, I will explain the messiah and activist archetypes in more detail as they appear in the films in the sample. The following section focuses specifically on the messianic hero revolutionary character as it works in Black Panther, Black Dynamite, and Beasts of No Nation. I center my analysis on these 
specific three movies because they contain the clearest examples of revolutionary, messianic characters.

\section{Messiahs and Hegemonic Masculinity}

An example of a violent messianic character comes from the movie Black Panther (2018) and its main antagonist Erik Killmonger. Killmonger is a mercenary who has connections to royalty in Wakanda, the fictional African kingdom hidden from normal view that only Wakandan citizens can enter. After Killmonger's father was killed by the former king of Wakanda, Killmonger was left behind in the United States where he grew up in poverty and developed a grudge against Wakanda for not helping him or other black people like him. Killmonger spends most of his life training to become king of Wakanda since he does not think T'Challa, Wakanda's current king, is effective. Wakanda is a kingdom that is implied to always have or need a king who is chosen through trialsby-combat, a display of combat skill that is shown early on to be a violent ritual of domination. This hints that Wakanda is built on a premise of masculine domination that is reinforced throughout the film. Killmonger eventually finds an opportunity to challenge King T'Challa to a trial by combat for the throne. Killmonger kills Ulysses Klaue-a smuggler who stole Wakanda's most important resource called "vibranium"—-and uses Klaue's death to legitimize his claim to the throne. Before his fight with T'Challa, Killmonger explains that he returned to Wakanda to right the wrongs of racial oppression that T'Challa and his coterie of vassals and advisors refused to deal with,

Killmonger: "I'm standing in your house serving justice to a man who stole your vibranium and murdered your people... It's about two billion people all over the world that look like us. But their lives are a lot harder. Wakanda has the tools to liberate them all." 
Killmonger's claim that "Wakanda has the tools to liberate them all" reflects his role as a messianic male and the messianic male's desire for liberation from global racial oppression, and he reinforces his desires once he presumably commits regicide by throwing T'Challa over a waterfall and to his "death" in the trial. Once Killmonger becomes the king of Wakanda, he immediately dedicates the kingdom's resources towards waging war against "oppressors" who subjugate black people all over the world. He sits before the royal council and tells them he intends to turn Wakanda into an empire in which African people can never be oppressed again as Killmonger states below,

Killmonger: "You know, where I'm from, when black folks started revolutions, they never had the firepower or the resources to fight their oppressors. Where was Wakanda? Hmm? Yeah, that ends today. We got spies embedded in every nation on Earth... So we're gonna use their own strategy against 'em. We're gonna send vibranium weapons out to our War Dogs. They'll arm oppressed people all over the world so they can finally rise up and kill those in power. And their children...The sun will never set on the Wakandan empire."

Killmonger expresses his to desire to use Wakanda's government to attack white people who he says oppress black people all over the world. His desire to kill white people who have oppressed others is messianic.

Killmonger sees Wakanda's government as complicit in black oppression, which drives his crusade to overthrow the government by engaging in the violent rites of passage that are required of all aspiring Wakandan kings. His belligerence revolves around violent actions, violent political philosophy, and violent governmental power he plans to wield against world as king. Violence and bellicosity come to define Killmonger's goals. He believes his belligerence is noble because it is aimed at overthrowing an apathetic government in the name of black power and freedom. I 
consider Killmonger to be "revolutionary" because his actions are in response to black oppression writ large, and he seeks to eliminate that oppression through the language of violence that places him within a broader narrative of messianic masculinity. Commandant in Beasts of No Nation also fights against his own government to liberate himself and other Africans whose lives are ruined by war.

Commandant is the charismatic leader of the NDF, which is made up of black boys who have been orphaned by the war being waged against their people by the West African government. Commandant thinks of himself as a revolutionary and a hero, and his boys look up to him as a father-figure working in their interests. Commandant promises the boys revenge on the people responsible for killing their families in exchange for their loyalty. He first offers the boys a chance at revenge when he meets Agu, who had been captured by Strika, a mute child soldier who serves Commandant. Commandant approaches Agu, and introduces himself and tells him that the government killed his family. Commandant asks him if he wants to get revenge on the people who killed his family. Agu agrees, and Commandant takes Agu under his wing, transforming him into a child soldier.

To serve in Commandant's army, Agu and the other prospective soldiers must be willing to do whatever he asks on the battlefield, or be killed. Commandant feeds them propaganda about the NDF and tells them that their service in the NDF makes them "fortified" and "pure." He encourages them to fight for, and with, him to liberate themselves and West Africa from their oppressive government, which he explains in this speech he gives to his "army," 
Commandant: "We are defending ourselves. We have to get revenge. Huh? We have been defending ourselves against the killings and rapings of our own people from the PLF and now from the NRC junta. But it has awakened a sleeping beast. It has awakened a giant. It has put the weapons of this war back in the hands of you, the young and, therefore the powerful..."

Commandant's speech to his soldiers echoes Killmongers desire to "put the weapons back in the hands of" disadvantaged black people. Both Commandant and Killmonger see military violence as the most effective means to insure black people are liberated from oppressive forces. The difference is that while Killmonger pulls the levers of military power in Wakanda from the top down, Commandant pulls the levers of grassroots power from the bottom up. By having a more grassroots form of "revolution," Commandant commands his soldiers to individually commit acts of terrorism to prove their loyalty to him and their movement. Later in the film, Commandant encourages his soldiers to raid a village and kill "all of their enemies," including men, women, and children as a form of “justice.” Afterward, Commandant continues to make his soldiers fight for liberation even when it no longer looks like justice is possible. Commandant's masculine tendency to treat military violence as a sensible solution to oppression is prevalent not only in dramas and action movies, but in comedies like Black Dynamite.

Black Dynamite centers on the experiences of Black Dynamite, a former CIAagent and Vietnam war veteran who finds himself fighting a global conspiracy to weaken black men. This conspiracy is designed to further oppress black people, in an effort to empower "The Man," a conspiratorial euphemism in this movie for white people who purposefully use institutional racism to maintain their own power. While Black Dynamite's violence is more satirical than that seen in Black Panther and Beasts of No 
Nation, the movie still shows Black Dynamite as a character who is willing to engage in physical and political violence to eliminate the racism affecting black people.

Throughout the movie, we see Black Dynamite investigating who might have killed his brother in a drug deal. As he gets deeper into his investigation, he comes across plans and conspiracies more absurd than the last, and he learns about Operation: Code Kansas, a plan that is supposed to "fix all the niggers" as one person overseeing part of the operation explains. Operation: Code Kansas is a comically convoluted plan to use chemicals in Anaconda Malt Liquor to emasculate black men by shrinking their genitalia. This plan is but one part of a larger conspiracy to keep black men addicted to drugs and alcohol that will severely weaken them to maintain white supremacy throughout the United States. Black Dynamite eventually learns that Operation: Code Kansas originated from the President Richard Nixon. The movie implies that the drugs black people were being arrested and jailed for were deliberately manufactured by the government to justify racist policies that were designed to "fix all the niggers" who opposed Nixon.

Black Dynamite infiltrates the White House to stop President Nixon and bring justice to all black people who have been affected by Anaconda Malt Liquor and the drugs Nixon and his henchmen manufactured. Black Dynamite and Nixon have a fight to the death. Black Dynamite wins and they exchange dialogue. After their fight, Black Dynamite makes Nixon promise that he will use all of his powers as President to "take care of" black people, indicating that Black Dynamite is ultimately a savior of the black race as a whole in the U.S. While this scene is meant to be humorous, it does speak directly to the ways in which macho black males like Black Dynamite seek to dismantle 
racism in the U.S. This scene also reflects a real tendency for black males to be associated with violence as a tactic for broad systemic change. What all of these revolutionary men have in common aside from the fixation on liberating black people through violence, is that the violence is used to get revenge for wrongdoing.

Portraying black males as vengeful and violent reinforces hegemonic masculinity (Connell and Messerschmidt 2005; Tyree 2014). Concerning masculinity and violence, bell hooks (2003) argues, that violence helps men maintain their dominance over women and society. Aggression is required for men to gain respect in a society in which black male violence is a normalized masculine identifier. Tyree (2014) explains that the overuse of violence is part of the "tough guise," the mask males put on based on extreme notions of masculinity, that emphasize brutality, strength, and gaining respect through violence or the threat of it. This tough guise develops from a destructive and exaggerated masculinity (called hypermasculinity) that emphasizes domination and force and often develops among socially marginalized men (Herek 1987; Jewkes et al. 2011). Hypermasculinity in this case arises from the relationship between hegemonic ideals and some men's inability to meet them, indicating that the origins of exaggerated masculinity lie in adversity. Resulting from this adversity is the use of violence (Bourgois 1996; Jewkes et al. 2011, 2013; Mathews, Jewkes, and Abrahams 2011; Fulu et al. 2013). We see hypermasculinity, and its causes and effects, play out in these movies, especially in the displays of violence.

In each of these movies, the messianic male chooses violence as a solution to most of the problems in the film, and these men are respected for it. Killmonger becomes 
king of Wakanda after violently beating T'Challa almost to death and then asks Wakandans "Is this your king?" before throwing him over a waterfall—a show of mocking T'Challa's weakness and penchant for compassion as king. Commandant's command to each of his soldiers is to kill those who get in their way, and Commandant is respected for his actions and commands because he instigates his soldiers' anger at the government with promises of revolution and revenge. Black Dynamite is respected in his community for being willing to fight "The Man" with exaggerated kung-fu in an effort to vastly improve black communities all over the nation at a time when the government purposefully acted to disenfranchise them. These men are respected for their violence by other men, and they use their violence against women in an effort to physically dominate them.

Erik Killmonger, Commandant, and Black Dynamite embody messianic masculinity. They are all political actors, or become them, and the women in these movies are all marginalized in some way. Killmonger kills his own girlfriend to get to Wakanda, chokes one of his female attendants when she does not immediately do what he asks her to, and he fights the female members of his own royal guard to complete his plans to wage war against white oppressors. Commandant commands his soldiers to rape and kill women, while also promising that they will be rewarded for their efforts with beautiful women who will admire them after the war. Black Dynamite portrays women as sex objects for Black Dynamite as many of the women in the movie fawn over him and find him attractive. When we are introduced to Black Dynamite, he is shown in bed with two other women and we see women fawn over him throughout the film. Black Dynamite 
is also willing to fight women who get in his way such as when he fights Richard Nixon's wife and slaps her into a china cabinet. Women are objects, and sometimes obstacles, to these men and they marginalize women while empowering the men around them, especially when we see Commandant lead his group of male rebels to stop the government, and Black Dynamite's work alongside an all-male band of pimps, drug dealers, and activists to stop the President.

\section{Black Male Poverty, Stereotypes, and Re-Appropriation of Violence}

Historical representations of black men as violent originated in colonial portrayals of black men as beasts, which were often presented alongside the "noble savage" caricature and other controlling images. The controlling image of black men as violent and deviant encapsulates the perception that black men are inherently violent and criminal (Collins 2005). The perception of black men as inherently violent is usually associated with black poverty in the media (Collins 2000, 2005). Each of the messianic characters is presented as "threatening" because of his gratuitous overuse of violence to achieve their goals, a trait that Collins explains is often associated with the poor. What is interesting about Killmonger, Commandant, and Black Dynamite is that they adhere to messianic masculinities but they do not adhere to the class dimensions of the concept as laid out in Neal's (2013) work. The aforementioned notions of violence as a mechanism of the poor is where I begin to see the intersectionality of filmic "revolution" and its connection to expressions of masculinity.

To exhibit messianic masculinity, a black man is supposed to be one of the

"Talented Tenth" which is implied by his middle-class status and education. However, 
black revolutionary men in my sample are not highly educated, nor are they middle or upper-class. None of them have proper jobs or incomes, which means they are coded as poor. They do adhere to the messianic notion of "saving the black race" using various methods of governmental resistance. The concept of class nuances, but does not completely alter, how black male revolutionaries fight against systemic racism.

In theory, middle-class revolutionaries use their superior knowledge and education to save the black race, reinforcing the notion of "civility" inherent in messianic masculinity (Neal 2013). Given my findings from the sample, male revolutionaries seek change through terrorism and political violence while still fitting within the conceptual frame of messianic masculinity. Theoretically, "middle-class" messiahs seek to be more diplomatic in their approach to social change and thus might be more similar to male activists. In contrast, poor messiahs seek to be more coercive in their approach to social change. Masculinity is, theoretically, the common denominator between middle-class and poor revolutionaries, and class influences how that masculinity manifests. Both poor and upper-class male revolutionaries represent some form of hegemonic, messianic masculinity that affords them the agency to bring change.

Adding to the theme of masculinity, Collins (2005) explains that masculinity is heavily associated with "hyper-heterosexuality" in which black males are shown to be wildly sexual. Each messianic male revolutionary character is heterosexual. Commandant and Black Dynamite especially reflect the "hyper-heterosexual" nature of black male controlling images. Commandant explicitly encourages his soldiers to kill for him so they can be rewarded with adoration and sexual attention from women who will admire them 
as African heroes. Black Dynamite is introduced to the audience as a philanderer who sleeps with multiple women at a time and is adored by a harem of prostitutes. Killmonger is briefly shown committing crimes with, but not engaging in or talking about having sex with his girlfriend, who gets little screen time since she is a minor character in Black Panther. Hyper-heterosexuality is definitely a part of how these revolutionary males function, and it coincides with other concepts of violence and class to form the messianism that defines these men.

Despite the fact that these men harken back to classic colonial stereotypes of black men, the use of violence is reframed into character strengths that allows these black men to fight for themselves and others to achieve systemic change. This means that even though the overuse of violence is a stereotype of black males, black men in the sample reappropriate violence for their own goals. This means that the use of violence seems to subvert traditional narratives in which black characters are portrayed as incompetent as a result of their violent tendencies. In the case of these films, these black men are competent mostly because of their violent tendencies.

While "revolutionary" men frequently resort to violent, and sexist, methods to achieve liberation, their actions stand in contrast to women whose actions are less violent, more civil, and some cases more sexual. In contrast to messianic male characters, black women tend to resort to nonviolence to save or rescue others. In contrast to messianic men, women activist have slightly different goals since their work is focused more on localized racism in their communities. They achieve those goals through the use of 
protest as demonstrated in the movies Chi-Raq, Dear White People, and The Hate U Give.

\section{Women Activists and the Acquisition of Knowledge}

Chi-Raq centers on the actions of a poor woman, Lysistrata, who is in a relationship with local rapper Chi-Raq. Chi-Raq raps about gun and gang violence and is held responsible for encouraging gun violence in his community and he is often criticized for how his lyrics encourage gang activity. After some encouragement from Ms. Ellen, Lysistrata decides to find a way to stop the gang violence in Chicago, and around the world, by starting a sex strike to end male violence perpetuated specifically by black men.

To start the strike, Lysistrata recruits local women who have been impacted by gun violence. After convincing the women to join her cause, they go to a local church where a white pastor, a community leader, talks to them about their ability, and responsibility, to bring peace to the neighborhood. The pastor tells them they need to do more than protest and strike locally; he says they need to make institutional changes since gun violence is largely a systemic racism issue. Lysistrata vows not to perpetuate the "white man's murderous bidding for him" and the women come to believe gun violence is a byproduct of institutional racism. From this point in the film, Lysistrata is framed as a revolutionary whose job now is not just to save her black community but to save all black communities around the world — to "save us from us" as the pastor claims. Lysistrata leads a cadre of black women to take over the Chicago, Illinois National Guard armory to 
eliminate the supply of guns that is held there. Afterward, the women peacefully protest and demand justice.

Lysistrata's movement becomes a global phenomenon with women all around the world who begin restricting men from accessing their bodies, or their services, until men agree to end violence. The strike causes the global economy to shut down, triggering a response from the military - consisting entirely of men - that attempts to find a way to undermine the strike and send millions of women back to work. Mayor McCloud and Commissioner Blacks devise a plan to lure the women out of the U.S. National Guard armory—where they have taken refuge—with seductive music, but first, Commissioner Blacks tries to reason with Lysistrata one final time in the following scene,

Lysistrata: "Don't give us no smack. Or we'll beat you to death with pampers, Gerbers, and similac."

Commissioner: "Talk that talk, but you're going to jail. And don't even think about bail. Who do you think you are, Rosa Parks? What a damn farce." Lysistrata: "Yo, we in a hurry like a Ferguson or Staten Island jury." Commissioner: "Those judgments were fair. Look, y'all, nobody cares." Lysistrata: "Trayvon Martin. Mike Brown. Tamir Rice. Walter Scott. Rekia Boyd and Freddie Gray. Black Lives Matter everyday. Not just when you trigger-happy cops go astray. Dude, you think sister Sandra Bland hung herself? You kill us with impunity."

This exchange shows that the sex strike evolves from merely stopping all forms of black male violence into a movement meant to stop racism through exposing it and educating (black) people on how black men's own actions perpetuate racism and black disadvantage. The movement becomes critical of hypermasculinity and the patriarchy that creates suffering all around the world. Lysistrata emphasizes her frustration with patriarchy in her argument with Ole Duke, the leader of the Knights of Euphrates, a chauvinistic organization made up of members of a black country club, that managed to 
sneak into the armory. The Knights are frustrated by the sex strike and demand that Lysistrata call it off since they see it as a farce. Ole Duke criticizes Lysistrata's desire to demonize men because he thinks women are just as flawed. Thus, he believes Lysistrata to be a hypocrite. After calling Lysistrata an "ungrateful bitch" for constantly defying him and men all over the world, Lysistrata slaps him in the face and explains why she fights for justice,

Lysistrata: "This ain't no joke...Dude, this is about life and death, about a community that's a wreck. And you wanna sit here and talk about how women behave? Fool, we trying to free these slaves...Saving lives, that's our job."

Lysistrata's desire to use her platform to "free these slaves" and bring awareness to institutional racism and the patriarchy in an effort to change it makes her activism an extension of the controlling image of poor and working-class black women in the media as promiscuous and "too-strong" (Collins 2005).

Throughout Chi-Raq, Lysistrata is introduced and constantly portrayed in terms of her sexuality. At the beginning of the movie, she is shown having sex with Chi-Raq after his concert, she infiltrates and takes over the National Guard armory by seducing soldiers, and she is the leader of a sex strike. The movie revolves around sex and the use of sex as a means to stop violence. Lysistrata's effectiveness as an activist is enhanced by her sexuality and physical attractiveness, which is an extension of the controlling image of black women as hyper-sexual and ungrateful for the stability (black) men provide. Lysistrata's refusal to bow to men makes her strong, aggressive, and independent. According to the men in the movie, Lysistrata, and other women, do not deserve rights or 
"liberation" because of how aggressive they are, and society needs to return to patriarchy to re-establish the social order.

The desire to return to patriarchy is apparent when Ole Duke, and the Knights of Euphrates, confront Lysistrata and he refers to her as an "ungrateful bitch." The use of the word "bitch" is a term that is lobbed at poor black women who lack middle-class passivity and submissiveness (Collins 2005). Because Lysistrata and the women she revolts with are not giving men what they want, men all over the world get frustrated and come to believe that the oppression women experience is justified because, as Ole Duke says, women are just as flawed as men. Therefore, Lysistrata focusing her activism on criticizing men makes her an "ungrateful bitch" in the eyes of men. In this context, "bitches" must be resisted and silenced, especially if they complain about social injustice. Ole Duke's use of the phrase "ungrateful bitch" stigmatizes poor and working-class black women who lack submissiveness associated with the middle-class—a submissiveness that benefits men (Collins 2005).

As is the case with messianic characters, Lysistrata is framed using a controlling image that is used to ridicule and subvert black characters. Characters like Black Dynamite and Lysistrata, for example, are portrayed as unruly and upsetting to the social order because they openly defy the status quo. The difference between the aforementioned characters, however, is that men make change through violence, and women make change through protest and sex. Collins (2005) mentions that the "bitch," also called the "bad black girl" trope, takes control of her situation by manipulating her sexuality for her own gain. The reclamation of sex as a tool of liberation in Chi-Raq 
subverts the controlling image of the poor, hyper-sexual, and wild. While the "bitch," or "bad black girl," archetype plays out in Chi-Raq, Sam White, in the movie Dear White People, represents the "angry black woman" stereotype that also has elements of the "bad black girl" archetype.

Sam White is a student activist who protests racist housing policy at Winchester University that segregates students into dorms by race. Specifically, Sam criticizes the university for its segregationist housing policies that the school administration claims is actually random. Sam sees these racist policies as a way to encourage a form of apartheid at the university to eliminate the school's "blackness" in an effort to support white supremacy, and she seeks to "bring black back to Winchester." Her campus radio show, "Dear White People" is Sam's primary platform to criticize and explain racial and gender inequalities to students.

Early in the movie, we see posters around the university reading "Missing Black Culture. Sam White to Bring it Back." To "bring black back" to the university, Sam runs to be leader of the Armstrong-Parker dorms to oversee their housing policies and make changes she and other black students want to see. The dorms are overseen by Troy Fairbanks, a professional Obama-esque black male student, who seeks to maintain his position by not challenging the racial status quo at the university. She gives a speech in an auditorium to make her case for why she should be house leader after her rival Troy, who says he should be leader of Armstrong-Parker because of his previous and “exemplary” work as house leader,

Sam: “Troy, my brother, it's broke. Troy's a legacy kid. And yet it's under his watch that Armstrong-Parker, the bastion of Black culture here, was 
gutted. By the Randomization of Housing Act, second years of color no longer have a say in where they go...”

After giving her speech for why she should be house president, she wins and her friends pressure her to start using her position to protest and make real changes in the university. Sam's friends, Sungmi and Reggie want Sam to hold a rally on campus. Sam eventually backs off of her hardcore revolutionary position after experiencing an identity crisis.

After taking some time for self-care, Sam's final gambit against racism on the campus is to send invites to white students to a blackface party to then expose how many racist students exist on campus. She likens herself to anarchists who did the work to get black people civil rights. Lysistrata and Sam's actions are distinctly "anti-hegemony" and anti-racist and in many ways represent the opposite of what paternalistic men seek to represent: domination. Sam's activism in this movie is colored by a different controlling image than Lysistrata's activism in Chi-Raq. Lysistrata was more representative of the "bad black girl" image that allowed her to take a revolutionary stance using her sexuality and desire for autonomy as a black woman as a catalyst for systemic change. Sam, however, is not nearly as sexual, and notions of gender are more implicit with her character than Lysistrata's. However, gender is still present in the "angry black woman" image that Sam represents.

The trope of the angry black woman is about a black woman "acting up" and showing disregard for civility and decorum by expressing anger at sexism, racism, and whatever other social issue she is passionate about. Angry black women are typically lower-middle class, disagreeably, loud, and have chaotic impulses (Harris-Perry 2014; Judd 2019). Just as the "bad black girl" is an extension of the Jezebel, the angry black 
woman is an extension of the Sapphire who is also always angry. The Sapphire trope is designed to prevent women for speaking out against social injustice by stigmatizing them as perpetually angry and aggressive in an attempt to center their rage instead of their feelings (Jones and Norwood 2017). More insidiously, this trope is a distortion and negation of black women's knowledge. Throughout Dear White People, Sam expresses her anger at white people through her radio show "Dear White People." She is criticized for constantly browbeating white people, and she is mocked as a "wannabe Black Panther." She is also met with resistance from other black people like Troy and Coco, who think Sam is irrational, petty, and arrogant because she "boycotts hot combs" and thinks of herself as an "expert" on all things black.

Sam's anger is largely perceived as unproductive, unoriginal, and condescending. Like the "bad black girl" controlling image, Sam is maligned because she is "uncivil" and upsets the middle to upper-middle class sensibilities of the people at the school. Sam's anger is anathema to what the school is supposed to represent: culture, sophistication, and a semblance of whiteness. However, unlike the traditional angry black woman, whose anger is used to denigrate and belittle her, Sam's anger is channeled into activist praxis throughout the movie. Sam claims that her radio show and anger is "counter-cultural," at least in relation to the campus, because she problematizes the omnipresence of racism and sexism in the everyday lives of black students. Sam eventually realizes that her anger is her way of overcompensating for a perceived lack of "blackness" within herself since she is bi-racial. 
Additionally, Sam's anger did not help her to achieve anything on campus; it made her an unproductive laughing stock. This is present in a short scene where Lionel, a black student, tells Sam that there is a blackface party happening at the university long after she had decided to stop being an activist. She tells Lionel, "I'm done being everybody's angry black chick," and later embraces her role as a revolutionary anarchist instead. Sam being transformed by her anger into a more effective activist seems to be an extension of the angry black woman controlling image. Anger, when analyzed from a black feminist lens, is a "ritual of knowing" and self-discovery that can lead to activism (Collins 2005; Judd 2019). According to Collins (2000), anger leads to a woman's ability to create self-definitions that foster action. Sam's transformation indicates that her existence as an "angry black chick" was a moment of self-discovery that led to a more effective form of activism. The angry black woman stereotype is present in other movies about anti-racism like in the movie The Hate U Give where we watch Starr Carter who has to find her voice to stand up for her friend who was shot down by a cop.

Throughout the movie, Starr gets advice from her father, Maverick "Mav" Carter about how to speak out against police violence. Mav's role in this film is similar to Ms. Ellen's role in Chi-Raq. Ms. Ellen was an intellectual and academic well-read of black revolutionary thought. Likewise, Mav is also framed as well-versed in the Black Panther's Ten Point Program, a set of guidelines to the Black Panther Party that states their ideals and ways of operation (Anderson 2012). Point seven in the guidelines, which is referenced multiple times in the film, references the Black Panther Party's denunciation of police brutality and murder of black people. 
Mav raised Starr and her siblings to have the Ten Point Program memorized so they can apply it to their everyday lives. By teaching his kids how to apply the Ten Point Program, he begins to encourage Starr to speak out against Khalil's murder, and he tells her, "You know, not everybody got superpowers like you. Shine your light. I ain’t name you Starr by accident." Starr is unsure of how she should speak out or if she should reveal that was the witness to Khalil's murder. She eventually gets advice from April Ofrah, a local activist, community leader, and civil rights lawyer. Starr begins to challenge the racism around her more as she morphs into an activist. One scene with her white boyfriend, Chris, acts as the beginning of Starr's transformation into an activist who wants to fight for her people after Chris makes an insensitive remark about police brutality,

Starr Carter: "Have you ever seen somebody die?...Well, I have twice now. That's why my parents put me and my brothers in Williamson. To protect us. And now, it's like I have to hide who I am every single day...I turned my back on all of my people. Do you even know what that's like?"

Starr's desire not to "turn her back on" her people is similar to Lysistrata's desire to help save black people "from themselves" and the effects of systemic racism in her community. From this scene forward, Starr takes a much more active role in speaking out against police brutality. As tensions between police and activists intensify in her neighborhood, Starr decides to become the activist she believes she has to be in order to bring justice for Khalil's murder and to stand up for black people everywhere. During the "Justice for Khalil" protest, Starr takes a megaphone and decides to make a statement to the raucous crowd,

Starr Carter: "My name is Starr! And I'm the one who saw what happened to Khalil! I am the witness! But so are you all! We are all witnesses to this 
injustice! We see it all, and we will not stop until the world sees it too! We will not stop protesting!"

At the end of the movie, Starr decides to continue protesting for Khalil after she helped bring some peace to her community through her activism, citing her newfound “superpower" as her main motivation to keep going,

Starr Carter: "Khalil. I found out that name means something, too. Friend. I'll never forget. I'll never be quiet. I can't change where I come from, or what I've been through, so why be ashamed of what makes me me? And I'm going to keep on being Starr...Daddy says my name gives me my own superpower, to use it. And that's what I'm going to do. Light up the darkness."

Starr's journey into her role as an activist against injustice parallels the journey of

other activist women like Lysistrata and Sam because Starr evolves from a typical "angry black woman" character into an anti-racist activist. As is the case with Lysistrata and Sam, Starr's anger at the injustices of police brutality leads her on a journey of selfdiscovery and transforms her into an advocate for change. Starr does not start the movie as an activist, she has to become one. Similar to Starr going to her father, Lysistrata goes to stay with Ms. Ellen who then gives her knowledge on activism using leaders like Malcolm $\mathrm{X}$ as examples. Sam does not necessarily go to a person for advice, but it is implied that she is even more motivated to fight to "bring black back to Winchester" after she watches a news story about the eruption of a "race war" at another university. Lysistrata, Sam, and Starr all experience inciting incidents that get them into more aggressive activism against racism—-Lysistrata sees the effects of gun violence on her community, Sam sees a news story, and Starr witnesses Khalil's death.

Women only seem to advocate for justice when other people and/or events raise their consciousness around racism. Because of they seem to need some kind of support, 
black women revolutionaries are only "black saviors" through the support of others, as compared to black men revolutionaries who do not need as much support. Black female characters are less likely to be portrayed as having enough power and/or confidence to play an activist role from the get go. Thus, they have to rely on others to develop their confidence. This tendency for women to lack confidence and resources to be activists is a common trope in media. Women's activism tends to be invisible because black women often lack social, political, and intellectual power. Scholars find that women's visibility increases through avenues of political participation outside traditional electoral forms. Thus women's activism often takes the form of non-institutional participation and private activism (Holman 2016). In other words, women's activism tends to take place in communities and churches. Men have more ability to interact directly with institutions of power.

Lysistrata starts a sex strike in her community to bring awareness to how gun violence is bolstered by white supremacy and patriarchy; Sam runs a radio show on her campus that is designed to subvert people's assumptions about race and racism to "bring black back" to Winchester; and Starr speaks out against police brutality during local protest. Meanwhile, men like Killmonger do not do any community activism and go straight to the top to make social change. Black Dynamite does work a little with his community in his effort to stop Nixon, but he ultimately makes the most social change by attacking the U.S. government directly. Commandant works with local orphaned boys to fight back against the government. However, Comamndant's work is not really "activism," in the same way as female activists; it is paramilitary, terrorist action. Each of 
the aforementioned events highlight Holman's (2006) explanation of women's activism. The aforementioned events also highlight a difference between male messiahs and female activists. Men seek hegemony through military domination and violence, while women seek to intellectualize hegemony. Masculinity is the source of male power, and intelligence is the source of women's power, connecting their actions to Patricia Hill Collins's Black Feminist Thought (2000).

According to Collins, black feminist thought demonstrates black women's emerging power as agents of of knowledge and how that knowledge translates to activism; she refers to this knowledge as Afrocentric knowledge. Afrocentric feminist thought speaks to the importance that knowledge plays in empowering oppressed people. A key feature of Afrocentric thought is the insistence that social and political change emerge from people's consciousness being raised. In other words, new knowledge is important for change. Most of the actions female paternalists take is influenced by their knowledge of the oppression around them. Lysistrata realizes violence in black communities is systemic and it inspires her to make change and it inspires others to make change. Sam realizes that the university is segregating students and it inspires her to make change. Both women are encouraging the people around them to do as Audre Lorde and Toni Cade Bambara suggest, and locate and dislodge the piece of the oppressor that exists within each of us (Collins 2000).

Lysistrata, Sam, and Starr embody black feminism that emphasizes growth and self-discovery through anger, which leads to their pursuit of education, which leads to their evolution into activists. Their embodiment of black feminism is much different from 
Killmonger, Commandant, and Black Dynamite's messianism. Those three men do not go through a journey of self-discovery the way women do, since they seem to naturally possess the ability to more directly initiate change through violence. Black men represent a form of change rooted in destruction of others, while women represent a form of change rooted in the construction of themselves who then reach out to others.

Because movies about activists seem to focus more on feminist knowledge and mobilization, they are distinctly non-violent. By advocating for their positions, black women can get their voices heard in situations where their voices would not have been heard otherwise. Men, however, do not have the same struggle to be heard as women since revolutionary men are more likely to start movies off as staunch crusaders who do not always need a mass movement to achieve their goals or get taken seriously; men just need to strategically use or threaten violence to get massive social change. However, there is some evidence that males, when they are occupying the activist role, can act similarly to women activists in that they also do not engage in violence and also intellectualize oppression, but not necessarily from a black feminist perspective. However, outside of biographical films, there is only one film in the sample-Roman $J$. Israel, Esq. - that portrays a male as an activist.

\section{The Male Activist and Access to Power}

This one activist male character is different from the women because he is more socially and professionally powerful than movies featuring female activists characters. His "activism" is contingent upon his lawyer background and education. In Roman J. Israel, Esq, Roman is fired from his job working in his partners's office and taking his 
cases after it is evident that his partner will not be able to return to lawyering after having a heart attack. Roman is laid off and goes to find a job outside of criminal court, since he doesn't think criminal court is effective at bringing justice. He gets a job interview at a new firm where he meets Maya, to whom he explains his desire to work as a civil rights lawyer again,

Roman: “...I'm talking about igniting a sustained mass movement, supported by rule change and injunctive relief. And I could get results using class-action tactics. I'm talking about a return to using activist litigation creatively, defensively, counter-offensively...Now, I'm offering at this time to work exclusively as your...revolutionary, in-house, full-time, paid advocate." Roman initiates his desire to be an activist and, unlike women, his expertise gives him power to negotiate his position and demand that his activism be tied to his career advancement. Women's activism is tied to their identities as women since, if they do not act, their lives, or the health of their communities, could be in danger. Roman's activism, at this point in the film, is not to protect his own life, but merely to empower others through his profession by eliminating the structural barriers that hinder people's ability to be heard in court.

Lysistrata and Sam White do not possess formal jobs and they cannot, and do not, make overtures to institutions in the same way Roman can and does. Lysistrata starts her activism with local women, and she networks with a local pastor-she does not go to a professional organization that can directly implement or fight for policy change. Likewise, Sam networks with students and she does not ever go directly to the principal or any other organization at her university that can directly implement change because it is implied that she lacks the resources to do so and must rely on grassroots organizing to affect change. This seems to be because they lack jobs or any meaningful social status 
that grants them various forms of knowledge and power. Because women lack knowledge at the beginning, they have to seek out mentors and teachers who can educate them on racism and inspire them to become activists. Roman does not need this same education because he starts the movie with all the knowledge he needs, and a job that allows him to more effectively utilize his knowledge.

Roman can maneuver around Los Angeles and directly impact policy, and this difference between men and women activists indicates that men have more social, political, and intellectual power than women who often lack those forms of power and have to build their sources of power from the ground up. Lysistrata and Sam have to march and protest in the hopes that higher-ups create policy to address their concerns. Roman, however, is already in a position where he can create a policy reform, and advocate for it, in the hopes that it affects people who are worse off than he is as he explains in a scene with his new business partner and boss, Pierce,

Roman: “...Inside this case is arguably the most important legal brief in modern legal history. A sweeping federal challenge that could yield nothing less than a grand, new era of social reform. And I say that with all due competence. The Constitution guarantees us a right to a fair trial but there can't be fairness if ninety-five percent of cases never get heard."

Roman's monologue shows that he wants to reform the entire criminal justice system. He also mentions that the case he wants to bring up in court is one for a legend, or someone who wants to be one. Towards the end of the film, Roman inspires Pierce to fight for legal reform. Roman is assassinated and Pierce takes up Roman's case.

Roman J. Israel, Esq's display of activism reveals a dichotomy when compared to movies with women activists. Roman wants to be an activist against unfair litigation standards and trial laws that deter average people from bringing their cases to court. He 
specifically works to eliminate inequality that is implied — not explicitly stated - to greatly affect black males in the legal system since the movie shows Roman working exclusively with young black males. Roman is an educated career professional, which affords him much more agency than women activists, who up to now have been shown to be relatively limited in their ability to help others through their careers because they do not have careers or professional degrees. They are poor and lacking mechanisms of upward social mobility. Roman has access to the mechanisms of mobility which in turn gives him more agency than women. Thus, the main difference between men and women activists seems to be agency, and Roman's agency comes from his profession, whereas Lysistrata's, Sam's, and Starr's agency comes from developing knowledge of oppression and converting it into social movements. Therefore, male activists are presented as inherently more powerful and politically active than women since men are introduced as revolutionaries and activists.

\section{The Black Revolutionary as a Counter-Narratives to Whiteness}

To summarize my points in this chapter, "revolutionary" characters desire to engage with and bring about massive social changes. For revolutionary "black saviors," defeating oppressive racism, sexism, and classism at all levels of society (systemic, institutional, and interpersonal) is an imperative for black survival and justice. As their names imply, "revolutionaries," seek revolution as their main priority. These characters are portrayed as "urban," generally poor or low-income black men and women, and seek to make broad social changes to confront institutionalized and systemic racial and sexual oppression, usually through the use of physical violence, terrorism, and/or activism. 
Through the use of violence, anger, and aggression, the revolutionary character perpetuates pre-existing controlling images of black people as violent, angry, hostile "agitators." The image of violent black characters is especially pronounced with black male revolutionaries, who seem to be the most likely to engage in extreme physical violence, or the threat of violence, to make social change. Men engaging in extreme violence is a racial, and masculine, stereotype that is commonly associated with (poor) black men. However, the violent black men in the sample are often depicted as "noble" or "heroic" through their use of violence, so the violence is generally depicted as a form of "empowerment"-meaning that violence is the only way revolutionary male characters can get what they want from who they want—despite the fact that black male violence is frequently used as a justification to oppress black males.

On the other hand, women seem to be less likely to use overt physical violence and are typically presented as non-violent and "angry" activists who are more likely to protest, march, and strike for social change. This anger connects black women revolutionaries to the "angry black woman" controlling image that marginalizes black women. However, I believe that the anger these women express is a way for these women to find the motivation to fight for social change. In other words, anger is a catalyst for change in movies with female revolutionaries. Like black male violence, black female "anger" is depicted as a form of "empowerment" despite how the portrayal of black women as "angry" is used to mock and marginalize them. Regardless of the violence and anger the characters express, that violence and anger is aimed at dismantling the systems of racial oppression. 
Movies with revolutionary characters also provide images of hope that oppression will change. Therefore, the revolutionary seeks justice, and revenge in some cases, instead of racial reconciliation the way white saviors do. Movies with revolutionary "black savior" characters present three broad ideas:

1. that black people struggle from or are victims of intersectional racial, gender, and class oppression;

2. that racism is mostly, and will continue to be, perpetuated by white people against vulnerable people;

3. and the belief that black people must demand justice for oppression through either direct violence against whites and other "oppressors", or policy reform.

Movies with revolutionary characters are much more pessimistic about the nature of racism and "race relations" in the United States. However, the portrayal of black people as racially conscious is necessary for combating colorblindness. According to BonillaSilva (2017), “...the black masses must be as racially conscious as the leaders of the new movement" to make changes to the racial order (p.213). With Bonilla-Silva's discussion in mind, I believe revolutionary characters are "educators," and the movies they are in function as "educational tools." Thus, the purpose revolutionary characters serves seem to be to bring awareness of racism, and the tools and forms of resistance against the inimical effects of institutional racism and colorblindness, that continue to harm black people in the real world.

By existing as educational tools, movies with revolutionary characters also seem to be social commentary on racism, sexism, and classism and how those problems can be 
solved in the United States. Thus, movies featuring "black savior" revolutionary characters, as I have discussed them up to this point, provide counter-narratives to white savior films that depict people of color as wholly dependent on merciful white people by showing them as able to defend and fight for themselves without help from white people. In terms of race theory, counter-storytelling is also a tool that contradicts racist depictions and narratives in order to reveal how white privilege operates to reinforce and support unequal race relations. Counter-narratives give a voice to the oppressed and facilitate sociopolitical cohesion, survival, and resistance among marginalized groups, creating new discourses that have typically been ignored (Delgado and Stefancic 2000).

Following the aforementioned definition of counter-narratives, I theorize that movies about black revolutionaries are also counter-narratives to controlling images, that have been used to denigrate black people, by reframing violence, and black male rage, as a tool of resistance against white supremacy instead of black male rage's typical use as a tool that white people can use to demonize black men. Likewise, the "bad black girl" and "angry black woman" controlling images I discussed in this chapter have been reimagined as forms of self-discovery and activism, a la Collins' Black Feminist Thought, which allows black women to define and use their anger and sexuality as a form of resistance against white supremacist patriarchy.

With the black revolutionary's focus on raising audience's consciousnesses about racism and social justice, one would think that movies like Chi-Raq and The Hate U Give or Dear White People would catch people's attention and be very popular films because of how big of a topic racism was during the Obama era (Izzo 2015; Sanchez-Escalonilla 
et al 2016). However, films about revolution did not make a lot of money at the time of their release. According box office earnings of movies in the sample, movies with black revolutionaries made $\$ 7.54$ million dollars on average, which is very low compared to movies with vigilantes and altruistic characters. I use box office gross averages because box office profits are the only way for me to subjectively gauge the "impact" and/or "visibility" of all of these films during the Obama era. The average box office earnings for movies with revolutionary characters indicates to me that movies with revolutionary characters and messages were not extremely popular in comparison to movies with vigilante and altruist characters. Despite their seeming unpopluarity, these films do seem to empower blackness by connecting it to notions of strength and self-determination , which are embodied by individuals, putting these movies in line with civil rights cinema. As mentioned in the Literature Review, civil rights cinema reduces the complexity of the movement down to the actions of a few individuals fighting one aspect of oppression, the movies in the sample also reduce the broader efficacy of the movement down to specific men and women fighting for justice. This implies that while these types of movies reference institutional and systemic oppression, only specific individuals are "exceptional" enough to deal with them. In other words, movies with revolutionaries represent a type of individualistic narrative, despite how the movies revolve around systemic racial problems. This is not to suggest that it is odd to find a movie focusing on characters, as all movies do, but the focus on individuals who are destined to solve broad problems that are typically beyond any one person in movies about fighting for systemic reform is a curious pattern. 
Killmonger wanting to "liberate" black people from oppressors all over the world should be beyond his capabilities, even as a king, because oppression is a very broad socio-political and historical concept. Black Dynamite fighting "The Man" is something that should be beyond him because "The Man" is a broad, abstract concept of white supremacists conspiring to hold black people down via the military-prison-mediaindustrial complex. Likewise, Lysistrata fighting patriarchy with a sex strike is equally absurd, along with Roman J. Israel's desire to solve most or all of the issues in criminal litigation and trial law with a single case. However, despite how big the problems are, these characters can solve them because they are exceptional and thus more capable of saving others. Because they are exceptional, these characters are "mascots" for revolution within which the collective anger of all black people is projected and summed up.

The summation of an entire group's desire for change, and anger at those who prevent that change, affords the revolutionary character a sort of messianic power that justifies their desire and ability to save all black people because they are, in effect, all black people reduced down to one person seeking change. This puts these characters in the same category as activists in civil rights film in which entire historical moments are reduced down to the actions of one person who comes to represent the entirety of the black struggle in a particular moment (Monteith 2003). This reduction individualizes the historical moment, which means that these movies featuring a revolutionary character could actually be using oppression as a backdrop for an allegory about what (poor) individuals can do to solve the problem of oppression as opposed to how oppression can be solved via broad policy or systemic change. 
Movies with revolutionaries reinforce an individualistic ideology of social change that seems to care more about counseling black audiences to rely on themselves. These movies emphasize self-definition, self-determination, and changing oneself to make problems disappear. In the case of revolutionaries, "changing oneself" requires a person to take violent action if you are a man, or define yourself and grow into a protester if you are a woman. Following this logic, if black people each took personal responsibility for changing ourselves, social problems in the United States would vanish because we would each be doing our part to bring change. It is interesting to apply my logic to Chi-Raq that has a focus on fighting patriarchy and racism, but a subtheme of the movie is individual responsibility. The entire film revolves around Lysistrata's frustration with black men who refuse to take responsibility for their actions and stop perpetuating gun violence in black communities. The rapper Chi-Raq speaks the last line of the movie as he is being arrested for his crimes. Chi-Raq confesses to murdering a child and he lets the authorities take him away, "What y'all looking at? Time for you to do the same. Take the blame. Take the claim. Take it on the chin and confess your sins..." Chi-Raq's final monologue is a call to action for black people to take responsibility for their actions and for their own gun violence; he's calling for black people to make better choices in order to truly change black communities. The notion of individualism comes from Chi-Raq telling people to "take the blame" and "take it on the chin and confess your sins." The ultimate message of Chi-Raq is that, at the end of the day, the onus for eliminating gun violence is on black people just like how it was on Lysistrata to start a sex strike. In fact, Lysistrata's sex 
strike ends with Lysistrata and Chi-Raq agreeing that gun violence should stop and with Lysistrata, and her community, telling Chi-Raq to turn himself in.

The "revolution" led to a moment of clarity for Chi-Raq where he tells others to take responsibility for themselves as he decides to take responsibility for his crimes. This focus on individualism reinforces the neo-liberal notion of "taking responsibility" found in movies with vigilantes and altruists that also emphasize individualism and, to some extent, meritocracy as I explain in upcoming chapters. Ironically, the characters seek to eliminate systemic problems, but the narrative around those characters reinforces individualism. In other words, text and subtext do not match in this regard. Systemic change is front and center, but underneath it lies notions of individualism because the individuals who seek systemic change are somehow exceptional and perceived as the only ones who can bring change.

These revolutionary individuals are thus deemed "exceptional" and possess powers (that vary between men and women) that allow them to fight oppression by themselves because they are an amalgamation of the collective desires and actions of black people who seek change. They are portrayals of black people that are universalized and generalized to fit a particular narrative of how black people respond to oppression and how change is achieved via the individual skills and abilities of the generalized character. When we see characters like Starr in "The Hate U Give" talking about using her "superpower" to speak up and bring change, we can see that the movie sets her up as somehow exceptional compared to most other people around her. When we see Roman J. Israel impress Pierce and his colleagues with his high intellect, photographic memory, 
savant-like obsession with, and attention to, detail and a strong sense of justice, we can see a movie that wants its audience to think of Roman as fully capable of "saving the day" because he is so different compared to everyone else. Because of their exceptional nature, other characters should strive to be like them, hence the hegemonic nature of the characters. Let's take a scene from Chi-Raq for example where Lysistrata is being described by the movie's narrator, Dolemedes, as a superwoman capable of fighting the patriarchy,

"Now, I told you about the signifying Monkey and rapped about shine, but this here tales of two cities is one of a kind. It all started with a gorgeous Nubian sister. Baby so fine, she made George Zimmerman and Darren Wilson wanna kiss her. As tough as Coffy and sexy as Foxy Brown. Hell, Beyonce Knowles herself even had to bow down. They call her Lysistrata, a woman like no other...She could put fear in a pit bull, made Bruce Lee flee, knocked out Frazier and Ali, then ran Money Mayweather up a sycamore tree. With a mind like Einstein and a truly luscious behind..."

Lysistrata is described here as almost superhuman and sensual at the same time, which reinforces controlling images of black women as hyper-sexual and, as seen in Lysistrata's character arc, as "angry black women" who use their sexuality to their advantage. She is portrayed here as a woman with the power to "save the day" because she is a combination of all of the most desirable and idealized traits of a strong black superwoman by expressing that she has "a mind like Einstein" and "a truly luscious behind." The description thus reinforces Lysistrata's adherence to stereotypical expressions of femininity.

Moreover, the narratives of the films featuring revolutionary characters are often complemented by hegemonic gender ideologies that place the "revolutionaries" in positions of power and/or leadership. The revolutionary character's paternalistic 
expressions of power reinforces hegemonic and/or messianic masculinities if the paternalist is male, and the "angry black woman" controlling image if the paternalist is female. This means males are more likely to seek to rescue others through domination, violence, and rage. Women are likely to intellectualize and/or engage in protest against oppression, and women do not seek to save others through domination. In each of these movies, revolutionaries acknowledge broader institutional oppression, and they generally seek to defeat individuals who perpetuate that oppression. A focus on individualism is prevalent in vigilante films, which add to this theme of individualism. 


\section{CHAPTER V}

\section{VIGILANTE HEROES}

Like revolutionaries from the previous chapter, I find that vigilante movies rely on the motifs of revenge and violence to make broad systemic changes. The difference, however, is that the methods and strategies vigilantes use to achieve those changes are different from revolutionaries. Vigilantes use violence to directly confront specific individuals instead of institutions. As a result of those confrontations, it is implied that vigilantes make indirect institutional and/or systemic change such as police reform, and/or eliminating or reducing racism. Vigilantes also use violence to rescue specific people such as girlfriends, wives, children, or other loved ones from criminals, as opposed to large groups of people. While revolutionary messiahs and activists engage in terrorism or protest to combat racism and sexism, vigilantes carefully plan, strategize, hunt down, and murder racists and sexists who have wronged them. Regardless of the methods the revolutionary and vigilante seek to make, narratives surrounding both characters maintain the idea that specific exalted individuals can "save the day" to eliminate racism, sexism, and forms of corruption.

In this chapter, I analyze how vigilante characters "save the day" by fighting against local criminals. I begin this analysis by exploring the actions of three vigilante males and one vigilante female vigilante across five movies from the sample (See Appendix D). I follow that discussion with a look at masculine vigilantism and vigilante 
femininity that come to define these characters and how these concepts play out in the films. Finally, I end this discussion of the vigilante with a discussion of the implications of this character, and its connection to intersectional literature.

Unlike revolutionary characters, vigilantes do not subdivide into smaller more nuanced archetypes like the "messiah" or the "activist." Instead, the "vigilante" archetype found in the sample encapsulates the entirety of filmic vigilantism, and this chapter will examine how black vigilantes in film operate. While there are not any archetypal distinctions I notice, there are gender differences between men and women vigilantes. First, men adhere to masculine vigilantism, while the only vigilante female, Mary, adheres to vigilante feminism.

\section{Masculine Vigilantism}

Male vigilantes represent a masculinized form of vigilantism that seems to be a confluence of hegemonic masculinity and violent controlling imagery, in which men operate outside the bounds of the law by utilizing extreme violence to get revenge. By adhering to this type of vigilantism, vigilantes are angry, violent, hyper-masculine, and tough on crime. Male vigilantes lash out at individuals in society because they are frustrated by the failures of society. Films featuring vigilante black men present us with men who are both frustrated with and emasculated by the white power structure, so they circumvent it by operating outside the bounds of the law for the purpose of correcting the issues of police corruption and racism.

In the sample, there are more movies featuring black male vigilantes than black females, with there being only one movie in this study that comes close to having a proper vigilante woman as its main character. This shows that vigilantism is primarily a 
masculine strategy employed in worlds that revolve around the lives of men. Women are, more often than not, excluded from these stories. When women are included, they are girlfriends, wives, or damsels in need of a hero. The fact that women are portrayed as weak or submissive side characters and love interests implies that women in vigilante movies are subordinate to men. This means men are expected to rescue women and they look more heroic doing it.

Heroism is masculinized through physical violence which, as I explained in the previous chapter, perpetuates a controlling image of black males. A hallmark of vigilantism is that it arises from community insecurity that is brought about by the rise of criminal kingpins, pimps, drug dealers, corrupt police officers, and other "bad apples" who upset the social order and need to be eliminated. It is also implied that vigilantes are necessary in the neighborhoods depicted in the films because local law enforcement is ineffective or corrupt, meaning that community safeguards do not properly function or exist. By getting of rid of society's "bad apples," vigilantes aim to make society fairer and just for vulnerable people. Thus, vigilante men ultimately have the power to make society better for others.

The trials and tribulations that men go through in vigilante movies are wrought with hypermasculine indicators such as: men being the only people with the ability to save their local communities, exceptional "superhuman" skill, and the use of women and children as objects or trophies for men to save. The aforementioned indicators make vigilantes extensions of messianic male characters. The vigilante male is an amalgamation of masculine tropes and signifiers that contrast it with the vigilante female, which leads me to the second gender difference I find in the study: the lone female 
vigilante in the study, Mary from Proud Mary, uses violence to fight against her own domination by other men. This contrasts her with her male counterparts since she does not have the power to fight against broader problems like sexism, for example. Mary's efforts in her film represent vigilante femininity, which I discuss in more detail later on when I discuss Proud Mary in more depth.

The differences laid out above show that vigilante narratives in the sample are also intersectional entities. While black male vigilantes are shown saving women and children to shore up their image as masculine heroes, the lone woman vigilante is portrayed more as a character longing to be a mother who also saves a child, shoring up her image as a black matriarch. Vigilantes, both male and female, fight to help specific people, usually loved ones who are threatened by local kingpins and evildoers. The remainder of this chapter will explore just how vigilante characters "take matters into their own hands" and what implications their actions might hold in the movies Django Unchained, The Equalizer, and Proud Mary. These are the movies most useful from the sample in an analysis of the vigilante trope.

\section{Male Vigilantes: Defending the Vulnerable}

Vigilantes work to defend people who cannot defend themselves. However, how a vigilante defends the weak is gendered. This section focuses on how male characters, Django and Robert McCall, use their superior skills to help others. Specifically this section focuses on the aforementioned characters' extensive use of violence as tools to avenge themselves and others. Django's vigilantism in Django Unchained develops through his interactions with a white bounty hunter named Christophe Schultz, a German dentist-turned-bounty hunter, and Django a slave whom Schultz purchases from Ace 
Speck (before killing him) because of Django's knowledge of Schultz's targets. Schultz offers Django his freedom in exchange for Django's cooperation with him to find and kill wanted slave masters. After realizing that Django is naturally skilled with a gun and decides to train Django to a bounty hunter after learning that he is trying to rescue his enslaved wife, Broomhilda.

Schultz and Django leave together after killing Ace Speck, and they rest at an empty saloon. Schultz tells Django about his job as a dentist-turned-bounty hunter. It is implied that Schultz's role as a bounty hunter means that he operates outside of the law to hunt down and kill slave masters. Django wants to know more about what "bounties" are and how he can get involved,

Django: "What's a bounty?...You kill people and they give you a reward?...Bad people?"

Dr. Schultz: "Ah! Badder they are, bigger the reward..." Django immediately takes interest in learning to become a bounty hunter to kill "bad people" for a reward. Schultz and Django's first bounty takes them to the Bennett plantation in search of the Brittle Brothers. While Schultz goes into the mansion to make a deal with the owner of the mansion, Django waits outside, as he is not allowed into the mansion because of his skin color. Django speaks to Betina, one of the slaves on the plantation, and asks her for information on the Brittle Brothers. Django takes out his spyglass and points in the direction of a figure out in a cotton field and sees Ellis Brittle. Betina tells him how to reach Ellis Brittle and Django pursues him. We are shown a flashback of John Brittle tormenting Django and preparing to whip his wife. Django offered to receive the whipping instead, but John Brittle takes joy in whipping 
Broomhilda. Django begs John Brittle to stop whipping his wife, and John Brittle says to him "I like the way you beg, boy" and continues the whipping.

Returning from the flashback, Ellis is about to whip a slave and Django approaches him, “John Brittle!” John Brittle slowly turns and faces Django. "You remember me?" Django asks, extending his arm as if he is going to shake his hand. Dr. Schultz's derringer arm contraption hidden in his sleeve places a tiny gun into his hand and he fires a bullet into Big John's heart. "I like the way you die, boy." John Brittle looks up in shock and then dies. Little Raj reaches to get his gun but he fumbles and drops it to the ground, Django picks up John Brittle's whip and begins whipping Little Raj across the face and chest, all the other slaves gather behind and watch. Django whips him to the ground and then throws the whip away, he picks up John Brittle's gun and faces the others slaves watching him. He shoots Little Raj, emptying the gun. Schultz comes out of the mansion, after hearing the commotion, and kills the final brother, Ellis.

Django killing John and Roger "Little Raj” Brittle is purely vengeful and malicious, but it is presented as heroic and noble since Django was the victim of violence himself. This scene is the first of many "eye for an eye" scenarios that begin to make clear that vigilante films revel in violence as a form of cathartic revenge and power fantasy. The bloodlust for revenge against specific oppressors highlights Django's transformation into a vigilante. Django's vigilantism is emphasized further in a later scene as he and Schultz talk at a campfire about freeing Broomhilda from her enslavement.

As Django and Schultz eat dinner, Schultz tells Django the myth of Brunhilde, daughter of Odin, who is saved from imprisonment by a fearless hero, 
Schultz: "It's a German legend, there's always going to be a mountain in there somewhere. And her father puts a fire-breathing dragon there to guard the mountain, and he surrounds her in a circle of hellfire. And there Brunhilde shall remain unless a hero arises brave enough to save her."

Django: "Does a fella arise?"

Schultz: "Yes, Django, as a matter of fact he does. A fella named Siegfried." At a later point in the scene, Schultz finally decides to formally train Django to be a bounty hunter who works alongside Schultz, as opposed to simply working as his valet. After this scene, we are supposed to view the remainder of Django's journey through the lens of a Germanic fairytale, and Django's experience with racism and racial violence. Django becomes an example of black heroism in spite of the systems of oppression operating against him. After he hears the fairytale, Django's masculinity trumps race as he is framed as a man whose job it is to rescue a woman. In other words, gender becomes normative.

Django becomes superheroic, and his vigilantism is only enhanced by his new chivalrous edge that allows him to save the "princess." Thus, Django's image as a hero is (re)generated through violence and revenge, and his character falls into the conventions of a male vigilante. For Django Unchained the macho mythos created by the movie affords Django autonomy, authority, and power through the romanticization of violent revenge against slave masters (Fierce 2015:51). Django's autonomy and agency as a vigilante is legitimated by the Germanic fairytale of Brunhilde and Siegfried. The movie continues to demonstrate Django's vigilantism when he escapes the LeQuint Dicky mining company to rescue his wife. As he makes his way to Candyland, John Legend's "Who Did That to You" plays. The lyrics in the song speak directly to Django's role as a vigilante bent on revenge and vengeance against the slave master who owns his wife. Specifically, the song has this line, "I'm a vigilante, my love's defender..." This line 
directly frames Django as a vigilante male. He is positioned as his "love's defender," which uplifts his adherence to masculine vigilantism through making him the hero who saves the damsel, his wife, from bad people. Towards the end of the movie, we see that the way he plans to rescue his wife is through violent revenge. He makes his way back to Candyland where he gets revenge in one last scene where he kills the inhabitants of Candyland plantation.

Django finally shoots Stephen, a black slave who fully supported his slave master's mistreatment of Broomhilda and thousands of other slaves, in the knee caps and then reveals that he rigged the house with dynamite so it would explode as he left. Django and Broomhilda leave together. By the end of the movie, Django is a free man. The larger issue of chattel slavery and white supremacy are not fully eliminated. However, it is implied that Django will continue to be a bounty hunter who kills slave owners, meaning that Django will continue to use micro-level actions of defending vulnerable slaves and killing slaves masters to fight macro-level systemic racism. Defending the vulnerable is a motif in The Equalizer series where the main character, Robert McCall, is less a mythical bounty hunter like Django, and more of a violent mercenary. McCall's foray into vigilantism happens when he decides to help Teri, a local prostitute who goes by the name "Alina," who bonds with him over her desire to become a singer. McCall finds out that Teri is "owned" by a Slavic sex trafficker named Slavi. Slavi abuses Teri and allows other men to horribly mistreat her. McCall goes to Teri's rescue after Slavi flippantly gives him a business card in case he ever wants to see Teri again. McCall tracks Slavi down using the business card and bargains for Teri's 
freedom without ever contacting the authorities. McCall offers Slavi $\$ 9800$ for Alina's freedom,

Slavi: "You want to give me $\$ 9000$ ?"

McCall: "Ninety-eight hundred. Cash."

Slavi: "For what?"

McCall: "Her freedom."

Up until this point in the movie, "Alina" has been presented as beleaguered and defenseless. She feels like she is trapped and cannot be herself, and it is implied that her job as a prostitute is what makes it hard for her. After Slavi takes her away from McCall, she is brutally beaten and hospitalized. McCall goes to purchase her freedom so she does not have to be a prostitute any longer. This is McCall's version of "rescuing the princess,"as mentioned in Django's story, by getting revenge on Teri's white male captor. In other words, rescuing a woman helps emphasize McCall's "tough guy" image. Alina, a woman, is "weak" and defenseless, but McCall is "strong" and powerful because of his masculinity and courage — both of which Alina supposedly lacks. Thus, rescuing Alina makes McCall more "heroic" because the woman he is avenging is vulnerable. McCall is not vulnerable because he is not a woman being sexually exploited. He is a "tough guy" whose actions place him within the conceptual frame of hegemonic masculinity.

As the scene continues, Slavi rejects the payment and McCall decides to use violence. He goes to check outside the door to the room to make sure no one is around. He sees no one outside and locks the door behind him. McCall focuses om Slavi and all the men in the room with their weapons, presumably analyzing how he will kill or injure them. McCall quietly starts counting to himself and beats up Slavi's men and kills all of them with their own weapons. McCall finally shoots Slavi in the neck and he quickly bleeds out as McCall stands over him. In this instance, McCall's hegemonic masculinity 
becomes masculine vigilantism when he decides to murder Slavi and his men, which happens outside the confines of the law.

McCall's violence is so extreme and efficient that it makes him seem superhuman and he is framed, from Slavi's murder to the end of the movie, as exceptional just as Django is perceived as "exceptional" because of his affinity for creative displays of violence. As is the case with Django Unchained, The Equalizer comes across like a black power fantasy that, once again, paints a black man as completely independent, efficient, and self-sufficient. He uses his independence to get revenge on a white man who wronged him, which emerges as a theme across both movies presented thus far. McCall's fight against criminal white men continues in the film.

After killing Slavi, McCall takes a more active role in his community to help people in need like his friend Ralphie whose mother is being harassed by two white cops who extort money from her restaurant. McCall encounter the cops and encourages them to return the money or he will expose their corruption. When they refuse, he beats them up. As he does so, he says that they should represent justice, yet they have abandoned their responsibilities as officers, "You're supposed to stand for something, punk. Protect and serve. Uphold the law. Justice. Remember?" Afterwards, the cops return the money to Ralphie's mom. The reason McCall has to "take matters into his own hands" is because of corrupt officers refusing to do their job of maintaining security in society. Confronting the cops and meeting "violence with violence" seems to be a hallmark of masculine vigilantism. The movie concludes by showing McCall in a restaurant posting an ad on a website entitled "Odds Against You? Nowhere to Turn?" This ad is not fully shown on 
camera, but it is implied that he offers his services to anyone in need, evidenced by the response he receives reading, "I'm in trouble. Can you help?" McCall responds "Yes."

McCall embraces his role as a local vigilante, and his heroism continues into The Equalizer 2 where he hunts down and murders more corrupt cops to save people. In The Equalizer 2, McCall follows the same themes of defending those who cannot defend themselves, such as when he confronts a Turkish man on a train to make him release his daughter by to her mother. There is also a scene where McCall avenges a white woman who is implied to have been raped by a bunch of young white businessmen in a hotel room. The Equalizer 2 does not provide anything new to McCall's character or the vigilante theme that The Equalizer does not present, but The Equalizer 2 does continue to emphasize McCall's role as a local hero looking out for the little guy. Likewise, I find many of the same themes of rescuing and helping women and the vulnerable in Black Dynamite in which he does favors for and helps local women like the prostitute Honeybee whose money was stolen from her by a hustler named Nipsy for example. Each of these characters' actions are direct and specific, aimed squarely at "bad people" who hurt defenseless people, and the world is indirectly made better once those bad people are eliminated.

\section{Vigilante Males, Superheroism, and Stereotypes of Violence}

What is most emphasized for these vigilante male characters are the stereotypes affixed to them. First, the characters are hyper-violent. So, regardless of how they save people, they are still violent and angry killers who are to be feared to an extent. Despite their heroism, black men are always "threatening" in these movies. Second, the vigilante males in the sample are presented as urban and "ghettoized," except for Django who is a 
slave without a clear background. By situating these men as "ghetto," these movies not only center the experiences of men, but the notion that black men are dangerous (Guerrero 1995; Brown 2008; Tyree 2014). Black vigilantes want to change the world, starting with their communities. However, to "change the world," they operate at the micro-level by targeting individuals and I believe this is because violence is all they have access to. They cannot assault political leaders or overthrow political systems like revolutionaries because they lack power and access. Vigilantes can, however, assault cops and pimps, kill them, and "improve" society in that way. Django kills slave masters and Robert McCall kills corrupt, racist cops, Russian thugs, a thief, and a Slavic sex trafficker. To summarize: vigilante males typically make "better" worlds by fighting racist white men who make daily life worse for people. Swift, direct, violence is the strategy these characters use to eliminate racists. The traits outlined thus far connect black vigilantes to black superheroes.

Black superheroes are also pigeonholed into violent roles and identities, meaning that the link between vigilante men to superheroism is evident, especially since so many of these movies feel like power fantasies. The reason I describe them as "power fantasies" is that they show black men ignoring the rules to assert their power and authority over others with impunity. This sort of agency is often afforded to white men in film. If vigilante black men are met with a challenge, they can rebuff their challengers by killing them. Therefore, I return to my earlier claim that most vigilante movies in the study are black male power fantasies that use violence as a man's strategy employed in a man's world in which only men have power, and women are either marginalized or absent. Thus, vigilante movies center (hegemonic) masculinities. Masculinity in these 
films is generated to grant black men as much freedom and autonomy as possible, creating an idyllic image of black males as: the hyper-masculine, muscular, competent warrior as opposed to the incompetent, scrawny "wimp" (Tyree 2014).

By portraying black males in such an idyllic, hegemonic way, these movies also subtly reinforce heterosexuality—since the men only have affection for and avenge women - and this is shown in movies like Black Dynamite where Black Dynamite is shown early to be a Casanova who sleeps with multiple women. The black vigilante male's body is a site of hyper-masculinity and hyper-efficient physicality which, when these two concepts combine, create a theoretical "black superhero" (Coogan and O'Neil 2006; Tyree 2014). This is not to say that the vigilante and superhero characters are exactly the same, but there is a lot of overlap. They are similar in terms of their performance of masculinity and violence for the sake of making society "better" for people in need. Alongside vigilante men are vigilante females who use violence as well, but it is used to fight individual sexists (not sexism) instead of racism as seen in Proud Mary.

The Female Vigilante: Violence as Liberation

Proud Mary — the only movie in the sample with a vigilante woman—features Mary, an assassin, who kills her target Marcus Miller in his apartment. After she kills Marcus, she sneaks around his home and realizes that Marcus has a son, Danny, who does not hear the assassination because he is playing video-games with his headphones on. Mary feels guilty and quietly leaves the apartment instead of killing him since she does not target children. Mary spends a year monitoring Danny on the streets. After his father's death, Danny lives on his own and works for a drug dealer who calls himself 
Uncle. Danny delivers money to Uncle, who notices some of the money is missing. When Danny tells him he used some of the money to get food, Uncle beats him and threatens to cut off his hand if Danny steals from him again.

The beating leaves Danny with a concussion and he rests on a park bench. Someone steals his bag, and Danny chases him and retrieves his bag. The concussion causes Danny to pass out on the street where Mary finds and rescues him. She takes him to her apartment and decides to start taking care of him due to the guilt she feels after taking his father's life. Danny wakes up in Mary's apartment and looks for his bag with Uncle's drugs in it. He tells her he needs to get to Back Bay to give Uncle his drugs. Mary tries to feed him while she subtly interrogates him about his relationship with Uncle because she wants to help him. She finds out Uncle abused Danny and she drives off in her car to confront Uncle. Mary returns Danny's drug supply to Uncle and tells him that Danny is done dealing drugs. Uncle mocks her and they argue over Danny,

Uncle: "Danny belongs to me."

Mary: "Danny belongs to no one."

Uncle calls his men and Mary beats them up. Uncle pulls a gun on her and Mary kills him in self-defense. As Mary and Danny escape the scene, Danny asks what she just did to Uncle. She admits to Danny that killing Uncle was a mistake, but she did it for him. Mary killing Uncle for Danny's freedom mirrors McCall fighting Slavi for Alina's freedom, and fighting the Turkish man on the train for a child's freedom; and Django fighting the residents of Candyland plantation for his wife's freedom.

They return to Mary's apartment and she takes care of him and treats him well. However, once word gets out that Uncle is dead, his death sparks a turf war. Mary is 
called to a meeting with her "family," Benny (her black "father" and boss), Walter (a white assassin), and Tom (Mary's black ex-boyfriend) who are all members of an assassination ring. Before she leaves for the meeting, she tells Danny not to go into her room (that is where she hides her guns and disguises). The next day, Danny suspects that she killed Uncle and is impressed. Danny tells Mary his story about how his own mother abandoned him and, after his father died, his grandmother took care of him before she died. He ran away from Child Services and was brought to Uncle to work as a drug runner. The next day, Mary goes after her next target, Walter, whom her boss Benny assigned her to kill as a way to prevent the turf war. As she heads out to kill Walter, she reminds Danny not to go into her room. While she is gone, Danny goes into her room and finds her various weapons and disguises she uses in her assassinations. When Mary returns, she notices Danny went into her room and she scolds him,

Mary: "The next time I tell you to do something, you better listen." She moves closer to him and putting her finger in his face. "Do you understand me?" Danny: "Yeah, whatever, man."

Mary: "Don't 'whatever' me." She grabs him by his shirt.

Danny: "What are you gonna do, huh? If you gonna hit me, just do it." Mary apologizes for being so aggressive with him.

What is interesting here is that Mary apologizes for her aggression. Male vigilantes do not ever feel the need to apologize for their aggression, which points to a gender difference. Mary has to be careful and more thoughtful because she is acting as a motherfigure for Danny. This means Mary has to ultimately be less aggressive and violent than her male counterparts.

Later on in the movie, Mary takes Danny to go shopping for a nice suit to wear to Benny's wife's birthday party. She tells him to get rid of the hoodie he usually wears. 
Danny and Mary continue bonding and arguing the way a mother and child might argue at a store indicated in the following dialogue about getting Danny a new jacket,

Danny: "I don't wanna put on the damn jacket."

Mary: "Watch your mouth."

Mary is being built up to be a mother with these lines as she upbraids him for talking back to her. Danny asks her who is going to the event she's taking him to. She tells him it's Benny, Tom's father,

Mary: "Benny's Tom's father and he used to take care of me when I was a kid." Danny: "Take care of you like you take care of me?"

Mary: "Kind of..."

Danny: "Kind of how?"

Mary: "When I was a kid...I ran away. And I was living on the streets for a while."

Danny: "Like me?"

Mary: "Yep just like you."

What I find interesting about these lines is that Mary experienced the same traumatic experiences Danny experienced before she saved him. Mary acting as Danny's caretaker is all to keep him from going through any of the abuse and insecurity she experienced growing up. Vigilante feminism is rooted in protecting others from the trauma vigilante women experienced. Mary keeping Danny from living on the streets the way she did speaks to this particular element of vigilante feminism, and is generally not a facet of masculine vigilantism. Mary's desire to leave the business is expanded upon when she tells Tom that she wants to give up her life as a vigilante to raise Danny.

After the party, Mary talks to Tom privately, as they work together on a hit job, and she tells him that she wants to move on with her life, but Tom tells her than Benny will not let her leave — no one leaves the business once they are in it. Tom informs her that Benny basically owns her, and Benny feels entitled to that ownership because he raised her from a young age. During their mission, Mary is shot and she makes it home in 
time to keep herself from dying. Danny sees Mary lying on her bed weak and almost dead from the gunshot. He plots to find Benny and require him to set her free because he knows that she got shot doing a mission on Benny's orders. Eventually, Danny finds Benny in his office and threatens him with a gun. Danny demands that Benny let Mary go so she can be who she wants to be, paralleling how she attacked Uncle for Danny. Danny manages to take Danny's gun from him and threatens to shoot him with it. Mary comes in to rescue Danny. Mary begs Benny to let her go but Benny refuses. She shoots him in the heart and escapes with Danny. Tom learns of his father's death and he kidnaps Danny after one of his henchmen tells him that Danny killed Benny.

Mary gets in her car and goes to save Danny from Tom. We get a big action scene set to Tina Turner's "Proud Mary" as Mary kills Tom's men by running them over with her car and shooting them. Mary makes her way through a warehouse and kills several of Tom's men. She finds Danny strapped to a chair and gagged. Mary helps him by talking off his restraints as Tom approaches them,

Mary: "Tom, I'm leaving out of here, and I'm taking the kid."

Tom: "I can't let that happen." Mary tells Danny to get up and run to safety. Mary: "I'm walking out of here, I'm gonna find Danny and I'm leaving..."

Tom: "News flash, Mary: you ain't the mothering type." She kicks the chair Danny was restrained in at him. Tom shoots at her and misses, and Mary shoots him in the chest. She stands over him and says, "News flash, asshole: I am the mothering type," and shoots him in the head. Mary's last bullet in the movie was reserved for this line. This implies to me that the bullet was a metaphorical "period" at the end of a sentence that I sum up as: Mary is a woman with no agency, in an all-male organization, who wants to define herself as a woman by choosing to be a mother. This sentence makes Mary's vigilante feminism more apparent. While motherhood is not a 
requirement for vigilante feminism, it is part of a larger feminist project in Proud Mary in which Mary turns to vigilantism to fight against the men in her life. In Mary's case, these men are keeping her from being the woman she wants to be, therefore she has to fight them herself. What is noticeable is that she does not fight sexism or patriarchy the way men seem to fight racism. Men have the power to fight larger systems of oppression, but Mary only manages to fight for herself, indicating a gendered power difference between Mary and the men in the study. Mary's actions, including the scale of her actions, are encapsulated in the concept of vigilante femininity as I explain in the next section. Mary, the Othermother: Vigilante Femininity and the Angry Black Woman Controlling Images

Vigilante femininity is a form of feminism that performs "as an outlaw, working outside the boundaries of feminist praxis that is rooted in peace and the eradication of systems of power and dominance...” (D’Amore 2017: 390). Simply put, vigilante femininity refers to the performance of vigilantism by girls and women who protect others, and themselves, against physical or sexual violence and trauma. Mary's vigilante feminism is a combination of her feminine power with characteristics traditionally associated with masculinity, such as violence and revenge, in order to attain a sense of empowerment (Graham-Bertolini 2011). Mary’s femininity is militarized and she uses violence outside the bounds of the law. Due to its over-reliance on violence, vigilante feminism does not dismantle patriarchy but it reappropriates masculine tactics for feminine ends (D’Amore 2011). Thus, Mary’s vigilantism uses violence as a form of individual empowerment and rebellion against the men in her life. Mary does not 
dismantle patriarchy, she appropriates it and uses it to gain agency and control over her choices.

Vigilante feminism represents a type of feminist power fantasy that rebels against patriarchal men and sexist dominance over female bodies. By fighting sexists, vigilante feminism reflects themes of the "angry black woman" controlling image, like the activist characters in the previous chapter. Specifically, this genus of the angry black woman stereotype is more reflective of how the trope was used in blaxploitation films in which angry black women were like black male superhero counterparts. Angry black women in blaxploitation were physically attractive, and aggressive rebels, who were willing to use their sexuality and guns to get revenge on corrupt officials, drug dealers, and violent criminals. While black men were often targets for their rebellion, their anger was not focused solely, or primarily, at black men. Rather, it was focused at injustice and the perpetuators of injustice. Due to the vigilante female's connection to controlling images, the vigilante female archetype is intersectional because it is imbued with class and gender ideologies that inform the way Mary operates against evildoers.

The intersectionality of Mary's character comes from the fact that she acts as a mother for Danny. Since she is not Danny's biological mother, she is what Patricia Hill Collins (2000) would call an "othermother." Othermothers care for children the way biological mothers do. "Care" in this case is essentially adopting a child and/or guiding him. Mary saves Danny after he passes out in an alleyway and she immediately "adopts" him as her own by the end of the movie. Adopting Danny in this way serves the purpose of helping the vulnerable in her community since Danny is a poor, powerless drug dealer for Uncle. In addition to helping someone in need, Mary chooses to raise Danny which 
seems to be empowering for her as she is willing to define herself by the end of the movie as "the mothering type" before killing a man who tells her otherwise. By acting as an othermother, Mary discovers who and what she wants to be and that self-definition helps her fight the sexist men in her life.

Another intersectional aspect of Mary's character is how she exemplifies a "female outlaw" which has some connections to the "angry black woman" controlling image. The first peculiarity, aside from the fact that Mary is a sensitive leading woman in a subgenre dominated by stoic and belligerent men, is that Mary is mysteriously preoccupied with being an othermother in this movie. My interpretation of Mary's desire to be a mother-figure for Danny is that Proud Mary simply reflects a pattern of female subordination in vigilante action movies where women are subjugated and manipulated by men. Mary's subjugation as a woman triggers her motherly instincts, and it shows in her narrative arc with Danny. While this is my interpretation, there is some discussion of vigilante feminism that shows that Mary's behaviors are not just the result of creative freedom. Her behaviors subtly reinforce other narratives that have defined vigilante females in other media. It is important to understand what her behaviors, and motivations, are before I can connect them to literature.

As is the case with vigilante men, Mary is an urbanized black woman who relies on violence to achieve her goals. She is portrayed as violent, like men, and is thus "masculinized" since violence is often framed as a masculine trait. Because she is masculine, she adheres to similar controlling images that men fall into. Namely, because she is presented as poor, the only avenue for change, and thus the only power she really has throughout the movie, is violence. Recall that the association between poverty and 
violence is an age-old controlling image that is used to negatively frame black people as uncivilized and belligerent, necessitating disciplinary, political, and police intervention. This is even more pronounced in vigilante movies where black people work outside the bounds of the law.

Despite using violence to help herself and Danny, she is still violent at the end of the film, and she relies upon violence throughout the film, which connects her character to negative imagery of black men and women that has been used to justify their oppression. A difference between Mary and other male vigilantes is that she is not portrayed as a "superhero" character the way men are. She comes across as an "angry black woman" with a gun who defends Danny. I think this is because Proud Mary does not focus on Mary's skills the way vigilante male movies do. The movie instead focuses on Mary's desire to take care of a child. So, Mary's character is less "superhero" and more "aspiring mom" that presents a gendered contrast between her and her male counterparts.

What is interesting about how Mary's character is established, compared to male heroes, is that she is not helping Danny because she has some strong sense of justice. She helps him because she feels bad about leaving Danny alone with no father. As a woman, Mary is made to feel bad about her actions in a way that men are not. Male vigilantes do not feel bad about their actions and are often mindlessly violent. They are allowed to be violent and destructive, and there is often not much consequence for their violent tendencies. Their mindlessness is what enhances their ethos as heroes because it makes them look efficient, strong, masculine, and "moral." For Mary, however, violence is not "heroic;" violence is largely immoral outside of instances where she defends Danny from 
the men who try to hurt him. There are some instances in the film where Mary indicates that she does not truly enjoy her job but she is not allowed to leave, as Tom implies. Thus she is trapped in a cycle of violence. Despite murder being a job requirement, Mary is not allowed to be violent in the same way as her male counterparts. Her violence has to be purposive, thoughtful, and consequential lest she end up hurting the wrong people like Danny or even herself.

Moreover, Mary's use of violence is not a byproduct of her own agency. She works for Benny and Tom who, throughout the movie, tell her who to kill at different times and when she can and cannot leave her "job" as a hitman. The only time she has any agency of her own is when she is acting as a matriarch for Danny. She chooses how and when she takes care of him, she gives him orders like not to go in her closet, to stay at home while she goes out, and to watch his language. She tells him what to wear, and she decides that she wants to take care of him. When she is not surrounded by her male bosses, she makes choices.

Mary's preoccupation with some form of motherhood might be a way for her to liberate herself from the trappings of patriarchy that control. Being a mother is what gives her control over her life because she believes herself to be, or she wants to be, "the mothering type." Proud Mary is a narrative about Mary liberating herself and Danny from the men who control her by telling her who she is, such as when Benny refuses to let her leave the "family," and when Tom tells her she is not "the mothering type." Mary gets to define herself by the end of the film by killing off the men around her, and her character arc is one of oppressed femininity violently clashing with oppressive masculinity. Mary's story is is similar to how Lysistrata operates in Chi-Raq, for example, 
when she speaks out and protests against toxic masculinity and its harmful effects on black women's lives.

The main difference between Mary and male vigilantes is that Mary is more concerned with emancipation from, and revenge against, specific agents of patriarchy. In movies featuring black male vigilantes, patriarchy is normative, invisible, and unspoken. In Proud Mary, patriarchy is not explicitly named, but it is implied and it does more directly influence Mary by limiting the actions she is allowed to take. Mary's arc is about rebelling against the limitations placed upon her by patriarchal actors Tom and Benny. Mary embodies vigilante femininity because of how she employs physical violence to try and get out of her life as an assassin — a life she was implied to have been forced into when Benny found her living on the street.

Recall that vigilante femininity is defined by women rebelling against patriarchy through the use of physical violence. The type of violence her character embraces is gun and physical violence — hallmarks of the vigilante male. As I mentioned in this chapter's introduction, vigilante feminism combines femininity with masculinity for feminist ends. The "feminine end" in Proud Mary seems to be liberating Mary from the toxic men in her life, and guns seem to be the mechanism through which liberation is achieved. Mary's use of a gun in the movie empowers her because, like the men she associates with, she can threaten and kill others with impunity. What is interesting about showing a woman being as violent as Mary is that her vigilante femininity is not portrayed as powerful or effective enough to defeat or completely dismantle patriarchy. She uses violence simply to achieve her goal of preserving both her and Danny's lives - again, liberation is the endgame. Proud Mary is thus a black feminist power fantasy in which a black woman rebels against 
(black) men by employing their own violence against them, as a form of revenge, and as a way to seek restitution for all of the time she lost serving their needs at the expense of her own.

Returning to an earlier discussion of Mary's connection to controlling images, Mary's expression of vigilante feminism is masculine but not very "superheroic" like the males she is emulating. Mary's vigilantism reflects themes of the "angry black woman" controlling image, like the activist characters in the previous chapter. Specifically, this genus of the angry black woman stereotype is more reflective of how the trope was used in blaxploitation films in which angry black women were like black male superhero counterparts. Angry black women characters in blaxploitation were physically attractive and aggressive rebels who used their bodies, brains, and guns to get revenge on various "bad guys" for harming them and their loved ones. What is interesting about angry black women, as I explained in the previous chapter, is that they focus their anger at black men who perpetuate injustice. Mary reflects this controlling image more implicitly than characters like Sam White in Dear White People, for example. Despite how underplayed Mary's "anger" is in the movie, she laments the ways her life has been hobbled by men and the requirements of her job.

What separates Mary's expression of anger from Sam White's for example is that Sam came across to others as irrational and petty with her constant criticism of racism on her campus. Mary's anger is expressed through gun violence that allows her to exist as a leading lady who symbolizes vengeance rather than subservience like the "mammy" character that black women are constantly associated with. Because Mary represents a character that is oppositional to stereotypical depictions of black females who are 
subservient to men, Mary's use of a gun to fight off men suggests a subtle, and maybe more figurative, "call to arms" to other women who have fleeting but expressed doubts about what they are doing with their lives and how easily they do them.

Mary changes her life only by acting as a type of "angry black woman" with a gun who is fed up with men telling her what to do. So, she deals with those men the way they deal with her: through physical violence. Femininity is militarized to rebel against sexist men. Therefore, Mary's expression of anger is not "revolutionary" in the same way Sam White or Starr Carter's anger is because she is not directly advocating for systemic change. Mary's story is more personal and, thus, more individualistic than revolutionary women, and vigilante men who want broad social changes. Mary exemplifies this individualistic take on women's progress in a patriarchal system. She does not fight against patriarchy, but she instead fights individual men who embody it. This implies that she lacks the power to even make systemic changes the way men do because men unencumbered sexism and patriarchy that Mary deals with. Mary's oppression reduces her power to indirectly make broad systemic changes because she is so busy trying to gain agency in her life which is taken away from her by men. Men have agency and use it to their advantage.

\section{Individualistic Vigilante Heroism}

Vigilantes and are typically "urban," poor or low-income character that relies on extreme displays of violence to kill corrupt cops, racists, drug dealers, sex traffickers, hustlers, and other types of criminals. Interestingly, movies with vigilante characters made much more money on average compared to revolutionary characters, with an average box office gross of $\$ 166$ million dollars. This indicates that violent vigilante 
movies are much more "visible" compared to movies with violent revolutionary characters.

Movies with vigilante characters imply that killing "bad" people improves communities since society's "bad apples" have been eliminated. Compared to revolutionaries, vigilantes want to transform their communities and they do it by confronting individuals who are portrayed as having ruined said communities. So, instead of revolution and large-scale political reform, vigilantes want community reform that does not change people's lives all over the world, but it does bring justice to people in city's or neighborhoods for more localized forms of change. And, in making these social changes, vigilantes restore social order, normalcy, and community safety. In other words, vigilante characters are a combination of revolutionary and altruistic character traits given the vigilante's emphasis on individual actions to make indirect institutional changes. What vigilante movies imply is that social reform comes more from eliminating "bad" people. By eliminating "bad" people, society improves. So, vigilante movies offer slightly different methods for achieving social change when compared to revolutionary characters.

Since vigilante characters "save" their communities indirectly (while directly targeting corrupt institutional actors), it is easier for vigilante movies to focus on individualistic solutions to various problems. In other words, racism and patriarchy are treated as if they are something identifiable, isolated, and surmountable, by the individual vigilante, rather than larger systemic, ideological, and persistent problems. For example, in The Equalizer, McCall sends out his online ad for his services that reads "Odds Against You? Nowhere to Turn?" and replies to a person who wants his help. Along the 
lines of his ad, McCall offers his assistance throughout the movie, and he confronts a few different corrupt police officers and local criminals. Despite McCall assisting people who need help throughout the movie, by the end of the movie, institutional corruption for example, is never directly dealt with. The individuals who engage in corruption, however, are dealt with, and social change is a consequence of their elimination.

One outstanding example of McCall's insistence on individualistic justice is when he confronts the two corrupt white cops who harass Ralphie's mom. As McCall beats the cops, he says "You're supposed to stand for something, punk. Protect and serve. Uphold the law.” Beating up the cops is a vengeful power-fantasy that speaks to McCall's frustration that the cops had not been doing their job. Extrapolating this scene to the real world, police violence is a hot issue that frustrates people all over the United States. McCall's assault on the white officers could be subtle social commentary on the state of policing in the U.S. to express his anger that racism has not yet been overcome and was maintained by bad individual police officers. McCall beating them up is his way of making social changes that revolutionaries would try to make by attacking governments, or the institution of policing, for example.

Like The Equalizer series, where McCall resorts to violence as the only means of making change, Django directly confronts slave masters and gets his revenge on them for humiliating him and his wife. Django, being a former slave, lacks social power and thus he has to directly confront slave masters in order to get what he wants. Violence is the only way he save his wife since the racists around him do not take him seriously and have no problem trying to intimidate him. By confronting the individual slave masters, Django indirectly confronts slavery. Like McCall, Django seems like an avatar of black 
frustration with racism and the black power fantasy involving the humiliation and/or destruction of certain racists. In the same way Django and Robert McCall represent the frustration with racism, Mary represents black women's frustration with sexism and she eliminates the sexists in her life in order to be an othermother to Danny.

Movies with vigilante characters do not seek to "educate" people in the way movies with revolutionaries do. It seems that movies with vigilante characters take a slight colorblind stance that overlooks societal problems in favor of more individualistic ones. For example, despite Django Unchained using racism and slavery as the context for its narrative, and movies like The Equalizer having a scene where McCall fights off racist cops, I believe that both of these vigilante films encourage colorblindness. Both movies allow white audiences the opportunity to feel angry about racism, which enhances their own antiracist self-image and their sense of living in a "post-racial" society (Doane 2019). However, Django Unchained presents racism as a phenomenon endemic to chattel slavery, which has been outlawed. Therefore, the events of the movie are easily, and incorrectly, dismissed as the "past," which helps to fuel the colorblind storyline of "the past is the past" and that the effects of chattel slavery have no effect on the United States today. Therefore, Django Unchained can help people minimize the effects of racism today despite the movie's open disdain for, and rightfully negative portrayals of, racism and racists.

Likewise, in The Equalizer 2, Robert McCall does lean into colorblindness (more than he does in The Equalizer) when he tells Miles, a black male he mentors, “...You got a choice. You got talent. You got a chance. And I don't want to hear about your environment. And what your momma didn't give you. And the white man won't give you 
no shot..." McCall explicitly tells Miles not to blame "the white man," which reflects his colorblindness. Ultimately, vigilante films, featuring men or women, tell audiences that the solution to social problems are, or should be, individualistically solved via violence and the societal change will follow on its own. However, not all characters in the sample are violent. In the next chapter, I discuss altruistic characters who are vastly different from revolutionaries and vigilantes in terms of behavior. 


\section{CHAPTER VI}

\section{THE ALTRUIST}

In this chapter, I discuss black characters who are altruistic: they tend to other characters' well-being and rely on compassion, guidance, and counseling to empower those characters to make changes in their own lives. Unlike violent revolutionary or vigilante characters, altruists are more peaceful and do not attempt to make broad social changes. Instead they want to help others to: study harder, leave abusive relationships, think about their futures more, and to stop relying on narratives of victimization and helplessness to make sense of their struggle, I focus on teachers and parents because they share the same goal: to empower others by teaching them to take personal responsibility for their problems. When those characters take responsibility, they become more confident in themselves and achieve greater success by the end of the movie. Despite having the same goals, teachers and parents have different strategies for achieving those goals - strategies that reinforce paternalistic, colorblind, and hegemonically masculine ideologies. I do not focus on political characters like Dr. Helmsley, in 2012 who convinces world leaders to save people's lives during a catastrophe, or minor characters who might give some advice to others like Lisa in The Hate U Give because their "altruism" is minor and is not the focus of their character arcs in their respective films. 
In this chapter, I discuss how the altruists in my sample encourage individualism by counseling and advising other poor, uneducated black characters across eight films: Akeelah and the Bee, Night School, Precious, After Earth, Fences, Madea Goes to Jail, Big Momma's House 2, and The Help. First, I discuss the two categories - the "teacher" and the "parent"- that I find best encapsulate each "altruistic" character in the sample (See Appendix E). Second, I provide examples from my analysis of each of the aforementioned eight films to show how the characters in these eight films fit within either the "teacher" or "parent" categories. Finally, I synthesize my data and discuss the altruistic category, and its implications for the study, in terms of how paternalism can be used to empower and inspire others through the use of colorblind racial ideology.

While gender has an explicit influence on altruistic behaviors between characters in the sample - males are more prone to use "tough love," displays of aggressions, and punishment, while women tend to be more nurturing — social class has a more implicit influence on how altruistic characters interact with others. Social class is implied through language and imagery used throughout the films, especially in films with "teachers" who subtly rely on classist language and actions around their students. Women like Carrie in Night School and Madea in Madea Goes to Jail have a "masculine" edge that makes them similar to male altruists who tell their subjects what to do, which ultimately takes some agency away from their subjects. More "feminine" characters like Blu Rain in Precious and Big Momma in Big Momma's House 2, work to offer people choices and possibilities instead, providing their subjects with more agency than they use to have. 


\section{Teachers}

Teacher characters in the sample are wise, smart, and more educated than the people they interact with. Teachers typically work with young people who might be troubled or disadvantaged in some way that keeps them from realizing their full potential. These young people are portrayed as lacking the proper discipline to utilize their own skills and talents. Therefore, they require help and counsel from a teacher to educate them in order to help them reach their goals. By working selflessly to educate the youth, teachers help move them away from poverty, insecurities, or abuse. By moving people away from those negative forces, teachers inspire the youth to want better for their families, their communities, and, most importantly, themselves. To more effectively help people, teachers tend to be working or middle-class coaches and educators who demand that their subjects think about what they can do as individuals, without an analysis of the social structures, to help themselves improve and the people in their immediate surroundings. The movies in this sample with teachers imply that black characters in need have some deficiency brought about by their growing up in poverty. Thus, to escape the trappings of poverty, students need to make better choices that get them out of poverty and into the mainstream society, or other aspects of success.

These movies subtly suggest that, with the help of an educated middle-class benefactor, and the application of personal resolve, anyone can "make it." Disadvantage exists, but it is nothing a little hard work cannot overcome. They also perpetuate notions that the "urban black poor" and their communities do not possess the traits of "hard work" or "personal resolve." Because success is reduced to individual choices, there is no discussion of the larger society around these characters, and audiences are not encouraged 
to really think about the systemic perpetuation of inequalities such as: sub-par schools in predominantly minority areas, the effects of poverty on poor students' lives, and the students' lack of community support networks and social safety nets. This implicit focus on individualism means that these movies reflect the culture-of-poverty thesis.

The culture-of-poverty thesis falsely implies that residents of poor inner-city neighborhoods are poor because they have the "wrong values" and the "wrong attitudes" about their work, family, and school lives (Bulman 2002). The culture-of-poverty thesis implies that poor people do not have the "right values" to succeed. The values poor people need to adopt are the values of the "normative" middle class which coincide with materialism, rational calculation, and a belief in meritocracy. Thus, the poor remain poor because they do not adopt the aforementioned values (Bulman 2002).

The middle-class black teacher is a representation of blackness with origins that lie in the domesticated image of Uncle Tom and the commodified image of Uncle Ben (Collins 2005). Just like how Uncle Ben is used to sell consumer goods, the black teacher character is used to sell ideas of blackness and individualist solutions to racism that reinforce ideas of what black people should be like. This notion of what black people "should be like" is an example of the idea that black people should be denuded of their blackness, which reinforces colorblind, individualistic, and meritocratic ideals. Akeelah and the Bee, Precious, and Night School are "colorblind" by virtue of their lack of analysis on the effects of racism on people's lives, and the implicit assumption that anyone can make it if they make the decision to work hard enough. As I explain in upcoming sections, teachers initiate students into middle-class individualism.

Parents 
Parent characters in the sample fall into typical "mother" and "father" roles. Both mothers and fathers take care of, or provide for, a family or children, including nonbiological children. For example, Mary, acts as an "othermother" to Danny in Proud Mary. As one would expect, how the characters parent others depends on gender. In this study, I make a distinction between "parents" and "parent-figures." Parent-figures act as parents for kids in need, but they might not necessarily be the biological parent for the child. These characters tend to take the role and responsibility of mentoring or coaching kids when the kids' parents neglect them. For example, parent-figures include Dr. Larabee in Akeelah and the Bee who acts as a father-figure for Akeelah.

\section{Fathers and Father-Figures}

In terms of gender, fathers and father-figures in the sample are often strict and demanding of their kids. They come across as mean, intimidating, cold, distant, and/or harsh, and they are generally not very nurturing or caring. Some of the father-figures, like Troy Maxson in Fences, resort to violence or the threat of violence in order to control others. The use of violence is frequently associated with black males, reinforcing stereotypes of black men as barbaric and uncivil, which is frequently used to disparage poor black men.

Adding to their mean and/or violent behavior, fathers are often portrayed as tragic characters who have either lost kids or were raised in poverty themselves. Thus, they work to make sure their kids do not suffer as they did. Fathers and father-figures are motivated to help and/or raise other kids to atone for or cope with their tragic pasts as if parenting is a form of redemption. Black father figures in the sample reinforce stereotypes about low-income urban black males through how they work to distance 
themselves or their children from urban poverty. The desire to move children away from poverty is a strategy fathers and father-figures use to assimilate their children into, and construct their identities around, the middle-class (Lacy 2004; Pattillo 2005). Like other "altruistic" characters, fathers provide their kids with life lessons and advice that focus on individualistic solutions to social problems, suggesting that their kids' problems are purely personal. However, what separates fathers, and their lessons of individualism, from mothers is that fathers initiate their sons into masculinity and reduce it to a series of individual choices and personal failures. Mothers also utilize notions of individualism, but it is less gendered in comparison to fathers.

\section{Mothers and Mother-Figures}

Like fathers, mothers occupy a traditional gender role in which they act as caretakers. These women raise and/or support children, to help them escape their personal or environmental situations. This can be achieved through teaching them various life lessons. In order to teach their children, mothers are kind and caring to their children, and are much more involved in their kids' lives than fathers. As mothers teach their kids, they also stress the importance of taking personal responsibility for their actions. Mothers are typically working or lower class and tend to be uneducated, like men. However mothers do not usually use violence and are not portrayed as mean or intimidating.

The emphasis on women's kindness and nurturing behavior in these movies reinforces gender stereotypes of mothers. Mothers are traditionally expected to be involved in their kids' lives, and they are usually expected to be more involved with raising kids than fathers are. So, what is interesting about altruist characters in general is how quickly and easily they fall into gender roles, norms, and expectations. As I will 
explain in upcoming sections, mother characters are more one-dimensional than fathers, and they tend to be representations of "mammies" or "sapphire" controlling images that reduce them to servants or spitfires.

The reason I believe altruists in the study trend toward parenting and teaching is because they are the characters who are the most likely to interact with poor, abused, or unsuccessful black children or black young adults. Children and young adults tend to need guidance in these movies, and are often troubled in some way, requiring help from an older, wiser adult. Because altruists interact with children, whether their own or someone else's, they take the responsibility of raising them and giving them advice when no other adults will. The mothers and fathers in this sample have some overlap with teachers, since parents and teachers both seek to educate and advise their kids. This advice is used primarily to inspire students and children to make better life choices. I start the analysis of altruistic characters with an analysis of the three most prominent male teachers and parent characters male characters in this section, Dr. Joshua Larabee in Akeelah and the Bee, Troy Maxosn in Fences, and Cypher Raige in After Earth. In their attempts to be "helpful," these characters come across as authoritarian and hypermasculine, and I explain how these two qualities manifest. I then transition into a discussion of Blu Rain in Precious, Carrie in Night School, Minny in The Help, and Madea in Madea Goes to Jail. These are the teachers and mother characters whose altruism occurs in tandem with their emphasis on individualism.

\section{Altruistic Characters: Authoritarian Male Teachers}

Black teachers in film act differently based on their gender. I find that the only black male teacher in the sample is authoritarian, and thus does not provide his student 
very many choices. I begin this section with a discussion of Dr. Larabee in Akeelah and the Bee. Dr. Larabee is eager to become Akeelah's coach for the spelling bee after realizing that she has a natural talent for spelling. As he gets to know more about Akeelah, he is framed as being the only person who can help Akeelah achieve what she wants to achieve specifically because the movie emphasizes his role as the instructor who is brought in to improve student test scores at Akeelah's middle school.

To add to Dr. Larabee's ethos as a mentor, the movie quickly introduces the audience to Akeelah's neighborhood, its incivilities, and all of the urban decay that demotivates Akeelah. The neighborhood is portrayed as run-down and unkempt, indicating to the audience that the area is poor along with its residents. As Akeelah walks to school, she explains why she is apathetic about school due to how her neighborhood is "ignored" and "unimportant." She is self-conscious and does not value her skills or her community, putting her at risk of never reaching her full potential. The school's principal introduces Akeelah to Dr. Larabee and tells him about Akeelah's spelling talents. Dr. Larabee immediately takes interest in her development.

Akeelah easily wins her school's spelling bee and, as she walks off, Dr. Larabee, who is sitting in the audience, stands up and tells her to spell complicated words like "prestidigitation," which Akeelah does. She finally misspells the word "pulchritude," and school bullies laugh her out of the room. The principal and Dr. Larabee catch up with her and Dr. Larabee consoles her,

Dr. Larabee: "They laugh because you intimidate them. But if you'd have stood your ground, you might have earned their respect." He speaks to the principal,"Bob, the girl has potential but she needs to be coached." 
Dr. Larabee tries to insert himself into her life as a disciplinarian, but his sentiment comes from a place of kindness and sets his role as a mentor for Akeelah in motion. Akeelah "needs to be coached" because she is portrayed as unrefined, and she "needs to be coached" by someone more "pristine" and "proper" like Dr. Larabee who comes from a prestigious university. After Akeelah decides to compete in spelling bees in hopes of winning the national tournament, she goes to Dr. Larabee's home to start her training. Dr. Larabee lives in a nice suburb devoid of the incivilities shown in Akeelah's impoverished neighborhood. His home is portrayed as clean and, and he tends to a well-maintained garden in his backyard in his spare time. Dr. Larabee's altruistic desire to help Akeelah learn to be a "proper" speller is paired with his "no-nonsense" and humorless attitude that establishes him as an authority figure,

Dr. Larabee: “...The first thing most serious spellers do is learn all of the winning words and their origins."

Akeelah: "Well, maybe I ain't that serious." Dr. Larabee gives her a stern look before turning back to his garden.

Dr. Larabee: "Well, neither am I."

This argument is worth noting because it represents a clash of classes: middle-class versus poor. The class dimension is subtly emphasized in Dr. Larabee's line, "The first thing most serious spellers do is learn all of the winning words and their origins." When we look at Akeelah's background, Dr. Larabee's strategy sounds very out of touch since Akeelah is show to not have the resources to "learn all of the winning words and their origins" like Dr. Larabee does.

As their argument continues, Dr. Larabee continues to reinforce class-based stereotypes about "urban" black students. He implies that "real" spellers act and speak 
"properly" like Dr. Larabee, not "ghetto" like Akeelah. This brief exchange between them highlights Dr. Larabee's disdain for Akeelah's way of speaking,

Akeelah: "So why are you home during the day? Ain't you got a job?"

Dr. Larabee: "Do me a favor, leave the ghetto talk outside, alright?"

Akeelah: "Ghetto talk? I don't talk ghetto."

Dr. Larabee: 'Hm, 'ain't you got no job?' You use that language to fit in with your friends. Here, you will speak properly or you won't speak at all. Understand?"

Dr. Larabee has some contempt for Akeelah and her "ghetto talk" and he tells her to speak "properly." Films featuring teachers like Dr. Larabee typically focus less on a students' education and more on the process students go through to reject conformity to societal norms or expectations in order to express their true selves (Bulman 2002). The norms Akeelah subscribes to are those of her neighborhood, norms Dr. Larabee deems "ghetto." Dr. Larabee's lines imply that, with his help, she will receive the refinement and training she needs to succeed as a speller and, more importantly, as "herself." Hence, her "ghetto talk" is frowned upon because there is an implication that being "ghetto" is not who she really is, since "talking ghetto" is something he assumes she only does to fit in with other low-income black students. Thus, Dr. Larabee's job in the movie really is to move Akeelah out of her "ghetto" roots and turn her into someone more "respectable" and "serious."

Dr. Larabee's disdain for all things "ghetto" is a middle-class, mainstream, dismissal of qualities stereotypically associated with blackness. Because black people are stereotyped as "ghetto" and thus low-class and uncivilized, viewing urban black people's way of speaking as "ghetto" reinforces the idea that being "ghetto" and thus "too black" is a liability to black people's ability to be taken seriously (Lacy 2004). Therefore, Dr. 
Larabee requires that Akeelah adopt a different, more "proper" way of speaking in his presence since he has, more-or-less, assimilated into some aspects of middle-class "whiteness" as he is shown to live in an ostensibly middle-class suburb replete with white neighbors. It is implied that he is trying to strategically assimilate Akeelah into "whiteness" as well by teaching her to be like him so she can be taken seriously and succeed as a speller.

Later on, she returns to his house for serious coaching. They meet in his office and she tells him she can use her training with him to substitute for her summer school. He asks her if she has any goals,

Dr. Larabee: "Goals — what would you like to be when you grow up? A doctor, a lawyer, a standup comic?"

Akeelah: "I don't know. The only thing I'm good at is spelling."

Dr. Larabee: "Go over there and read the quotation that's on the wall. Read it aloud please."

Akeelah: "Our deepest fear is not that we are inadequate. Our deepest fear is that we are powerful beyond measure...And as we let out own light shine, we unconsciously give other people permission to do the same."

I provide most of this scene because it is a continuation of a theme throughout this movie:

Dr. Larabee's job is not to help Akeelah make better grades, it is to help her make what he believes are "better" choices for her life and success—choices that will help her get taken "seriously" as a speller and help her fit into the social "mainstream." Dr. Larabee asks Akeelah if she has any goals, and she says she does not. If she is going to him for spelling bee coaching, why ask her if she has goals that do not relate to her spelling? It is because spelling is a means to a subtler end of helping Akeelah discover how to be a "better" more "proper," "serious," and more confident version of herself. Thus, one of the choices Akeelah has to make is to believe in herself. Despite Dr. Larabee's altruistic attempts to 
help Akeelah believe in herself, he yells at her at one point in the movie, scolds her, and makes her go through extensive training drills. It is implied that all they do is train for the spelling bee and it causes Akeelah to experience burn out. In other words, Dr. Larabee is, as Akeelah describes him, "dictatorial," "truculent," and "supercilious," as shown in this brief exchange,

Akeelah: "All we've done for eight months is study words. Why can't we take a break, go to a movie, to a basketball game? Why can't we have fun?"

Dr. Larabee: "I told you...you can have fun after the bee," he yells.

The most important takeaway here is that Dr. Larabee's lessons are implied to be grueling. The difficult nature of his training adds to his cold and calculated exterior that makes him seem like an authoritarian. Dr. Larabee's behavior seems distinctly hegemonically masculine. Hegemonic masculinity legitimates unequal gender relations between men and women (Connell and Messerschmidt 2005). In this case, Dr. Larabee telling Akeelah what she will definitely do, and not do, in his presence reinforces his character as one that is much more powerful than Akeelah, who lacks power to make her own choices. Dr. Larabee's "authoritarian" impulses are not unique to him. Father characters in the sample also display authoritarianism towards their sons.

\section{Altruistic Characters: Authoritarian Fathers}

The fathers in this section stand out because of their adherence to hegemonic masculinities that emphasizes traditional signifiers of masculinity such as toughness, aggression, and the domination of women (Connell and Messersachmidt 2005). While fathers do not seem to explicitly advocate for dominating women, they do try to teach their sons to be more traditionally masculine by being emotionless and aggressive. The 
theme of hegemonic masculinity is prominent in the movies After Earth and Fences, which both feature intimidating, tough guy fathers who interact with their meek sons.

Cypher Raige in After Earth is noteworthy because of his relationship with his son, Kitai. It is a relationship marked by tension as we watch Cypher give his son orders in a cold, commanding tone that connects Cypher to characters like Dr. Larabee who are strict and authoritative. When Kitai and Cypher crash land on the planet Iphitos, Cypher gives his son a direct order, “...You are going to retrieve that beacon, or we are going to die..." He ends with one final comment, "Do exactly as I tell you and we will survive." This line is very similar to Dr. Larabee's line where he tells Akeelah "You'll win using my methods" as they begin training for the spelling bee. Both characters are framed as the only ones who can lead their kids to their goal. Additionally, Cypher has to guide, or coach, Kitai through his mission.

The entire time, Cypher gives Kitai orders and commands, just like Dr. Larabee does for Akeelah. Just as Dr. Larabee acts as a disciplinarian for Akeelah, and helps her make better choices to become a champion, Cypher does the same for Kitai. For example, when alien monkeys attack Kitai, Cypher chimes in over Kitai's headset and yells at him. While Dr. Larabee and Cypher approach how they interact with their kids (or in Dr. Larabee's case, student) with strong and direct commands, what is different between Dr. Larabee and Cypher is that Cypher's coaching and guidance is meant to make his son's masculinity a choice. To become like Cypher, and thus to become respected, Kitai has to learn the ghosting technique. To learn the technique, Cypher tells his son that he has to let go of all of his fear,"... and it dawned on me...Fear is not real...Now, do not misunderstand me. Danger is very real. But fear is a choice." Claiming that fear is not 
"real" strikes me as a way for Cypher to encourage his son to be hypermasculine since being emotionless and fearless are typically associated with men and, coincidentally, being fearless is a form of empowerment that will save their lives.

Like the teacher characters I previously discussed, Cypher's job in this movie is not merely to save their lives, it is to encourage his son to make a choice to be a "real man" or not. Kitai makes that choice by deciding whether he wants to give into fear or not, which requires that he believe in himself. This means that if Kitai fails his mission, he will have failed because he was not "man enough" to succeed. His failures can then be attributed to his choice to embrace fear and emotion instead of apathy and cold detachment. The focus on Kitai's emotions and choices allows Cypher, and the audience, to ignore the reality of the mission's difficulty. Cypher's coaching is really designed to initiate Kitai into masculinity, which is framed as a solution to his problems. I also see this happen in Fences in interactions between Troy Maxson and his son.

Troy's relationship with his son, Cory, is very tense and defined by masculinity. Cory, tries to emulate his father-who was denied a chance to become a baseball player due to racism - by trying to become a professional footballer. Troy is dismissive of Cory's chances of playing professional football, claiming that he does not want Cory to fail in athletics like he did. Troy does not necessarily "coach" Cory in this movie, the way Cypher does for Kitai, but he does try to advise his son in a harsh and mean way.

Troy is very strict with Cory and tells him that he cannot play football because of racism in sports. He wants Troy to learn a trade so he can have a steady stream of income so he can live a better life than Troy does as a garbage collector. Troy wants this for Cory because he believes "real men" take care of their family. Cory believes that Troy "ruins 
his life" by disallowing him to do things he wants to do because he believes Troy hates him. Troy tells Cory that he does not hate him,

Troy: “...I go out of here every morning ...bust my butt... 'cause I like you? ... It's my job. It's my responsibility! You understand that? A man got to take care of his family..."

Troy operates on traditional gender norms that place the man as the family breadwinner.

Both Cypher and Troy treat masculinity as an individual choice and treat their sons with contempt when they do not make the choice to adhere to hegemonic masculinity. To get their sons to be more "masculine," both fathers engage in aggression, either through the use of harsh commands and language, or through physical violence such as when Troy and Cory have a fight in the backyard. In After Earth and Fences, being a "real man" is the only mission in a man's life.

Both Cypher and Troy have an inability to emotionally respond to and embrace their children due to their masculinities. Due to their adherence to highly toxic notions of hegemonic masculinity, Cypher and Troy create situations for their sons in which they will never be good enough until they are "man enough." This "aggressive father" trope is rooted in patriarchy that demands that men be "emotional cripples" (hooks 2010). In patriarchal systems, males are denied full access to emotional well-being and their lives are worse as a result. Patriarchy in these films is about children living up to lofty standards of "manliness," and their fathers expect them to choose to live up to those standards or risk being seen as supposed failures. Along those lines, Cory and Kitai are being taught to use stoicism as self-defense mechanisms to help them survive in the world. 
Sons with Emotions, Fathers Without

The ghosting technique I discussed earlier seems to be a metaphor for the "tough guise." The ghosting technique in After Earth masks a person's emotions to make them unreachable, undetectable, and unfazed by the world around them, and this technique it said to have saved all of mankind from extinction. At the beginning of After Earth, Kitai's mother describes him as a "feeling boy," but those feelings have to be suppressed if he wants to survive on Iphitos. Likewise, Troy's expectation that Cory be a "real man" is also a way to protect him from being hurt in the racist ' 50 s as demonstrated in these lines,

Troy: “...The white man ain't gonna let you get nowhere with that football no way. You go on and get your book-learning so you can work yourself up in that A\&P or learn how to fix cars or build houses or something, get you a trade. That way you have something can't nobody take away from you. You go on and learn how to put your hands to some good use."

Troy does not want Cory to play football because white people will never give him a chance to succeed anyway, and Troy thinks it is more important for Cory to be responsible and take care of a family by doing traditionally masculine things like putting his "hands to some good use." Troy had his future taken from him by racism, and it made him bitter; he does not want Cory to have the same problem. Troy is trying to "buffer" his son from the effects of racism by preparing him to face racism. By trying to prepare his son, Troy is helping Cory strategically assimilate into the "mainstream" by encouraging him to learn a trade so he can earn decent pay, have a decent living, and ultimately live a life with dignity — these are things Troy believes white people cannot take away from Cory. 
Not only is Troy trying to help his son "assimilate" into the mainstream, he is also trying to buffer him from the "hidden injuries" of class (Sennett and Cobb 1972). The "hidden injury of class" refers to how class societies create "injuries" in which being poor and black (in the case of this film) limits Cory's freedoms and social mobility, especially in the 1950s. In this case, Troy was unable to be the athlete he wanted to be due to racism. He tries to get his son to realize that sports leave him vulnerable to class "injuries" and he tells him that he cannot and should not play sports. Society is upheld by an unjust social class order that provokes feelings of anger and personal responsibility for his, and his family's situation. Thus, Troy tries to correct the situation by making sure his son is on track to living a more successful life than he did. The problem here is that Troy's career loss made him bitter and angry, and he turned that anger toward his son whom he believes will be a "failure" if he does not start "taking responsibility" and taking care of himself and his family "like a man." Masculinity warps Troy's relationship with Cory and makes Troy into an authoritarian figure who, in trying to aggressively "help" his son, hurts his son by actively reducing his son's agency in order to ensure that his son does not get hurt by racism and the "injuries" of class.

Along with Troy's loss, Cypher lost his daughter because Kitai expressed fear around an Ursa alien and the loss made Cypher stern and stoic. Cory's sole mission, like Kitai's mission, is to provide and defend himself and his family, not to ever be emotional. Like Troy, Cypher tries to buffer his son from supposed failure by trying to make sure his son is as emotionless (and hypermasculine) as possible. In this film's case, Cypher wants to help his son succeed by assimilating him into the "mainstream" through demanding that his son be emotionless in a society that honors stoic males. 
The "ghosting" both Cypher and Troy ask their sons to do occurs in different contexts, but "ghosting" and the "tough guise" are both masculine responses to past traumas that reassert the effect hegemonic masculinity has on Kitai and Cory's lives, similar to how aspects of hegemonic masculinity manifest in the lives of characters like Erik Killmonger, Black Dynamite, Commandant, Django, and Robert McCall discussed in previous chapters. The tough guise makes all of these men bitter and aggressive, and their aggression is born from past traumas and grievances which influence their expression(s) of paternalism. In the case of After Earth and Fences, Cypher dismisses his emotional son Kitai, while Troy emotionally abuses his "lazy" son Cory, all because they are not as masculine as their father's want them to be. Fathers are very similar to teachers in that they both act as unquestionable authorities to the children, even though they act as authoritarians in different situations. However, in contrast to authoritarian male teachers and fathers, female teachers and mothers are more humanitarian. Blu Rain, a black female teacher in Precious, is more loving, compassionate, and open to giving her students more choices than her male counterpart Dr. Larabee and fathers like Troy and Cypher.

\section{Altruistic Teachers: Humanitarian Women}

Precious tells the story of Claireece "Precious" Jones, a poor, pregnant black teen who lives in a dangerous part of Harlem with her abusive, lazy mother. Her mother constantly demeans her intelligence, makes fun of her weight, and physically abuses her to the point that Precious has no self-esteem and very little motivation to succeed. On top of being abused, Precious is pregnant with her second child and has no real forms of support. Early in the movie, Precious takes her high school teacher's advice to get her 
GED and she ends up in Blu Rain's preparatory course. Blu Rain comes into Precious's life at a time when she needed it the most and works with her to become who she wants to be: educated and independent. However, to be educated and independent from her mother, Precious has to decide to be a "better" mother for her children by getting an education, which Blu Rain encourages her to do.

When Precious meets Blu for the first time, Blu directs her to a desk at the front of the class and tries to get her to discuss something she does well during her icebreaker, but she cannot find anything, showing her lack of self-esteem. This is Blu's "Have you any goals?" moment that Dr. Larabee has with Akeelah. Just like how that moment between Dr. Larabee and Akeelah establishes the lesson Akeelah must learn, Blu's icebreaker establishes that Precious needs to learn self-confidence. To help her gain confidence, Blu works with her very closely and gives her kind and helpful advice, making her a compassionate and caring teacher opposite of Dr. Larabee's more drill sergeant-like approach to helping Akeelah. For example, toward the movie's midpoint, Precious gives birth to her second child and spends time in the hospital. In the hospital, Precious completes a journal assignment where she writes about possibly giving her baby up for adoption. Blu leaves responses to Precious, "Dear Precious, I think your first responsibility has to be to yourself. If you keep Abdul, you might have nothing...” The two of them write back and forth and respond to each other through Precious' journal entries. Each entry explains Precious' angst as a mother and each of Blu's responses is a piece of advice to help guide Precious toward "optimal" life choices,

Precious: "Ms. Rain, you ask too many questions...I just wanna be a good mother." 
Blu: "Being a good mother might mean letting Abdul be raised by someone who's better able than you to meet your child's needs."

Precious: "Ms. Rain, I is the best to meet my child's needs."

Blu: "Who's gonna help you? How will you support yourself? How will you keep learning to read and write?"

Each of these entries and responses is important because they each feature Precious expressing decisions about her role as a mother with Blu gently telling Precious how to be a supposedly "better" single mother by getting her GED in the short-term and thinking more strategically about her long-term future. Specifically, Blu tells Precious to focus on herself because, at this point in the film, Precious is not able to fully take care of her children. While Blu subtly pressures Precious to give up her child, Abdul, Blu asks Precious more questions, rather than telling her what she should definitely do, because she is concerned about Precious' future. She questions Precious' choices, which ultimately gives Precious some semblance of autonomy over herself and her choice to give up her child. Blu's method is different from Dr. Larabee's, Troy's, and Cypher's methods that are more direct, disciplinarian, and judgmental. For example, Akeelah was told she had to speak properly, or else he would stop coaching her. Blu never threatens to turn her back on Precious, in fact she offers to let Precious and Abdul temporarily live in her home until they can find a place to live. In other words, Dr. Larabee is authoritarian; Blu is humanitarian. I believe this difference is rooted in gender stereotypes of men as stoic and "aggressive" and women as more comforting, loving, and/or more open to giving their students choices for how they want to proceed in life.

The love Blu has for Precious develops over the course of the film as we see when Blu and her wife take Precious into their home and help her raise Abdul. As Precious and Blu bond, Precious expresses her gratitude for Blu in a brief narration, "They're so nice 
to me and Abdul." Dr. Larabee is never described as "nice" or "kind." He is framed as qualified and knowledgeable, but kindness is not a quality that is ever associated with him. Blu, however, is associated with kindness. This is reinforced in a bit of narration at a party Blu throws for Precious after she wins an award for literacy. Blu and her classmates celebrate. Thanks to Blu's kindness, Precious develops enough self-confidence to take her two children, leave her mother, and start a new life. While kindness and nurturing are be gendered in the female "teacher" role, Carrie, from the movie Night School, for the most part, does not neatly fit into this gendered role. She is not an "authoritarian" like Dr. Larabee, nor is she very nice like Blu Rain.

Carrie is a combination of masculine (aggressive) and feminine (kind) traits. She is introduced as a raunchy, no-nonsense spitfire when she is first introduced to Teddy, a black man who never finished high school, who goes to night school to get his GED. Teddy is in an interesting position in his life. He is low-income and uneducated, since he does not have a GED, but he pretends he is high-income to impress his upper-class girlfriend. However, once Teddy loses his job, he cannot maintain the illusion of his wealth, thus he has to get a GED to get a job that pays well to prevent his girlfriend from learning he has been lying. However, to get his GED, he needs to go through Carrie. She is described as having an attitude such as when she sarcastically tells Teddy "No, I'm just the bitch that likes to wear blouses. Yes, I'm the night school teacher" when he asks her if she is really the night school teacher. This line is supposed to be a sarcastic and funny way to introduce her character, and she comes across as angry while she says it, reinforcing the fact that she has an "attitude." She also tells her students that if they are 
not in her class to learn then they should immediately get out of her class, and that they will not pass by trying to suck up to her.

She is immediately presented as intimidating, but passionate, like Dr. Larabee, albeit with more curse words for comedic effect. And, like Dr. Larabee, she is harsh with her students and even yells at them such as when she discovers that they cheated on their GED exam. Unlike Dr. Larabee, Carrie is shown to be a nurturing individual when Teddy watches her play cards with a special needs student, which is reminiscent of Blu teaching Precious to read. Teddy asks her for her assistance in helping him work past his learning disabilities to pass the GED. Carrie helps him prepare for the GED, but she does so through comedic violence, which involves her taking him to a mixed martial arts (MMA) octagon and punching him repeatedly until he gets the right answer to her questions.

I attribute Carrie's use of violence to the fact the movie is trying to be funny, but I also think that Carrie's character is an "angry black woman," or "sapphire," a stock character in black sitcoms who is loud, stubborn, and violent in order to belittle "lazy," “ignorant," or "flawed” black male characters (Jewell 1993). Angry black women are frequently used in sitcoms with "egocentric" black male leads. In the context of comedy films, angry black women exist to keep black men's egos in check by exposing their flaws, usually through insults and sassy witticisms. While Carrie is aggressive, she is not an "authoritarian" given her willingness to work with Teddy and offer him the choice to succeed or not; she does not tell him what he will do or how he will do it.

In Akeelah and the Bee and Precious, the teachers are interacting with black girls who have little confidence and self-esteem given their poor upbringing. Those girls become more confident at the end of the movie. However, Night School features a low- 
income, pompous black male student who is overconfident, but does not openly admit his faults the way Akeelah or Precious do. Since Teddy has an ego, it is implied that he cannot be reached in the ways Akeelah and Precious can be. Since Akeelah and Precious are presented as destitute, they are portrayed as being in need of a mentor to guide them towards a goal.

However, Teddy is not portrayed as destitute from the beginning (since he has a fiance who is well-off), and he does not yet seem to require a mentor to guide him towards a goal. But, the moment Teddy loses his upper-class fiance, his job prospects, and his nonchalant attitude is when he finally becomes someone whom Carrie can help because, in those moments, Teddy lacks confidence. In this case, "confidence," can be replaced to mean he lacks the "right values" that encourage hard work instead of "laziness," lying, and quick solutions to problems, which are all stereotypes associated with urban black males. Carrie's implied role in the movie is to ultimately move Teddy away from that stereotypical association and towards something more "serious" and successful. At the beginning of Night School, Teddy's overconfidence comes from his having the "wrong" values that move him toward cheating and manipulating others to get by. When those strategies stop working, Teddy has to develop new values of hard work.

Carrie is presented as an "angry black woman" stereotype because she is mentoring Teddy who has gone his whole life pretending he is better than he actually is. Teddy believes he can smooth-talk his way through night school instead of working, creating a point of contention between him and Carrie. Carrie's angry sassiness is a way for her to break down Teddy's ego, and point out his penchant for always taking the easy solution to problems. Once Teddy sees and accepts his flaws, Carrie opens up to him and 
he goes to her for guidance so she can do what altruistic teachers do: teach him a lesson that requires him to make a choice. In this case, Teddy has to choose to be a hard worker or a liar and cheater, and I surmise Carrie's use of violence in the MMA octagon is a way to slowly encourage Teddy to make this choice. Either he chooses to study for, and pass, the GED or she will fight him the way angry black women in comedies do with black men. In the following scene, Teddy has decided getting his GED is not worth it and he works at a fast food restaurant. Carrie finds him and convinces him to take the test, or else,

Teddy: “...I appreciate the whole after-school special treatment. But...I am where I'm supposed to be..."

Carrie: "Your destiny is to work at a fast food joint next to a strip club?...Teddy, you are a lot of things... But you are not dumb...Now, you either get in the car and take that test, or I continue to tenderize your ass! Your choice." Teddy dropping out of night school to work at a fast food restaurant perpetuates a class stereotype that people who do not work to get their education are destined to work in fast food places; it is where they are "supposed" to be, as Teddy claims. This scene is meant to be humorous, but Carrie is acting as an "angry black woman" by threatening to "tenderize" Teddy in this scene to get him to take the GED because he is allowing his flaw of always taking the easy way out influence his choice to work at a fast food restaurant. Additionally, Carrie is doing to Teddy what Dr. Larabee did to Akeelah where he tries to convince her that being "ghetto" is not who she really is. Carrie tries to tell Teddy that working in fast food is not who he really is evidenced by her question, "Your destiny is to work at a fast food joint next to a strip club?" This question signals to Teddy, and the audience, that working a low-wage job is not who Teddy is and he has to make the choice to be "better." It also implicitly devalues low-wage work (at strip clubs 
and fast food joints), which reinforces class stereotypes and the implicit value of being middle-class instead of poor.

Teddy takes the test and fails the GED, but he is willing to keep working to get his GED, which he does by the end of the movie. This montage showing Teddy working hard to get his GED is a very direct overture to class-based notions of individualism and hard work that pervade these kinds of movies. After Teddy finally passes his GED, he says during a graduation speech, “And it wasn’t until I met my amazing night school classmates and a teacher that actually believed in me that I was able to accept who I was..." As with other teacher movies, Carrie helps her student discover and find confidence in himself - through adopting "meritocratic" values - to work hard to get what he wants, a narrative pattern throughout all of the movies discussed thus far that all emphasize the necessity of making "good choices." While Blu and Carrie use "compassion" to encourage their students, mother characters also rely on compassion to encourage children and young adults.

\section{Altruistic Characters: Humanitarian Mothers, Mammies, and Sapphires}

When a mother is in a movie, she is often a minor character. Because of how minor mothers tend to be, there are only three mothers who stand out in the sample: Big Momma, in Big Momma's House 2, Minny in The Help, and Madea, in Madea Goes to Jail. These characters are interesting when compared to father characters because of how these characters represent controlling images that help justify black women's oppression. Compared to fathers, mothers are not working to socialize kids into a gender. Instead, mothers act as advisors who teach people, often white people, life lessons and give individualistic advice on how to solve their personal problems by instilling confidence in 
them. This section will focus on Big Momma, Minny, and Madea since I have not discussed them in previous sections. I also find their representation as mammies and sapphires an interesting contrast to fathers and teachers, who are not portrayed as pure controlling images.

The representation of mammy characters places the filmic portrayal of mothers within the intersectional theoretical framework of controlling images since the mammy is central to interlocking systems of race, class, and gender. The mammy controlling image is associated with poor and working-class black women (Collins 2000, 2005). Mammies are faithful, obedient domestic servants used to justify the economic exploitation of house slaves and to explain black women's long-standing affinity for domestic service (Collins 2000). The mammy is also a character who tends to take care of, and serve, a white family, which requires that they leave behind their own black families. The description of the mammy controlling image perfectly fits Big Momma in Big Momma's House 2.

This movie is about detective Malcolm Turner who puts on a fat suit and wig to investigate a white family's mob connections. Malcolm leaves his eight months pregnant wife, Sherry, at home to infiltrate the middle class white family, the Fullers, as a nanny known as "Big Momma" who loves taking care of kids. The Fullers neglect their kids and the kids have very regimented schedules and lives. Because the Fuller kids do not see their parents often, they each lack confidence and guidance. Big Momma takes it upon herself to help the Fuller kids and save the family from danger with the mob and from falling apart. For example, Big Momma tries to save the Fuller family by using her wisdom to upbraid Mrs. Fuller, 
Leah: "I want my children to be able to seize every opportunity that they can. And they might want to go to Harvard. And if they do, I want to make sure that that is a possibility."

Big Momma: "Andrew is jumping off the cabinets, eatin' Brillo pads. He's not goin' to Harvard...These red pegs, you might wanna go easy on 'em, all right?"

What is implied in this scene is that Mrs. Fuller is a negligent mother who has high, and unrealistic, expectations of her kids, like wanting them to go to Harvard. Mrs. Fuller does not spend time with her kids and instead micromanages her children's lives with a peg board designating the activities they have to do and at what time. Because Big Momma spends time with the children, and cares about them, she knows that they are not going, and do not want to go, to Harvard. Big Momma tries to help repair the dysfunction in the family as she gives Mr. Fuller subtle advice on how to be a better father,

Big Momma: "Ooh, That's a nice family you got back there."

Mr. Fuller: "Yeah."

Big Momma: "The reason I point it out—Because I'm not sure you're around enough to notice."

Big Momma's work throughout the movie is essentially about "healing" the Fuller family, by listening to the excuses the parents and children make to justify their misbehavior, and paying attention to their flaws which she uses to leave the family better than she found it. Let's take this scene between Big Momma and the oldest daughter, Molly, is a rebellious white teen who is involved in a relationship with a guy Big Momma does not think is safe. Molly is involved in this relationship because she wants affection. However, Big Momma uses her wisdom to try and advise her while they are on the beach,

Molly: "I don't want to be here."

Big Momma: "Really? But you look so comfortable."

Molly: "Yeah, well, this is who I am, okay? So get used to it." 
Big Momma: "Ooh. Well, it might be. It might be exactly who you are. Or maybe it's just something you're tryin' to impress some boy you got no business trying to impress."

Once again, Big Momma is trying to help restore the family by helping Molly think about her actions to insinuate that her rebelliousness is not who she really is. Likewise, when Big Momma speaks to Mr. and Mrs. Fuller, she subtly tries to convince them that the way they behave is not who they really are or should be. Recall that Dr. Larabee and Blu Rain work with their students to help them discover themselves and help them make better life choices; Big Momma is doing the same things throughout this movie with Molly. Trying to get Molly to make "better choices" in regards to what she rebels against and who she dates is an example of Big Momma encouraging individualism. Once Big Momma successfully helps the family, and solves the case, her job is done and she disappears. So, what Big Momma does is: enter the Fuller family's life, calls out the family's flaws, fixes those problems by providing advice, and then disappears. Likewise, characters like Minny in The Help also work to heal white families.

The Help has multiple story lines, but the one of most important in this analysis is the story of Minny, a black maid, who is "sassy" and frequently angry at the white families she works for, especially a mean white woman named Hilly. After losing her job working for Hilly for using her bathroom, Minny is hired to be a maid for a white woman, Celia. Minny teaches Celia how to cook, and other basic household and social skills, to save her marriage, and keep her social life from collapsing. After Celia is shunned by the women she wants to be friends with (after vomiting at a fancy party), Celia tells Minny she wants to move away to Sugar Ditch, but Minny consoles her and tells her not to give up on her goals, 
Minny: "You can't go back to Sugar Ditch. You gon' leave your husband 'cause you throw up at some party? ... But if you leave Mister Johnny, then Miss Hilly done won the whole ball game..."

Minny tells Celia that she needs to stay and stand up for herself against Hilly and her friends. By giving Celia this advice, Minny is trying to help Celia maintain her relationship with her husband, Johnny, the way Big Momma works to maintain the Fuller family. Towards the end of the movie, Johnny Foote, accosts Minny and tells her, “...I also know the minute you started working here, she started getting better. So you saved her life." Celia and Johnny's relationship is repaired thanks to Minny's help. Johnny tells Minny that she is a lifesaver and he is grateful.

Not only does Minny help keep Celia and Johnny’s relationship together, she helps to make Celia more confident as a wife who now knows how to cook and make friends. Celia evolves from an outsider who is afraid of not belonging to a braver woman, just like how Big Momma works with Molly and Mrs. Fuller, for example. This theme of mammies coming into people's lives and making them better is repeated in Madea Goes to Jail, where Mabel "Madea" Simmons, briefly helps empower black female inmates. However, compared to Big Momma and Minny, Madea's role as a mammy is overshadowed by her role as sapphire or angry black woman character.

Madea is a mammy character who is more angry, bitter, and aggressive. In this way, she is an amalgamation of the "mammy," who is nurturing and motherly, and "angry black woman" stereotype, who is easily frustrated and prone to violence. Despite Madea aggression and anger, she still behaves similar to Big Momma because she gives advice on how the inmates in the movie can change the course of their lives. Madea Goes to Jail has a few plot lines, but the most important one is the story of the prostitute Candace, a 
poor young black woman who is frequently shown with messy hair and dirty clothes, who is in dire straits as she struggles to survive on the street. Men mistreat her and it is implied that she is raped at one point in the movie. She tries to get help, but it is too little too late and she is thrown in jail after she refuses to show up to her trial for prostitution after unknowingly soliciting an undercover officer for sex. Madea meets Candace after she is sent to jail for destroying a white woman's car. While in jail, Candace is attacked by hostile inmates. Madea protects Candace and the two decide to take a self-help class while in prison. This class focuses on forgiveness and healing the pain that helped put them in prison.

One inmate begins discussing how she is angry at her father for abusing her, but Madea interrupts her and gives the inmates advice for how to heal,

Madea: “...You're in jail because of what you did. Learn to take responsibility for yourself...I can't stand folks who want to be the victim...No matter how good, or how bad, the life was it's up to you to make something of it... What you do with that life is up to you. Stop being a victim."

Madea's lines here are examples of crude straight talk to transform the inmates from victims to victorious (Morrison, Trimble, and Okeowo 2015). She suggest that the way that they heal is through taking responsibility, to "stop being a victim," and to take control of their own lives. This is what the mammy characters in the sample do: they ultimately try to get characters to discard the idea that they are byproducts of their upbringing and environment in favor of a more individualistic understanding. Just like how Big Momma came into the Fuller family and disappeared once she helped them get better, Madea does the same thing, although her interaction with Candace is short. Madea goes to jail, meets Candace, notices the excuses she makes for herself, and then calls them out in class in an effort to help Candace get her life on track. 


\section{Mammies, Sapphires, and Magical Negroes}

Movies with mammies as mother-figures ultimately seem like movies that suggest racial reconciliation is possible. This makes these characters similar to magical negroes. Entman and Rojecki (2001) claimed that the magical negro served three key purposes in relation to white characters in film: 1.) to assist them, 2.) to help them realize and make use of their spirituality, and 3.) to offer "folk wisdom" used to resolve their problems. Denzin (2002) adds that in magical negro films, "interracial friendships in movies arise from the need for Blacks to get what they need from Whites and for Whites to get what they need from Blacks, usually soul" (p.61). Denzin suggests that magical negroes work with whites, and vice-versa, to achieve some form of enlightenment or empowerment by the end of the film.

The interactions between Big Momma and the Fullers, and Minny and Celia, falls in line with Denzin's thesis. Mammies come into white households and gain something they need through interacting with them, while white people gain something in return: Malcolm learns how to be a better father to his family, and Minny finds the courage to leave her abusive husband. This connection to magical negroes implies that these mother characters are doing something more than raising white families - they are doing what teachers do and encouraging white people to make better choices. How mammies advise is rooted in individualism.

Likewise, Madea tries to convince (mostly black) female inmates that they need make the choice to stop "playing the victim." This message resonates with Candace, who eventually does learn to take control of her life while in prison. Madea's whole purpose for being in prison with Candace is to be an example of strength, resilience, and 
independence which changes Candace's self-perception and causes her to be more independent like Madea. Candace stopped "playing the victim," which helped her make better choices towards the end of the film, from which she becomes a better, more confident woman and is eventually set free from literal (and figurative) prison.

Madea's frustration with "victims" is a fairly typical presentation of the angry black woman/sapphire trope because the angry black woman is really a way to portray "passion and righteous indignation...used to silence and shame black women who dare to challenge social inequalities, complain about their circumstances, or demand fair treatment" (Pilgrim 2015:121). I infer that Madea's frustration with victims comes from her adherence to aspects of hegemonic masculinity, which emphasizes toughness and enhances her anger. Her "masculine traits" are more obvious when we take into account how violent she is throughout the movie. She is shown to have an extensive criminal record, a willingness to engage cops in a car chase, wields a gun and threatens people with it, and a judge sentences her to anger management classes for her excessive use of violence.

Madea's combination of masculine and feminine traits is similar to Carrie's characterization that allows her to break down Teddy's ego. In this film, Madea's character is used to build up other women. Madea's age, combined with her masculine and feminine qualities, gives her authority in the prison. Her authority as a matriarch is grounded not in nurturing affection of a traditional mother, but in a frank, violent sternness typically associated with men like Robert McCall in The Equalizer and Carrie in Night School. Because of the masculinity of the character, Madea's reaction to the pain young women experience is not to coddle, like mammies, but to empower them to fight 
back, resist, and/or get revenge. In Candace's case, Madea encourages her, and other inmates, to resist the temptation to be victims and "suck it up and shut the hell up," as she tells them.

Interestingly, movies with altruistic characters like Big Momma, Minny, and Madea are much more "visible" and profitable than movies with revolutionaries and vigilantes. Movies in the sample with altruistic characters made $\$ 188$ million dollars on average in the Obama era. The discrepancy between box office averages is interesting when we look at how different the altruist character is compared to revolutionaries and vigilantes. What is interesting about altruistic characters is that they want people to look into themselves and think about how they can make different life choices to "improve" their lives. Because altruists focus on individual choices, instead of institutional changes, they want their subjects to engage in reflection in order to take personal responsibility. By demanding reflection and "responsibility," altruists inspire the people they work with to make personal changes in their lives that are implied to be "improvements" from their current situation, similar to white saviors. Altruistic characters reify and reproduce racial inequality and oppression while making it seem natural.

Compared to vigilantes, altruists more rely almost entirely on colorblind individualism to teach others "life lessons." The altruist's deference to colorblindness is why I believe they made the most money in the Obama era. In other words, I argue that they earned more money because of how "safe" most of the "altruistic" black characters are by comparison. "Altruistic" characters like Dr. Larabee and Blu Rain, for example, are characters who do not require audiences to have any sort of racial consciousness because these characters are generally "relatable" as "blank slates" onto whom audiences 
can project any number of meanings and associations. Dr. Larabee and Blu Rain do not bring a racial consciousness into their stories in a way that disturbs the audience. I theorize that movies with black "altruist" characters in them are so popular because they have no, or hardly discernible, racial plot lines or elements aside from the fact that the casts in these movies are mostly black. I believe this lack of discussion or plot focus on race is important to make the characters in these movies as "non-controversial" as possible by making the movies as "universally appealing" to (white) American audiences as possible.

When movies with primarily black casts and themes are made, studios are supposedly taking an economic "risk" in making and promoting them (Erigha 2019). These movies are "risks" because, generally, they are thought of as "too black" and "too political," which is why movie studios shy away from "black films," and movies with strong "black themes," revolving around race and racism, which are both seen as "political" and therefore not universally appealing (Erigha 2019). This creates a negative feedback loop in which "black films" are often either underfunded or not produced by major movie studios because they are "too black," and blackness supposedly does not sell. So, whenever a "black film" is made, it stands out as unnecessarily "political" because that movie focuses "too much" on issues that are important to, impact, and/or harm black people. Therefore the movies with black characters like Dr. Larabee, in Akeelah and the Bee, and Carrie, in Night School, need to be as "marketable," palatable, and likable as possible.

Another issue that I believe drives the supposed popularity of these films with altruistic character is how whiteness is privileged at all levels of production in the film 
industry, from writers to actors, directors, producers and marketers (Hughey 2014; Erigha 2019). Black people, and other marginalized groups, are largely underrepresented at each level of a movie's development. As a marginalized group in Hollywood, black people have very little control over how black characters are portrayed, thereby allowing racist stereotypes and culturally racist assumptions about black people to dominate “mainstream” and/or big budget movies (Erigha 2019).

Understanding Hollywood now, and in the Obama era, requires an understanding that the film industry developed colorblind discourses in the $1960 \mathrm{~s}$, a time when overt racism was outlawed. Hollywood openly disavowed outright racism — taking a "progressive" stance on race - in favor of a market rationale that assumed movies with white casts would make more money than movies with casts of color. The reasons for this subtle racial discrimination are couched in cultural and economic language, theoretically creating an industry preference for colorblindness and whiteness in films designed to sell to as large an audience as possible.

By taking "progressive" stances on social issues, especially those involving race and racism, Hollywood offered themes and characters that rejected notions of racial exclusion but also provided "symbolic gestures of liberalism" that offered symbols of diversity and inclusion without there being concrete evidence of such inclusion in the industry (Erigha 2019:30). These “symbolic gestures" are similar to Collins' (2000) discussion of the "new racism" that can be summed up in the film industry as, using Bonilla-Silva's phrase, "racism without racists." I infer that one of these "symbolic gestures" in film was to have a black character like Dr. Larabee play the role that would have otherwise been occupied by a white character. In other words, I suspect some of the 
black "altruists" in the sample are really race-bent white saviors for the sake of "diversity" and "inclusion," even though Hollywood struggles with diversity at all levels.

So, movies with "altruist" characters were so popular in the Obama-era because they represented the idea that racism had been overcome; they were generally "optimistic" about racism, just like white saviors tended to be. On top of this optimism, these movies focused on black characters, giving people what they wanted in terms of diverse representation. Because audiences demand racial parity in films to keep movies from being white dominated, it seems like blackness is grafted onto colorblind "whiteness" to maintain the lauded liberalism of white savior films while giving audiences what they claim to want: more faces of color on screen. This realization, in tandem with the fact that these altruistic movies do not overtly blame white people for black suffering or inequality, also likely contributes to "altruistic" movies' commercial success. They satiate audiences' desire for diversity and inclusivity while secretly maintaining the status quo. These movies are very "safe" as a result. In other words, they make more money because more people are more comfortable seeing them and thus they draw in larger crowds.

I theorize that movies like Chi-Raq, Beasts of No Nation, Dear White People, or The Hate U Give are "less appealing" to audiences and the Hollywood film industry because these movies explicitly address and aggressively confront white racists, and they link white people to contemporary racism, which is controversial and uncomfortable for many people. This also helps explain why some vigilante movies do so well: they subtly encourage colorblindness by reducing racism to one particular time period, location, or the actions of a few "bad apples." Therefore, vigilante movies are (mostly) "safe" to 
produce and watch. But, the question becomes, why do vigilante movies make less than films with altruistic characters? The answer is, once again, fairly complex, if not impossible to answer succinctly. But, I argue movies with vigilante characters make less money than movies with altruists because of the vigilante's use of hyper-violent content, which could be offensive to some audiences. So, the difference between altruists and vigilante box office earnings could be a function of the differing types of violence in the films rather than the themes of the movies, although vigilante movies do tend to show black people beating up on white people.

Given that movies with subtle controlling images and colorblind themes seemed to be more "popular" in the Obama-era, one question arises: do American audiences prefer "colorblindness" in their movies? While I cannot make any substantive claims about what American movie-goers "prefer" without proper survey data, based on all of the arguments I previously made, I would say that Americans do not seem to necessarily "prefer" colorblindness in films. For one, colorblindness is often reinforced and normalized through its invisibility and subtly. Many people may not pick up on the colorblind racial ideologies, rhetoric, or controlling images in the films they watch. Additionally, most films in the sample made several millions of dollars, or even billions of dollars like Black Panther, which is an outlier in the study in terms of box office earnings and worthy of a brief discussion.

Black Panther's success is anomalous, and comes in large part due to its connection to the Marvel Cinematic Universe, an extremely successful, and popular, American media franchise and shared universe revolving around a series of superhero films produced by Marvel Studios. When Black Panther came out, it received a lot of 
mass marketing and merchandising that generated a lot of excitement for the film. Additionally, because the movie had a majority black cast, which is rare for a superhero film, it was considered to be a cultural moment, especially since Black Panther (the character) was going to be the Marvel Cinematic Universe's first major black superhero. As a result, Black Panther was a box office success and was extremely profitable.

I mention Black Panther's success, for example, to show that people are watching these movies regardless of "character type" or paternalistic "strategy" employed in them. However, it seems the "liberal" film industry does like to produce these "colorblind" movies because of how easy they supposedly are to make, consume, and profit from. Compared to movies with altruistic characters in them, vigilante and revolutionary characters are more likely to be "offensive" given their tendency to vividly portray the brutality and cruelty of racism and how black people respond to such racial cruelty, issues many people in the United States are uncomfortable with. The unfortunate thing is, colorblind movies do not help people confront racism, but they do teach people how to confront personal "failures." This means that if we want the problem of colorblindness to become less profitable in film narratives, the film industry has to become decoupled from its all-encompassing whiteness, and the worldviews and assumptions of whiteness, at the structural level which might help reduce the colorblindness, and other racist imagery and ideologies, in movies.

\section{Filmic Altruism: Benevolence, Colorblindness, and Individualism}

To summarize this chapter, ultimately, "altruistic" characters are more "suburban" and middle-class and focused on "individual, personal change." Unlike revolutionaries and vigilantes, altruists are the most similar to white saviors in terms of how they help 
people. For example, white saviors take a broad activist stance and engage in "acts of racial uplift" to help dismantle structural and ideological racism — by upbraiding racist individuals instead of the racist systems of inequality - that prevent people of color from being treated with respect (Schultz 2014:207). Altruists function similarly, assuming they deal with individual racists. Schultz's description of white saviors as characters who make changes to the system by only engaging with racist individuals also sounds like my description of vigilante characters. So, the vigilante and the altruist also have some similarities in terms of their engagement with individualistic, and colorblind, notions of social change.

Regardless of how these characters encourage others, all of the "altruists" discussed in this chapter minimize racism and structural race and class inequalities, while simultaneously reproducing them, and rely upon abstract liberalism to stress the importance of meritocracy. Gender inequalities are also minimized, but through intersections with race and class. This minimization is an example of "colorblindness."

"Abstract liberalism," is an aspect of colorblindness that asserts that society is not contingent on racial formations and social practices, but on meritocracy, equal opportunities and the idea that people of color should work harder if they want to get ahead (Hughey 2015; Bonilla-Silva 2017). Along the same lines as abstract liberalism, "minimization" downplays the effect of racism in life outcomes and experiences. This frame shrinks the import of race because it frames racial progress as slow, if not impossible, because racism is not recognized (Hughey 2015; Bonilla-Silva 2017). These two frames drive how altruists function. All of the characters discussed in this chapter, from Dr. Larabee to Madea, encourage their subjects to ignore external social forces and 
focus on their own failures, stop "playing the victim," and not to blame their failures on how white people treat them.

Despite how these characters might hint at their awareness of how society oppresses and mistreats people of color, altruists demand that their urban, low-income or poor subjects subjects overcome whatever barriers hold them back by working hard; this perpetuates racial and class stereotypes. The film suggests that poor, disadvantaged, and/ or misguided characters can only achieve if they display the requisite: work ethic, respect for authority, obedience, lawfulness, and discipline, all of which fail to indict social structures for their role in creating disadvantage. Thus, the dominant gender, class, and racial ideologies of colorblindness, benevolent paternalism, and individualism supported in these movies creates false consciousness about how progress can be made and how altruists can ultimately lift people out of perdition. This colorblindness is also problematic because it invalidates people's struggles with racism and opens a discussion of the "benefits" or the necessity of individualism.

Additionally, what I find interesting is that movies with "altruistic" characters use black characters to reinforce specific notions of individualism. In fact, throughout my discussions of revolutionary, vigilante, and altruist characters, I have discussed how each character category reinforces individualism in some way either by reducing the solution to systemic oppression, disadvantage, or personal failure down to the actions and choices of one person. The focus on specific individuals throughout all of the films in this study places an emphasis on how each character "saves," "rescues," and "empowers" other people. In the next chapter, I discuss how the focus on individuals who save others makes them a type of "savior" character similar to white saviors. 


\section{CHAPTER VII \\ DISCUSSION \& CONCLUSION}

In this chapter, I summarize my findings from the previous three chapters and discuss their implications for, and connections to, past literature on white saviors. Specifically, I return to the arguments I introduced in Chapter I where I suggest that the paternalistic black characters mentioned in this study fit a different kind of "savior" role (some more than others) in such a way that they are what I call "black saviors" that is different from white saviors. "Black saviors" operate in some similar ways to white savior characters, given the "black savior's" desire to intervene in people's lives to improve them in some way. Thus, I use the "savior" concept to discuss black characters given their actions which are directly or indirectly meant to "save" people in various ways. However, "black saviors" are different from white saviors because they (at least revolutionaries and some vigilantes) in some ways critique and "resist" white supremacy, patriarchy, and capitalism in ways that white savior characters do not. These movies also afford black people agency that white people used to have a monopoly on in film. I explain these nuances more throughout this chapter.

First, I summarize and nuance this study's findings from the previous three chapters and the discussion of the nuances of those findings. Second, I provide a discussion of the implication of the aforementioned nuances by discussing Collins' (2000) discussion of controlling images. Finally, I conclude with a brief discussion of 
what my study's findings mean, and what these black characters could mean going forward, and how future scholars could advance the study on these black characters.

\section{Summary of Black Savior Characters}

To study black revolutionary, vigilante, and altruistic characters more closely, this study sought to answer three key questions:

1. How does a black character's class and gender influence how they rescue, inspire, guide, or redeem other characters in Obama-era films from 2006-2018?

2. How are their acts of rescuing, inspiring, or redeeming similar to or different from white saviors?

3. What are the implications of these similarities or differences?

Through my analysis of the twenty films used in this study, I have found very prominent differences in regards to how paternalistic black male and female characters behave. Men tend to rescue, inspire, guide, or redeem other characters through "tough love," aggression, and violent confrontation either with the people who need to be "saved," or the people causing harm. The theme of aggression is prevalent across all of the types of characters (revolutionary, vigilante, altruist) being analyzed. Women tend to vary in the methods they use to "save" others. However, they tend to be more motherly and nurturing for the people they save and, in some cases such as in The Help or Big Momma's House 2, black women come across as mammies and Jezebels who are servile. Other black women like Mary in Proud Mary, or Madea, in Madea Goes to Jail, take on more aggressive masculine traits making them come across as angry black women and sapphires. Regardless of their presentation, black women tend to protect and fight for 
children and/or their local communities, while men tend to fight for the entire black race or very large groups of people at once.

When engaging with the sociological literature, it is clear that academia focuses heavily on white people as the only ones who can "save" and help others given their portrayal as "better" than the people they are saving, which uplifts whiteness writ large. However, my findings from this study shows that the concept of a filmic "savior" is not just a white phenomenon and can be extended to certain black characters as well. How these black characters "save" and "rescue" others is highly nuanced, with each complexity influencing how they attempt to make social change.

Since each character type works differently to engage with social change, each character's actions lie on a "spectrum" with "broad societal change" (correlated with revolutionary characters) on one end, and "individual, personal change" (correlated with altruistic characters) on the other end, with more "localized social change" (correlated with vigilante characters) sitting in the center, which I explain in future chapters. In addition, each character on the spectrum has different priorities that are focused on revolution (revolutionary characters), reform (vigilante characters), or reflection (altruistic characters).

These "priorities" seem to be influenced by class, with poorer characters advocating for revolution and reform, and characters who are more generally middle or upper-class advocating for reflection. These priorities are also important because they simply indicate what each character's "strategy" aims to accomplish in terms of dealing with racism, sexism and other forms of oppression, and what type of "consciousness" each character possesses. For example, I believe revolution is correlated with "race 
consciousness" in general, while reflection/responsibility is correlated with "colorblindness." Reform is correlated with elements of both colorblindness and race consciousness.

Despite each character's differing characteristics, each type of character seeks to save, empower, and protect vulnerable people from racial and/or gender oppression or harm. What ultimately separates each "type" of black character, and the strategies they each use, is how they achieve that "salvation." Each character archetype discussed in this study embodies some form of power because the characters are portrayed as having power and/or status through their ability or efforts to make change (even if it is simply personal change). Black men are portrayed as violent, and actually as having greater physical power, but they are also portrayed as educated, knowledgeable, and capable, as I discuss with the altruistic characters. So, black men are shown to embody greater diversity in characteristics across all of the films as compared to women. Black women are portrayed in more disempowering ways across all the films, and are generally not as educated, knowledgeable, or capable.

\section{Black Saviors and Malleable Controlling Images}

What I theorize from these nuances, and what I believe is this study's major contribution to the literature, is that the black characters I have discussed in this study have more nuances in $21^{\text {st }}$ century film that allow both characters to reject and conform to certain controlling images. Returning to the theory of controlling images, Collins (2000) argues that controlling images are pervasive, negative, stereotypical representations and images of black women that continue to justify their oppression. She implies that controlling images are "static" and immutable caricatures that are constantly repeated 
without variation across time and institution with very little complexity or nuance. Controlling images are simply reductionist takes on black womanhood that are meant to mock black women as "inferior" to white women.

Contrary to Collins, I reiterate that controlling images are not static images, as evidenced by some of the characters and categories discussed in this study. These characters change and evolve over time in their movies based on the narratives around them, their motives, and their character arcs. My argument opens space for characters to exist as typical "mammies" and "angry black women" at the beginning of their movies, who then end up fighting their oppressor, and encourage others to do the same, by the end of their movies. In fact, even when different characters supposedly represent "controlling images," how these characters represent them is often completely different. For example, Sam White's expression of the "angry black woman" is different from Starr Cater's expressions. Django's expression vigilantism is different from Robert McCall's. This implies that the "controlling image" concept may need to be thought of as being more varied instead of a one-dimensional expression. In other words, controlling images can be reframed, repurposed, and/or re-appropriated to create different expressions of the stereotype that do not neatly fit Collins' original conceptualizations.

For example, Lysistrata is only able to become the "activist" because she is an "angry black woman" whose anger motivates her to improve her community. Being an "angry black woman" in this case, does not hinder her agency and make her seem "subordinate" or "inferior," the way Collins theorizes controlling images do. I find that being an "angry black woman" enhances Lysistrata's agency, and allows her to take the necessary actions to make change. Lysistrata's activism against systemic patriarchy and 
racism subverts the racism inherent within the "bad black girl" and "angry black woman" controlling images by reframing her supposed "bitchiness" (that she is seemingly known for in the film) as something righteous and revolutionary.

Likewise, Big Momma is only able to help the people around her, because of her status as a "mammy." Big Momma starts off being portrayed as a simple, lowly "mammy" who takes care of the Fuller household, but her character develops in the film and she ends up acting as a "mammy" at the end of the movie who saves the Fuller family from harm which is only possible because of her "mammy" role. In other words, Big Momma is able to both take care of a family and fight off evildoers who seek to harm it which seemingly contradicts the traditional description of the mammy image as someone who is incapable of anything other than raising a white family. Her portrayal as a doting, servile nanny is actually reframed, and portrayed, as one of her strengths because her role as a "mammy" makes her unassuming and makes it easier for her to help others by investigating crime. Therefore, Big Momma does not neatly fit into the "mammy" archetype even though she is a mammy on the surface. I see this same dynamic with male characters who embody certain black male stereotypes.

Take Black Dynamite, for example. He starts his movie off as a poor, violent, black male, all of which are controlling images of black men that seek to justify black male oppression. However, Black Dynamite undergoes an evolution in his movie in which his portrayal as a "violent black male" is reframed, and portrayed, as a "positive" for him at the end of the movie in which he is portrayed as a hero only because of his belligerence. The stereotype associated with him does not make him seem "inferior"; it makes him seem "heroic." 
Like Lysistrata and Big Momma, Black Dynamite's violence subverts the typical narratives of black "incivility" that often utilize white characters to "tame" violent black men. Subverting controlling images through the repeated use of stereotypes as tactics for liberation instead presents a counter-narrative to the idea that black men are "uncivil" and "savage" and in need of a white person's help. Theoretically, Black Dynamite, and other violent black men in their movies, becomes self-sufficient and independent because he uses violence, and he uses it for "liberation" instead of destruction. Thus violence becomes a masculine liberation strategy for men like Black Dynamite, just as being an "angry black woman" is a "liberation" strategy for women.

Therefore, I return to my early assertion that these characters, and their expressions of controlling images, might be "counter-narratives" to the white supremacist notions inherent within these controlling images. Thus, the use of controlling images as a way to subvert racist ideas of what black people are capable of seems to be a way to reclaim the black image as emblematic of strength and self-determination instead of weakness, degeneracy, and unruliness as Collins' original definitions imply. This could mean that controlling images can be used as purely negative literary devices that dehumanize black men and women. Or, as I find in modern movies, they can be nuanced and used as ways to tell stories that challenge the dehumanization of black people and white supremacist patriarchy as a whole. With this in mind, I think Collins' discussions of controlling images can be expanded to include these newfound nuances that makes the controlling image concept more amorphous and influenced by the period in which they are used. The images I discuss in this study seem to be influenced by the time period in which they were used (i.e. the "Obama era") which means that they are likely not going 
to reinforce the same themes as controlling images developed during slavery, for example, and will always shift over time. This seems to be a deviation from Collins' conception of controlling images.

Black Saviors: Reinforcing Controlling Images and the "New Racism"

In addition to my previous argument, I also argue that even in films with more nuanced black characters and representations, I still see the reproduction of ideas about racism that perpetuate colorblind racism, white supremacy,. In other words, while each character each archetype I analyze in the study is portrayed as having power and/or status through their ability or efforts to make change, the ways that they make change often reproduces pre-existing controlling images that oppress and marginalize black people. Their acts of "empowerment" in some ways actually serve to continue black male and female disempowerment in society. Therefore, while I previously argued that characters could reject controlling images, I also argue that in some instances they can reinforce them, often simultaneously and at different points in their movies. This seems to creates a paradox in my analyses. If I claim that some of the characters in the study represent more nuanced controlling images that may actually help "subvert" and "challenge" white supremacy and patriarchy (at least in the context of a movie narrative), how can these characters also help reproduce white supremacy and patriarchy?

Part of this paradox is a concept called the "new racism." New racism supports the social order while seemingly challenging the racial inequality within the social order (Collins 2005; Hughey 2009). The new racism explains contemporary racial inequality as reproduced in ways that make up the "post-racial" myth of America and American racial politics (Collins 2005; Hughey 2015; Bonilla-Silva 2017). As I have shown for the 
movies in this study, because all of the characters represent specific controlling images and stereotypes, I argue that these images and portrayals play some part in perpetuating the oppression of black people through portraying them as "ghettoized," "urban," and "violent." The perpetuation of negative themes through the mélange of mass media representations of black men and women creates a (global) context for a type of racism that frames black people as "problematic," "violent," "ghetto," or "uncivil" all without needing specific racial, racist, or sexist language that once defined the racism of the past (Collins 2005). The portrayal of black people as "problematic" is easily perpetuated through subtle characterizations and narrative choices in movies, which helps to create and perpetuate colorblind ideology, undercutting racial progress globally.

Undercutting racial progress is even more alarming when we realize that it comes from certain black characters. Since the characters in the movies in the study are all black, it may make it harder for audiences to notice that the movies in some ways reinforce colorblindness and/or the "new racism." Therefore, many people might see movies with black characters calling for revolution, like Chi-Raq, and view the movie as "positive" and "progressive" even though the movie ends with a black character ranting about how black people need to "take the blame" for the role they play in their own oppression. Because movies have such a large reach, and the film industry is an industry with the ability to shape cultural perceptions, this means that movie plots and their subliminal messages are very important and can seep into the broader collective consciousness, which gets me into another related topic: cinethetic racism.

One extension of "new racism," in relation to film, is called "cinethetic racism" (Hughey 2009). "Cinethetic racism," according to Hughey (2009), is a type of racism that 
describes "black friendly" and racially "progressive" films. However, these films combine overt manifestations of racial "equality" with covert expressions of anti-black stereotypes (Hughey 2009). Movies like The Equalizer, The Equalizer 2, Big Momma's House, and The Help fit into Hughey's description of cinethetic racism because they show characters like Robert McCall, Big Momma, and Minny who work and cooperate with other people to help "save" others. Yet, despite their "heroism," they are still stereotyped as violent (Robert McCall) or subservient (Big Momma and Minny).

Likewise, even characters like Lysistrata and Sam White are presented as heroic and fearless activists who stand up to oppressors, even though they embody specific degrading stereotypes of black women as angry, petty, mean, and bitter. This mismatch between empowerment and dehumanization in the films in this study demonstrate the problem of "new racism": the perpetuation of certain aspects of the status quo while seemingly "challenging" it, specifically around black people's place in the social order.

For example, recall from Chapter V where I discuss that vigilante characters, similarly to black superheroes, are portrayed as "superheroic" yet are also portrayed as extremely violent, which subtly reinforces black superheroes and vigilantes as "threatening" or "harmful" all without needing to explicitly say it. That is an example of cinethetic racism because the portrayal of vigilantes seems to highlight the power, efficiency, and heroism of black males while underlining those portrayals with a negative stereotype. The aforementioned portrayals are thus the equivalent of getting a backhanded compliment. This also brings into perspective why the theme of "exceptionalism" is so prominent in these movies: only the black characters who are "not like the others" get to be powerful heroes and leaders while the black characters who are 
not "exceptional" need to be "saved." So, the malleability of the controlling images

discussed in this study in some ways seems to be a function of this new, cinethetic racism that is meant to add to a post-racial, "back-handed" (to use my own term) colorblind discourse that in many ways framed Obama's presidency.

\section{Conclusion}

Ultimately, this study furthers Patricia Hill Collins' discussion of controlling images by showing that controlling images are malleable, as opposed to static, entities. The malleability of certain controlling images implies that movies in the $21^{\text {st }}$ century that present black characters as "saviors" of some kind, while still using stereotypes to frame them, still perpetuate racism, sexism, and classism in very nuanced ways. The contradiction between the "positive" portrayals of black characters and the racist imagery and assumptions that underlie those portrayals implies that movies with "black savior" characters are actually part of the "new racism" fueled by the same colorblind individualism that framed Obama's presidency.

This study takes a novel approach to studying black characters in film by focusing on black main characters in movies released during the Obama era from 2006-2018. Throughout this study, I have analyzed how black characters act paternalistically using three different strategies: revolution, vigilantism, and altruism. In addition to analyzing these strategies, and the characters in the sample who seem to use them, I analyzed how these characters' race, class, and gender influenced how they utilized the aforementioned "strategies" to rescue, inspire, guide, or redeem other characters in Obama-era films from 2006-2018. Obama's presidency showed a powerful, authoritative black man leading the nation into "prosperity" and "change." His presidency also represented "proof" that 
America had overcome its racist past, meaning that his presidency ushered in a wave of colorblind rhetoric that downplayed the effects of racism as a "thing of the past," and this rhetoric may have made its way into film narratives and representations

Despite the colorblindness Obama's presidency represented, race and racism were dominant themes of the movies at the time in which black people were characterized in Obama's image as powerful and paternalistic. Analysis of paternalistic black characters in films, released during Obama's presidency, reveals how blackness and black agency was framed and conceptualized in order to impact the ways race was understood then, and how race is understood in the United States today.

With this study, I also sought to understand how black characters addressed the issues of racism that tends to pervade movies released at the time. I ultimately found that many movies featured black characters who were angry at and sought to partially correct the harmful effects of institutional racism through "revolution" or "vigilantism." Other black characters, like most of the "altruists" in the study, did not deal with racism at all and opted to focus on individualistic, and colorblind life lessons and general advice to "help" others.

Of these three character types, and their preferred strategies discussed in this study, the movies that were the most colorblind - movies that reflected the "post-racial" ideologies that Obama ultimately represented—were the most "profitable" and "popular," meaning that movies with colorblind and individualistic narratives were generally most effective at drawing crowds at the time. The popularity of all of the more colorblind "black savior" films also seems to be the result of a structural issue in the film industry that is white-dominated and infamous for its portrayal of black people as "leaders" as a 
symbolic display of representation and inclusivity. While these representations are typically viewed as "progressive," these movies also subtly reinforce the social status quo, which represents the harmful effects of the "new racism."

One way to address this new racism is to have more directors, writers, and producers of color in control of their narratives and the portrayals of people of color. This will not totally eliminate the production of racial stereotypes and the cynical desire to depict people of color in order to appease racially diverse audiences. But, what having more directors of color will do is wrest control of the film industry away from people who are more interested in tokenizing people of color rather than humanizing them. However, even with directors and writers of color in the industry, we still see portrayals of black males as dependent on physical violence, aggression, and rage to get their way, and we continue to see black women portrayed as mammy, sapphire, and Jezebel controlling images.

All of these portrayals across every movie I discuss in this study, except for portrayals of "altruistic" characters, continue to reinforce the "savagery" and "incivility" that black people have been associated with since the colonial narratives of the "noble savage." Altruistic characters are presented as "civilized" or "domesticated," since they have, in some ways, assimilated into certain aspects of whiteness like middle-class social values. This connection to the middle-class makes altruists not only the most similar to white saviors, but the most similar to Obama himself given their adherence to colorblindness, and their desire for their subjects to follow rules and develop the "right values" that will help them succeed and escape their "urban" environments. Thus, it makes some sense that movies with these characters were not only the most profitable in 
the Obama-era since these movies implicitly suggested ways for society to create more "respectable," "successful," and "introspective" people who sought to only change themselves instead of the status quo.

\section{Limitations of the Study}

The primary limitation of this study is that the analyses of the characters in the films used in the study are limited to films selected through my criteria which limits the "depth" of the sample. First, the sample for this study is relatively small and does not include "true stories" or biographical films. I discuss my reasoning for the size of the sample and for not including biographical films in previous sections. However, the selection process I used in this study limited the kinds of characters I analyzed and the conclusions I drew from these analyses. For example, one of the criteria for the study was that the study needed to have a black/main antagonist and/or protagonist character who occupied a role associated with power and/or leadership in relation to other characters.

This study's focus on black main characters hindered the overall scope of the analysis because I did not focus on all of the potential characters who could have also been paternalistic, which may have added an additional layer to my discussion of "black saviors" because of their differing interactions with the lead and/or other characters. Because I only focused on lead characters, I did not provide an analysis of "minor" or "supporting" characters. This lack of focus on all characters in the films greatly limits the scope of the study and the analyses herein. To elaborate, I focused on main characters because many studies did not focus on black main characters. In fact, most studies of black characters in film focus on supporting or minor black characters, but I decided not to focus on them because black main characters were unexplored. Despite the novelty of 
my approach, an analysis of all potentially paternalistic black characters in films would have added more depth to the analysis by adding more depth to my analysis character interactions at all character "levels," main characters, supporting characters, and minor characters.

The timeline of the study is also a limitation. This study only analyzes films from 2006-2018. The use of this specific timeline limits the sample and prevents the study from looking at movies with characters who could have also added depth to the study. I used a timeline to reduce the "universe" of films down to an amount of films with a shared context (the Obama era) that was more manageable. By creating this specific timeline, I actually prevented the study from looking at movies like Big Momma's House, the first movie in the Big Momma's House series, which may have added more to my discussion of Big Momma's character. The timeline keeps the study from looking at films before 2006, which limits the depth of the sample.

Finally, I lacked resources that would have helped me conduct this study more efficiently. For example, while I ultimately preferred to use Microsoft Word to do my analyses, that preference was influenced by my lack of resources to afford and/or use more advanced technology that would have made staying organized and systemic in my analyses a little easier. The lack of resources in general limited the number of films I would reasonably be able to analyze in a reasonable timeframe. Therefore, with more resources, I believe this study could have been expanded to include more films and/or an audience analysis of the films which would have moved the study away from my personal interpretations. A view on these movies from an audience is what I believe this study is missing, and it is missing the audience perspective because I lacked the time, 
finances, and other necessary resources to assemble an appropriate audience, which limited the scope of the analyses to twenty movies that I interpreted.

\section{Recommendations for Future Research}

Future research into supposed "black savior" characters could look at a larger sample of films as this study settled on twenty films. With a larger sample, researchers will have more data from which to develop more new categories for analysis and discussion that could potentially add nuance, or challenge, the concept of black agency and power in film. Future research could analyze films in which there is possible a "black savior" who is more of a supporting character, and how the supporting role compares and contrasts with "black savior" lead characters. Since this study only focused on "leads" there may have been nuances that I missed because I was not looking at every character's interactions. Along these same lines, future studies could look at the lead characters in blaxploitation films to try and answer the same research questions I addressed in this study. Black lead characters in blaxploitation films almost exclusively work to rescue or "save" other black people, and a study that looks at how that is done in comparison to white savior characters, or even the characters I have discussed in this study, could provide an analysis on the differences between white saviors and blaxploitation characters in various racialized and gendered ways.

An analysis of these types of "black savior" characters could incorporate an "audience analysis" that focuses less on how the researcher conceptualizes characters and instead focuses on the ways in which movie-going audiences make sense of these characters. Utilizing audience analysis and commentary adds additional layers of complexity to the understanding of paternalistic black characters, whether such 
"paternalism" exists, or whether the actions of black characters in this sample or an extended sample can be considered "paternalism" at all. How people make sense of what they watch could provide more powerful and theoretically interesting insights into how racial meanings are constructed through filmic imagery, and what kinds of people make what types of meanings from what they watch. This could not only add to literature on the effects of media on people's understanding of race and racism, but it can also add to our understanding of how different people's intersectional identities influence what movies they consume and how that might influence how different people interpret movies, what movies are produced, and how those movies are reviewed. An analysis of the "cycle" of audience perception-movie production-movie review could provide a nuanced understanding of the film industry and its relationship to its audience that goes beyond simple market trend data and into a discussion of the social construction of (racial) reality, and (race) knowledge, and their relationship to capitalist production and consumption writ large.

Given the context of the Black Lives Matter protests and broader cultural shifts, future research should also consider how the portrayal of black characters in film might reflect, or influence, the way in which people perceive these racial movements and shifts, and/or how filmic portrayals of black people might influence how mainstream media, and politicians, discuss these movements given that the media and political actors influence policies that impact the ability to engage in social protest. It would be interesting to compare how the "modern" language that is often used to describe the current protests, and protestors, reflects or is influenced by the portrayal of black people in movies and/or television shows. 
Finally, there are some questions that arise from this study that future studies can attempt to answer:. Do black people need a "savior" and a "hero" especially in the movies? Are these characters even helpful? Can a "black savior" truly be a "revolutionary" character who truly upbraids or "fights against" systemic racism? What would that look like given how the film industry produces movies? Answers to these questions, which are neither simple nor succinct, will allow a deeper analysis of the film industry itself and its importance in shaping culture.

\section{Final Words}

I want to conclude by saying that the study of black characters in film is not just about the film industry, but the humanization and dignity of black people in the United States. While there are endless depictions of white people, white men in particular, there are not that many versions of black people in the culture. Culture has a powerful way of telling people what they can and cannot be. For people of color, the options for what we can be are limited. This study was an attempt to expand those options to show that black people can be more than "magical negroes" who are dependent on white people's mercy. Black characters can fight for, and "redeem" ourselves because we are also powerful, and the narrative of "black people as powerful" is a narrative that has only developed in the past few decades. The centuries-long repertoire of black representation is full of embarrassing and dehumanizing imagery with harmful implications for the black experience throughout United States history, and that harm continues to this day.

Since the film industry has gained more racial and gender diversity — with more people of color and women directing movies in the past five or six years - the amount of movies with strong racial or gender themes, narratives, and allegories has become more 
prevalent. However, despite the diversity gains, Hollywood still has a long way to go before it really becomes inclusive and devoid of its colorblindness. Movements like \#OscarsSoWhite are so important due to their focus on placing a spotlight on "black movies" like Black Panther and Dear White People and The Hate U Give that all problematize the whiteness that pervades the United States. \#OscarsSoWhite specifically highlighted the ways in which film and television awards shows like The Oscars, Golden Globes, Critics' Choice Award, and Screen Actors Guild Awards overlooked the contributions of black directors, writers, and actors in favor of mostly white male directors, writers, and actors, which only served to perpetuate the exclusive whiteness of the film industry.

Theoretically, this means movies with no overt or "controversial" racial themes that challenge white supremacy will continue to make a lot of money, win a lot of awards, and get more opportunities to be produced, while movies that challenge white supremacy, like the movies with revolutionary characters and themes, will be "fringe" novelties that get little recognition. Likewise, this continued focus on creating colorblind movies for white consumption highlights the necessity for the current Black Lives Matter movement and the current protests for Breonna Taylor, George Floyd, and other victims of police brutality. These movements highlight the myriad ways in which black people are oppressed, dehumanized, and failed by society. The common portrayals of black people in films with colorblind narratives play a role in that societal failure because they encourage people to overlook black oppression.

But, fortunately, people are becoming more aware of racial oppression thanks to mainstream mega-hits like Black Panther that speak very directly to racial animus in the 
United States. There are other movies about the struggle against racism, like BlacKkklansman and Selma, and several television shows like Watchmen that have received "mainstream" recognition, which goes a long way in raising people's consciousness about racism and its global legacy. As society grows more aware of racism, we might see a surge in racially progressive and conscious films with more "revolutionary" characters and themes. For example, Black Panther is slated to get a sequel in the year 2022 which might have more racially charged themes that raise people's awareness of and desire to combat racism. This gives me hope that the future of black portrayals in film will continue to trend toward more "positive," powerful, and progressive images that humanize and dignify blackness all around the world. These positive images and narrative will not come just because of the increased diversity in Hollywood, but because people will realize, with help from movie narratives, that black lives have always mattered, they just have not mattered much in the movies. Hopefully, the Oscars will not look so white in the future. 


\section{REFERENCES}

Aldoni, Hanna and Sherrill Mane. 1984. "Media and the Social Construction of Reality: Toward an Integration of Theory and Research." Communication Research 11(3):323-340.

Appiah, Kwame. 1993. "“'No bad nigger:” Blacks as the ethical principle in the movies.” Pp. 77-90 in Media Spectacles, edited by Marjorie Garber, Jann Malock, and Rebecca L. Walkowitz. New York: Routledge.

Baldwin, Andrew. 2011. "Whiteness and futurity: Towards a research agenda." Progress in Human Geography 36(2): 172-197.

Bernardi, Daniel. 1996. The Birth of Whiteness: Race and the Emergence of U.S. Cinema. New Brunswick, NJ: Rutgers University Press.

Berry, Gordon L. 1998. "Black Family Life on Television and the Socialization of the African American Child: Images of Marginality." Journal of Comparative Family Studies 29(2):233-242.

Blumer, Herbert. 1951. "Paternalism in Industry." Social Process in Hawaii 15:26-31. Bogle, Donald. 2001. Toms, Coons, Mulattoes, Mammies, and Bucks: An Interpretive History of Blacks in American Films. New York, NY: Continuum. 
Bonilla-Silva, Eduardo. 2017. Racism without Racists: Color-Blind Racism and the Persistence of Racial Inequality in America. Fifth Edition. Lanham, MD: Rowman \& Littlefield.

Bourdieu, Pierre, and Loic Wacquant. 1992. An Invitation to Reflexive Sociology. Chicago, IL: University of Chicago Press.

Bristor, Julia M., Renee Gravois Lee, and Michelle R. Hunt. 1995. "Race and Ideology: African-American Images in Television Advertising." Journal of Public Policy \& Marketing 14(1):48-59.

Brookhiser, Richard. 2001. "The Numinous Negro.” National Review, August 20. Retrieved September 2015 (http://www.nationalreview.com/article/220766/numinous-negro-williumrex).

Brown, Timothy J. 2008. "I am who I am: Black masculinity and the interpretation of individualism in the film Barbershop." Qualitative Research Reports in Communication, 9(1):46-61.

Bulman, Robert C. 2002. "Teachers in the 'Hood: Hollywood's Middle-Class Fantasy." The Urban Review 34(3): 251-276.

--------. 2015. Hollywood Goes to High School: Cinema, Schools, and American Culture. New York: Worth Publishers.

Burke, Meghan A. 2017. “Colorblind Racism: Identities, Ideologies, and Shifting Subjectivities." Sociological Perspectives 60(5):857-865.

Butler, Paul. 2013. "Black Male Exceptionalism?: The Problems and Potential of Black Male-Focused Interventions." Cambridge University Press 10(2): 485-511. 
Carbado, Devon W, Kimberle Crenshaw, Vickie M Mays, and Barbara Tomlinson. 2013. “Intersectionality: Mapping the Movements of a Theory." Du Bois Review 10(2): 302-312.

Charmaz, Kathy. 2006. Constructing Grounded Theory: A Practical Guide Through Qualitative Analysis. London: SAGE Publications.

Cho, Ji Y., and Eun-Hee Lee. 2014. "Reducing Confusion About Grounded Theory and Qualitative Content Analysis: Similarities and Differences.” The Qualitative Report 19(32):1-20.

Choo, Hae Yeon and Myra Marx Ferree. 2010. "Practicing Intersectionality in Sociological Research: A Critical Analysis of Inclusions, Interactions, and Institutions in the Study of Inequalities.” Sociological Theory 28(2):129-49.

Collins, Patricia H. 2000. Black Feminist Thought: Knowledge, Consciousness, and the Politics of Empowerment. Routledge.

-------. 2005. Black Sexual Politics: African Americans, Gender, and the New Racism. New York, NY: Routledge.

--------. 2015. “Intersectionality’s Definitional Dilemmas.” Annual Review of Sociology 4:1-20.

Connell, Raewyn W., and James W. Messerschmidt. 2005. "Hegemonic Masculinity: Rethinking the Concept." Gender and Society 19(6):829-859.

Coogan, Peter, and Dennis O’Neil. 2006. Superhero: The Secret Origin of a Genre. Austin, TX: Monkey Brain Books. 
Corbin, Juliet, and Anselm L. Strauss. 1990. "Grounded theory research: Procedures, canons, and evaluative criteria." Qualitative Sociology 13(1):3-21.

Crenshaw, Kimberle. 1993. "Mapping the Margins: Intersectionality, Identity Politics, and Violence Against Women of Color." Stanford Law Review 43(6):1241-1299.

Cunningham, Phillip L. 2018. "The Limits of Neo-Blaxploitation: Considering David F. Walker’s Nighthawk and Power Man and Iron Fist.” Fire!!! The Multimedia Journal of Black Studies, 4(2): 94-112.

Davis, Kathryn A. 1992. "Validity and reliability in qualitative research on second language acquisition and teaching: Another researcher comments." TESOL Quarterly 26 (3):605-608.

Delgado, Richard and Jean Stefancic. 2000. Critical Race Theory: The Cutting Edge, Temple University Press, Philadelphia.

Desmond, Matthew and Mustafa Emirbayer. 2009. “What is Racial Domination?” Du Bois Review 335-355.

Dey, Ian. 1999. Grounding Grounded Theory. San Diego: Academic Press.

Doane, Woody. 2019. "Colorblindness the Lens that Distorts." Pp. 13-33 in The Myth of Colorblindness: Race and Ethnicity in American Cinema edited by Sarah E. Turner and Sarah Nilsen. Switzerland: Spring Nature.

Dovidio, John F., Samuel L. Gaertner, and Tamar Saguy. 2015. “Color-blindness and commonality: Included but invisible?" American Behavioral Scientist 59(11):1518-1538. 
Du Bois, W.E.B. 1903. “The Talented Tenth.” The Negro Problem, edited by Booker T. Washington. James Pott and Company.

Dworkin, Gerald. 1972. "Paternalism." The Monist, 56: 64-84.

-----.2002. "Paternalism." in Stanford Encyclopedia of Philosophy, edited by Edward Zalta. https://plato.stanford.edu/archives/sum2020/entries/paternalism/.

-----.2005. “Moral Paternalism.” Law and Philosophy 24(3): 305-319.

-----.2012. "Harm and the Volenti Principle."Social Philosophy and Policy 29: $309-321$.

-----.2013, “Defining Paternalism.” Pp. 25-39 in Paternalism: Theory and Practice, edited by Christian Coons and Michael Weber. New York: Cambridfge University Press.

Dyer, Richard. 1997. White. New York, NY: Taylor \& Francis.

Eberwein, Robert T. 2004. The War Film. New Brunswick, NJ: Rutgers University Press.

Ellingson, Terry. 2001. The Myth of the Noble Savage Berkeley, CA.: University of California Press.

Elo, Satu, and Helvi Kyngas. 2008. “The qualitative content analysis process.” Journal of Advanced Nursing 62(1): 107-115.

Entman, Robert, and Andrew Rojecki. 2001. The Black Image in the White Mind: Media and Race in America. Chicago: University of Chicago Press. 
Erigha, Maryann. 2019. The Hollywood Jim Crow: The Racial Politics of the Movie Industry. New York: New York University Press.

Fanon, Frantz. 1967. Black Skin, White Masks. New York: Grove Press.

Fierce, Rodney M.D. 2015. "The Exceptional Nigger: Redefining African American Identity in Django Unchained." Pp. 45-56 in Movies in the Age of Obama: The Era of Post-Racial and Neo-Racist Cinema, edited by David G. Izzo. Lanham, MD: Rowman \& Littlefield.

Francis, Jill J., Marie Johnston, Clare Robertson, Liz Glidewell Vikki Entwhistle, Martin P. Eccles, Jeremy Grimshaw. 2010. "What Is An Adequate Sample Size? Operationalizing Data Saturation For Theory-Driven Interview Studies. Psychological Health 25(10):1229-1245.

Francis, Terri. 2014. 'Whose 'Black Film' Is This? The Pragmatics and Pathos of Black Film Scholarship.” Cinema Journal 53(4):146-150.

Foucault, Michel. 2008. The Birth of Biopolitics: Lectures at the Collège de France, 1978-79. New York, NY: Palgrave MacMillian.

Frankenburg, Ruth. 1993. The Social Construction of Whiteness: White Women, Race Matters. Minneapolis, MN: University of Minnesota Press.

Gallagher, Charles A. 2003. "Color-Blind Privilege: The Social and Political Functions of Erasing the Color Line in Post Race America." Race Gender and Class 10(4): 2237. 
Gamson, William A., David Croteau, William Hoynes, and Theodore Sasson.1992. "Media Images and the Social Construction of Reality." Annual Review of Sociology 18:373-93.

Glaser, Barney G., and Anselm L. Strauss. 1967. The Discovery of Grounded Theory. Chicago: Aldine.

Glenn, Cerise L., and Landra J. Cunningham. 2009. “The Power of Black Magic: The Magical Negro and White Salvation in Film.” Journal of Black Studies 40(2): 135-152.

Goldkuhl, Goran, and Stefan Cronholm. 2010. "Adding Theoretical Grounding to Grounded Theory: Toward Multi-Grounded Theory." International Journal of Qualitative Methods 9(2): 187-205.

Gomm, Roger, Martin Hammersley and Peter Foster. 2000. "Case Study and Generalization.” Pp. 98 - 115 in Case Study Method, edited by R. Gomm, M. Hammersley and P. Foster. London: SAGE.

Gregory, Robert W. 2010. "Design Science Research and the Grounded Theory Method: Characteristics, Differences, and Complementary Uses." Proceedings of the 18th European Conference on Information Systems (ECIS 2010). Pretoria, South Africa.

Griswold, Wendy. 1986. Renaissance Revivals: City Comedy and Revenge Tragedy in the London Theatre 1576-1980. Chicago, IL: University of Chicago Press. ------. 1992. “The Sociology of Culture: Four Good Arguments (and One Bad One)."Acta Sociologica 35: 323-28. 
Groat, Linda, and David Wang. 2002. Architectural Research Methods. New York, NY: Wiley \& Sons.

Grounded Theory Institute. 2013. What is Grounded Theory? Retrieved from http:// www.groundedtheory.com/what-is-gt.aspx

Guerrero, Ed. 1995. The Black man on our screens and the empty space in representation. Callaloo, 18(2), 395-400.

Gunter, Barrie. 1987. Television and the Fear of Crime. London: John Libbey and Co.

Gyrus. 2009. War \& the Noble Savage. London, England: Dreamflesh.

Hancock, Black Hawk. 2008. “"Put a Little Color on That!'” Sociological Perspectives 51(4):783-802.

Harris-Perry, Melissa V. 2014. Sister Citizen Shame, Stereotypes, and Black Women in America. New Haven: Yale University Press.

Harvey, David. 2005. A Brief History of Neoliberalism. New York, NY: Oxford University Press.

Herman, Daniel J. 2012. Rim County Exodus: A Story of Conquest, Renewal, and Race in the Making. Arizona: University of Arizona Press.

Holman, Mirya R. 2016. "The Differential Effect of Resources on Political Participation Across Gender and Racial Groups.” In Distinct Identities: Minority Women in U.S. Politics, edited by Nadia E. Brown and Sarah Allen Gershon. New York: Routledge. 
Holtzman, Linda, and Mike Sharpe. 2014. Media Messages: What Film, Television, and Popular Music Teach Us About Race, Class, Gender, and Sexual Orientation (2nd ed.). Armonk, NY: M. E. Sharpe Publishers.

Hughey, Matthew W. 2009. "Cinethetic Racism: White Redemption and Black Stereotypes in ‘Magical Negro’ Films.”' Social Problems 56(3):543-77. -----. 2010. “The White Savior Film and Reviewers' Reception.” Symbolic Interaction 33(3): 475-496.

------. 2012. “Racializing Redemption, Reproducing Racism: The Odyssey of Magical Negroes and White Saviors.” Sociology Compass 6(9):751-767.

------. 2014. The White Savior Film: Content, Critics, and Consumption. Philadelphia: Temple University Press.

-------. 2015. “The Whiteness of Oscar Night.” Retrieved April 21, 2019, (https:// contexts.org/blog/the-whiteness-of-oscar-night/).

Hughey, Matthew W., David G. Embrick and Ashley "Woody" Doane. 2015. "Paving the Way for Future Race Research: Exploring the Racial Mechanisms within a ColorBlind, Racialized Social System.” American Behavioral Scientist 59(11):1347-57.

Izzo, David G. 2015. Movies in the Age of Obama: the Era of Post-Racial and NeoRacist Cinema. Lantham, MD: Rowman \& Littlefield. Jacobson, Matthew F. 1998. Whiteness of a Different Color: European Immigrants and the Alchemy of Race. Cambridge: Harvard University Press.

Jackman, Mary R. 1994. The Velvet Glove: Paternalism and Conflict in Gender, Class, and Race Relations. Berkeley, CA: University of California Press. 
Japtok, Martin. 2004. “'The Gospel of Whiteness': Whiteness in African American Literature." American Studies, 49(4): 483-498.

Jewell, K. Sue. 1993. From mammy to Miss America and beyond: Cultural images and the shaping of US social policy. New York, NY: Routledge.

Jhally, Sut, and Justin Lewis. 1992. Enlightened racism: The Cosby show, audiences, and the myth of the American dream. Boulder, CO: Westview Press.

Johnson, Cedric. 2007. Revolutionaries to Race Leaders: Black Power and the Making of African American Politics. Minneapolis, MN: University of Minnesota Press.

Johnston, Les. 1996. "What is Vigilantism?” The British Journal of Criminology, 36(2): 220-236.

Jordan, Winthrop D. 1968. White over Black: American Attitudes Toward the Negro, 1550-1812. Chapel Hill, NC: University of North Carolina Press.

Joseph, Ralina L. 2013. Transcending blackness: From the new millennium mulatta to the exceptional multiracial. Durham, NC: Duke University Press.

Kellner, D. 1995. "Cultural Studies, Multiculturalism, and Media Culture.” Pp. 5-17 in Gender, race, and class in media: A Text-Reader, edited by G. Dines \& J. M. Humez. London: Sage.

Ken, Ivy. 2008. "Beyond the Intersection: A New Culinary Metaphor for Race-ClassGender Studies." Sociological Theory 26:2:152-172.

Kleinig, John. 1983. Paternalism. Towata, NJ: Rowman and Allenheld. 
Konstan, David. 2000. “Atruism.” Transactions of the American Philological Association, 130(2000):1-17.

Krippendorff, Klaus. 2004. Content Analysis: An Introduction to Its Methodology. University of Pennsylvania: SAGE Publications.

Lacy, Karyn R. 2004. "Black Spaces, Black Places: Strategic Assimilation and Identity Construction in Middle-Class Suburbia.” Ethnic and Racial Studies, 27 (6):908930.

Lewis, Amanda E. 2004. "What Group? Studying Whites and Whiteness in the Era of ColorBlindness." Sociological Theory 22:623-646.

Lombard, Matthew, Jennifer Synder-Duch, and Cheryl C. Bracken. 2003. "Content analysis in mass communication: assessment and reporting of intercoder reliability." Human Communication Research 29: 469-472.

Lovejoy, Arthur O. 1923. “The Supposed Primitivism of Rousseau's 'Discourse on Inequality." Modern Philology 21(2): 165-186.

Macnamara, Jim. 2005. "Media Content Analysis: Its Uses; Benefits and Best Practice Methodology.” Asia Pacific Public Relations Journal 6(1):1-34.

Manchel, Frank. 1990. Film Study: An analytical Bibliography, Volume 1. Fairleigh Dickenson University Press.

Marco, Derilene. 2018. "Vibing with Blackness: Critical Considerations of Black Panther and Exceptional Black Positionings." Arts 7(85): 1-10. 
Marshall, Catherine and Gretchen B. Rossman. 1989. Designing Qualitative Research. Newbury Park, CA: SAGE.

Mastro, Dana. 2015. "Why the Media's Role in Issues of Race and Ethnicity Should be in the Spotlight." Journal of Social Issues 71(1):1-16.

Mill, John Stuart, 1859, On Liberty, Indianapolis: Bobbs-Merrill.

Miller, Chris. 1998. "The Representation of the Black Male in Film." Journal of African American Men 3(3):19-30.

Monk-Turner, Elizabeth, Mary Heiserman, Crystle Johnson, Vanity Cotton, and Manny Jackson. 2010. "The Portrayal of Racial Minorities on Prime Time Television: A Replication of the Mastro and Greenberg Study a Decade Later.” Studies in Popular Culture 32(2):101-114.

Monroe, Kristen R. 1994. "A Fat Lady in a Corset: Altruism and Social Theory." Midwest Political Science Association, 38(4): 861-893.

Monteith, Sharon. 2003. "The Movie-Made Movement: Civil Rites of Passage.” Pp.120143 in Memory and Popular Film, edited by Paul Grainge. Manchester: Manchester University Press.

Morris, Carlos D., Jacqueline A. Trimble, and Ayoleke D. Okeowo. 2015. "The Power of Performance: Tyler Perry's Madea as Village Sage and Superwoman.” Pp. 89100 in Aging Heroes: Growing Old in Popular Culture, edited by Norma Jones and Bob Batchelor. Lanham, MD: Rowman \& Littlefield Publishing Group, Inc. 
Motion Picture Association of America. 2018. Theme Report: A Comprehensive Analysis and Survey of the Theatrical and Home Entertainment Market Environment (THEME) for 2018.

Mukherjee, Roopali. 2006. The Racial Order of Things: Cultural Imaginaries in the Post-Soul Era. Minneapolis, MN: University of Minnesota Press.

Nayak, Anoop. 2007. “Critical Whiteness Studies.” Sociology Compass 1(2):737-755.

Neal, Ronald B. 2013. "Savior of the Race: The Messianic Burdens of Black Masculinity". Exchange 42:51-67.

Neuendorf, Kimberly A. 2002. The Content Analysis Guidebook, Thousand Oaks, CA: Sage Publications.

Nielsen. 2012. "How People Watch: A Global Nielsen Consumer Report." The Nielsen Company. Retrieved from: http://www.nielsen.com/content/dam/corporate/ us/en/reports-downloads/Global\%20Video\%20Report\%20How\%20People \%20Watch.pdf.

Okorafor-Mbachu, Nnedi. 2004. "Stephen King's Super-duper Magical Negroes." Strange Horizons.com. N.p. Retrieved 23 March 2018.

Omi, Michael, and Howard Winant. 2015. Racial formation in the United States: From the 1960s to the 1990s. New York: Psychology Press.

Pattillo, Mary. 2005. "Black Middle-Class Neighborhoods." Annual Review of Sociology 31(1):305-29. 
Peterson, Richard and Narasimhan Anand. 1976. "The production of culture: a prolegomenon." Pp. 7-22 in The Production of Culture, edited by Richard A. Peterson. Beverly Hills, CA: Sage.

------. 1979. "Revitalizing the culture concept." Annual Review of Sociology $5: 137-66$.

------. 2000. “Two ways culture is produced.” Poetics 28:225-33.

-------. 2001. "Production of culture." International Encyclopedia of Social Behavioral Science 8:328-332.

--------. 2004. “The Production of Culture Perspective.” Annual Review of Sociology 30:311-44.

Pogge, Thomas. 2008. World Poverty and Human Rights ( $2^{\text {nd }}$ ed). Cambridge: Polity.

Projansky, Sarah. 2001. "The Postfeminist Context: Popular Redefinitions of Feminism, 1980- present." Pp. 66-89 in Watching rape: Film and television in postfeminist culture, edited by Sarah Projansky. New York, NY: New York University Press.

Rajakumar, Mohanalakshmi and Alisha Saiyed. 2015. "I am Trayvon Martin: Obama and the Black Male in Cinema." Pp. 105-110 in Movies in the Age of Obama: the Era of Post-Racial and Neo-Racist Cinema, edited by David Garrett Izzo. Latham, MD: Rowman \& Littlefield.

Rideout, Victoria J., Elizabeth A. Vanderwater, and Ellen A. Wartella. 2003. "Zero to six: Electronic media in the lives of infants, toddlers, and preschoolers." A Kaiser Family Foundation Report. Menlo Park, CA: Kaiser Family Foundation. 
Riffe, Daniel, and Alan Freitag. 1997. "A Content Analysis of Content Analyses: TwentyFive Years of Journalism Quarterly." Journalism and Mass communication Quarterly 74: 873-882.

Roediger, David. 1998. The Wages of Whiteness: Race and the Making of the American Working Class. London: Verso.

Sartorius, Rolf. 1983. Paternalism. Minneapolis, MN: University of Minnesota Press. Sanchez-Escalonilla, Antonio and Araceli R. Mateos. 2016. "Recovery of the US president character in Hollywood film during Barack Obama’s terms." Cogent Arts \& Humanities 3:1-13.

Saunders, Benjamin, Julius Sim, Tom Kingstone, Shula Baker, Jackie Waterfield, Bernadette Bartlam, Heather Burroughs, Clare Jinks. 2017. "Saturation in Qualitative Research: Exploring its Conceptualization and Operationalization.” Quality \& Quantity 52:1893-1907.

Schudson, Michael. 1989. "How Culture Works: Perspectives from Media Studies on the Efficacy of Symbols.” Theory and Society 18(2):153-80.

—. 2002. "How Culture Works: Perspectives from Media Studies on the Efficacy of Symbols.” Pp. 141-148 in Cultural Sociology, edited by L. Spillman. Malden, MA: Blackwell.

Schultz, Jaime. 2014. "Glory Road(2006) and the White Savior Historical Sport Film." Journal of Popular Film and Television 42(4):205-213.

Sennett, Richard and Jonathan Cobb. 1972. The Hidden Injuries of Class. New York: W. W. Horton \& Company. 
Shohat, Ella, and Robert Stam. 1994. Unthinking Eurocentrism: Multiculturalism and the media, New York, NY: Routledge.

Silverblatt, Art. 2004. "Media as Social Institution.” American Behavioral Scientist 48(1):35-41.

Small, Mario L. 2009. “'How Many Cases Do I Need?’On Science and the Logic of Case Selection in Field-Based Research.” Contemporary Sociology 10(1):5-38.

Smith, Herman W. 1975. Strategies of Social Research: The Methodological Imagination. Englewood Cliffs, NJ: Prentice-Hall.

Tinsley, Howard E.A., and David J. Weiss. 1975. "Interrater Reliability and Agreement of Subject Judgements.” Journal of Counseling Psychology 22:358-376.

Van den Bulck, Jan. 1999. "Mediation: Toward a Media Theory of the Social Construction of Reality." Communication 26(1\&2):3-11.

VanDeVeer, Donald. 1986. Paternalistic Intervention: The Moral Bounds on Benevolence. Princeton, NJ: Princeton University Press.

Vera, Hernan and Andrew Gordon. 2003. Screen Saviors: Hollywood Fictions of Whiteness. Lanham, MD: Rowman \& Littlefield.

Weber, Max. 1922. Economy and Society: An Outline of Interpretive Sociology. Berkeley: University of California Press.

Weber, Robert P. 1990. Basic Content Analysis. Newbury Park, CA: Sage Publications. Weiner, Marli F. 1985. "The Intersection of Race and Gender: The Antebellum Plantation Mistress and Her Slaves.” Humboldt Journal of Social Relations 13(1):374-286. 
West, Cornel. 1993. Race Matters. Boston, MA: Beacon Press.

Wilson, Kerry B. 2013. "Selling the White Savior Narrative: The Help, Theatrical Previews, and US Movie Audiences." Pp. 22-41 in Mobilized Identities: Mediated Subjectivity and Cultural Crisis in the Neoliberal Era, edited by Cameron McCarthy. Champaign, IL: Common Ground Publishing.

Zhang, Yan, and Barbara M. Wildemuth. 2005. "Qualitative Analysis of Content." Analysis 1(2):1-12. 
APPENDIX A

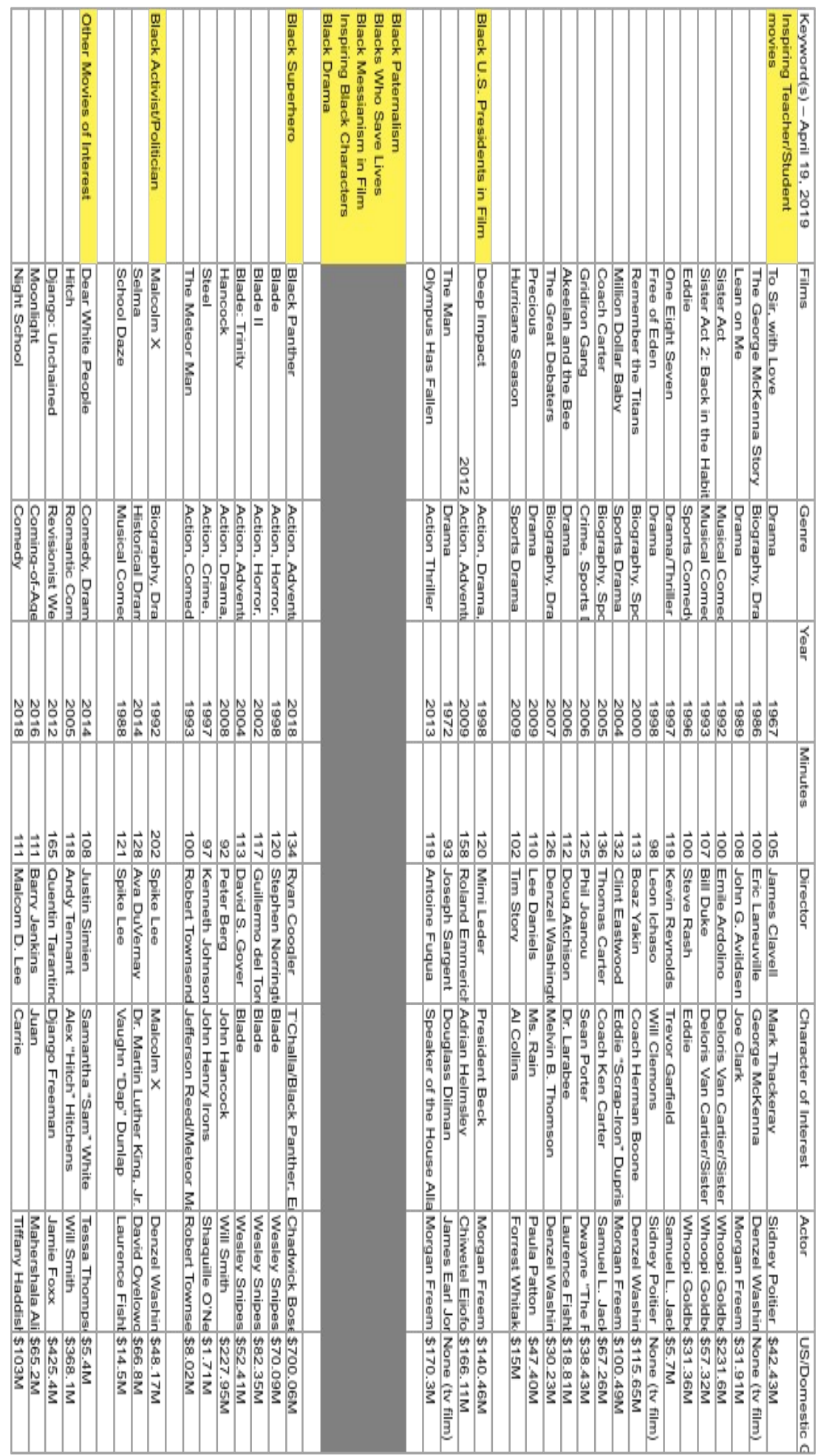




\section{APPENDIX B}

\begin{tabular}{|c|c|c|c|c|c|c|c|c|c|}
\hline Film & Year & Genre & Minutes & Director & Distributor & $\begin{array}{l}\text { Gender of } \\
\text { Lead }\end{array}$ & $\begin{array}{l}\text { U.S. Box } \\
\text { Office } \\
\text { Gross }\end{array}$ & $\begin{array}{l}\text { Savior } \\
\text { Occupation }\end{array}$ & Social Class \\
\hline Akeelah and the Bee & 2006 & Drama & 112 & Doug Atchison & Lionsgate & Male & $19 \mathrm{M}$ & Teacher & Working-middle class \\
\hline Big Momma's House 2 & 2006 & $\begin{array}{l}\text { Action/Crime/ } \\
\text { Comedy }\end{array}$ & 99 & $\begin{array}{l}\text { John } \\
\text { Whitesell }\end{array}$ & 20th Century Fox & Male/Female & $138.3 \mathrm{M}$ & $\begin{array}{l}\text { FBI } \\
\text { agent/grandmothe } \\
r\end{array}$ & Working class \\
\hline 2012 & 2009 & Disaster & 158 & $\begin{array}{l}\text { Roland } \\
\text { Emmerich }\end{array}$ & Columbia Pictures & Male & $769.7 \mathrm{M}$ & $\begin{array}{l}\text { President of the } \\
\text { United States }\end{array}$ & Upper class/elite class \\
\hline Black Dynamite & 2009 & Action Comedy & 84 & Scott Sanders & $\begin{array}{l}\text { Apparition; } \\
\text { Destination Films }\end{array}$ & Male & $\begin{array}{l}296,557 \\
\text { thousand }\end{array}$ & $\begin{array}{l}\text { War veteran/ CIA } \\
\text { officer }\end{array}$ & \\
\hline $\begin{array}{l}\text { Tyler Perry's Madea Goes } \\
\text { to Jail }\end{array}$ & 2009 & Comedy-Drama & 103 & Tyler Perry & Lionsgate & Female & $90.5 \mathrm{M}$ & Minister & Working class \\
\hline Precious & 2009 & Drama & 110 & Lee Daniels & Lionsgate & Female & $47.4 \mathrm{M}$ & School teacher & Working \\
\hline The Help & 2011 & Period Drama & 146 & Tate Taylor & $\begin{array}{l}\text { Walt Disney } \\
\text { Studios Motion } \\
\text { Pictures }\end{array}$ & Female & $216.6 \mathrm{M}$ & Maid & Poor-working class \\
\hline Django: Unchained & 2012 & $\begin{array}{l}\text { Drama/ } \\
\text { Blaxploitation/W } \\
\text { estern }\end{array}$ & 165 & $\begin{array}{l}\text { Quentin } \\
\text { Tarantino }\end{array}$ & $\begin{array}{l}\text { The Weinstein } \\
\text { Company }\end{array}$ & Male & $425.4 \mathrm{M}$ & Slave/Apprentice & Classless \\
\hline After Earth & 2013 & $\begin{array}{l}\text { Post- } \\
\text { Apocalyptic } \\
\text { Science Fiction }\end{array}$ & 100 & $\begin{array}{l}\text { M. Night } \\
\text { Shyamalan }\end{array}$ & Columbia Pictures & Male & $243.8 \mathrm{M}$ & General/Ranger & Upper class \\
\hline Dear White People & 2014 & Comedy-Drama & 108 & Justin Simien & $\begin{array}{l}\text { Lionsgate: } \\
\text { Roadside } \\
\text { Attractions }\end{array}$ & Female & $5.4 \mathrm{M}$ & $\begin{array}{l}\text { Student/Anti- } \\
\text { Racist Activist }\end{array}$ & Poor-working class \\
\hline The Equalizer & 2014 & $\begin{array}{l}\text { Vigilante Action } \\
\text { Thriller }\end{array}$ & 132 & $\begin{array}{l}\text { Antoine } \\
\text { Fuqua }\end{array}$ & Columbia Pictures & Male & 192.3M & Retired Marine & Working class \\
\hline Beasts of No Nation & 2015 & War Drama & 137 & $\begin{array}{l}\text { Cary Joji } \\
\text { Fukunaga }\end{array}$ & $\begin{array}{l}\text { Bleecker Street; } \\
\text { Netflix }\end{array}$ & Male & $\begin{array}{l}90,777 \\
\text { thousand }\end{array}$ & Rebel Leader & Low class \\
\hline Chi-Raq & 2015 & $\begin{array}{l}\text { Musical } \\
\text { Comedy-Drama }\end{array}$ & 127 & Spike Lee & $\begin{array}{l}\text { Roadside } \\
\text { Attractions }\end{array}$ & Female & $2.7 \mathrm{M}$ & Community leader & Poor \\
\hline Fences & 2016 & Period Drama & 139 & $\begin{array}{l}\text { Denzel } \\
\text { Washington }\end{array}$ & $\begin{array}{l}\text { Paramount } \\
\text { Pictures }\end{array}$ & $\begin{array}{l}\text { Male (Troy) } \\
\text { and Female } \\
\text { (Rose) }\end{array}$ & $64.4 \mathrm{M}$ & Parents & Middle-working class \\
\hline Roman J. Israel, Esq. & 2017 & Legal Drama & 122 & Dan Gilroy & Columbia Pictures & Male & $13 \mathrm{M}$ & Lawyer & Poor-working class \\
\hline Black Panther & 2018 & Fantasy/Sci Fi & 134 & Ryan Coogler & $\begin{array}{l}\text { Walt Disney } \\
\text { Studios Motion } \\
\text { Pictures }\end{array}$ & Male & 1.347 billion & King of Wakanda & Upper class/elite \\
\hline Night School & 2018 & Comedy & 111 & $\begin{array}{l}\text { Malcolm D. } \\
\text { Lee }\end{array}$ & Universal Pictures & Female & $103 \mathrm{M}$ & Teacher & Working class \\
\hline Proud Mary & 2018 & Action Thriller & 88 & Babak Najafi & $\begin{array}{l}\text { Sony Pictures } \\
\text { Releasing }\end{array}$ & Female & $21.8 \mathrm{M}$ & $\begin{array}{l}\text { Assassin/maternal } \\
\text { figure }\end{array}$ & Classless \\
\hline The Equalizer 2 & 2018 & $\begin{array}{l}\text { Vigilante Action } \\
\text { Thriller }\end{array}$ & 121 & $\begin{array}{l}\text { Antoine } \\
\text { Fuqua }\end{array}$ & $\begin{array}{l}\text { Sony Pictures } \\
\text { Releasing }\end{array}$ & Male & 190.4M & Retired marine & Working class \\
\hline The Hate U Give & 2018 & Drama & 133 & $\begin{array}{l}\text { George } \\
\text { Tillman Jr. }\end{array}$ & $\begin{array}{l}20^{\text {th }} \text { Century } \\
\text { Fox }\end{array}$ & Female & $34.9 \mathrm{M}$ & $\begin{array}{l}\text { High-school } \\
\text { Student }\end{array}$ & Classless \\
\hline
\end{tabular}




\section{APPENDIX C}

\begin{tabular}{|c|c|c|}
\hline \multirow[b]{2}{*}{ Dimension Observed } & \multicolumn{2}{|c|}{ Revolutionary Archetype } \\
\hline & Messiahs & Activists \\
\hline Key Elements of Each & $\begin{array}{l}\text { Work to save the world or entire } \\
\text { groups of (black) people at once, } \\
\text { usually through military/political } \\
\text { violence or terrorism. }\end{array}$ & $\begin{array}{l}\text { Work to bring awareness to racial } \\
\text { injustices. They tend to be non-violent } \\
\text { and engage in protest and/or marches to } \\
\text { bring about certain changes. }\end{array}$ \\
\hline $\begin{array}{c}\text { Hegemonic } \\
\text { Characteristics? }\end{array}$ & $\begin{array}{l}\text { Yes. Messiahs tend to be men who } \\
\text { are hegemonically masculine. }\end{array}$ & No. \\
\hline $\begin{array}{l}\text { What Problems are } \\
\text { Being "Solved"? }\end{array}$ & $\begin{array}{l}\text { Institutional or systemic racism } \\
\text { that oppresses black people. }\end{array}$ & $\begin{array}{l}\text { Institutional or systemic racism and/or } \\
\text { injustice that oppresses black people. }\end{array}$ \\
\hline $\begin{array}{l}\text { Is the Problem Being } \\
\text { Solved Individual; } \\
\text { Institutional; Systemic? }\end{array}$ & $\begin{array}{l}\text { Systemic and global. Racial } \\
\text { oppression in these films tends to } \\
\text { be perpetuated by governments. }\end{array}$ & $\begin{array}{l}\text { Institutional and/or systemic such as: } \\
\text { racism and patriarchy. }\end{array}$ \\
\hline Character Moti & $\begin{array}{l}\text { These men tend to have } \\
\text { experienced, and have seen others } \\
\text { experience, the effects of racism } \\
\text { and want to eliminate it. }\end{array}$ & $\begin{array}{l}\text { These characters tend to have } \\
\text { experienced, and have seen others } \\
\text { experience, the effects of racism and } \\
\text { want to eliminate it. }\end{array}$ \\
\hline $\begin{array}{c}\text { Consequences of } \\
\text { Revolutionary's Actions? }\end{array}$ & $\begin{array}{l}\text { Usually, the black diaspora is } \\
\text { "saved" or is at least "better off" } \\
\text { in some way. }\end{array}$ & $\begin{array}{c}\text { There is some massive social reform } \\
\text { passed to correct broad injustices OR, } \\
\text { people become much more aware of } \\
\text { injustices. }\end{array}$ \\
\hline $\begin{array}{l}\text { Associated Controlling } \\
\text { Images? }\end{array}$ & Violent/angry black male & $\begin{array}{c}\text { Angry black woman; “Bad black girl.” } \\
\text { None for male activists }\end{array}$ \\
\hline $\begin{array}{l}\text { Movies Associated with } \\
\text { each category }\end{array}$ & $\begin{array}{c}\text { Black Panther; Beasts of No } \\
\text { Nation; Black Dynamite } \\
\text { (Total: 3) }\end{array}$ & $\begin{array}{c}\text { Chi-Raq; The Hate U Give; Dear White } \\
\text { People; Roman J. Israel, Esq. } \\
\text { (Total:4) }\end{array}$ \\
\hline
\end{tabular}




\section{APPENDIX D}

\begin{tabular}{|c|c|c|}
\hline & \multicolumn{2}{|r|}{ Vigilante Archetype } \\
\hline Dimension Observed & Masculine Vigilantism & Vigilante Femininity \\
\hline Key Elements of Each & $\begin{array}{c}\text { Use extralegal violence to } \\
\text { rescue women and children. } \\
\text { Similar to black superheroes } \\
\text { who fight white men }\end{array}$ & $\begin{array}{l}\text { Use extralegal violence to rescue a child and herself. Violence is a way for female } \\
\text { vigilante to fight black men }\end{array}$ \\
\hline Hegemonic Characteristics? & $\begin{array}{l}\text { Yes. Hegemonic } \\
\text { masculinity }\end{array}$ & $\begin{array}{l}\text { No. However, femininity is combined with masculine traits (ex. Use of violence, } \\
\text { etc) }\end{array}$ \\
\hline What Problems are Being "Solved”? & $\begin{array}{c}\text { Vigilante males tend to fight } \\
\text { white male racism }\end{array}$ & The vigilante female character fights black men/ elements of patriarchy \\
\hline Character Motivation for Vigilantism & \begin{tabular}{|c} 
Revenge (for harming loved \\
ones/community) to restore \\
social order
\end{tabular} & Liberation/Freedom (from male control) so she can be a mother \\
\hline Consequences for Vigilante’s Actions? & $\begin{array}{c}\text { People/community is save } \\
\text { and vigilante treated like a } \\
\text { hero }\end{array}$ & Child is saved and vigilante moves forward with her life \\
\hline Associated Controlling Images? & Violent/angry black male & Angry black woman \\
\hline Movies Associated with each category & $\begin{array}{c}\text { Black Dynamite; Django: } \\
\text { Unchained; The Equalizer; } \\
\text { The Equalizer } 2 \\
\text { (Total: 3) }\end{array}$ & $\begin{array}{l}\text { Proud Mary } \\
\text { (Total: } 1)\end{array}$ \\
\hline
\end{tabular}




\section{APPENDIX E}

\begin{tabular}{|c|c|c|c|}
\hline \multirow[b]{2}{*}{ Dimension Observed } & \multicolumn{2}{|c|}{ Altruist Archetype } & \multirow[b]{2}{*}{ Mothers } \\
\hline & Teachers & Fathers & \\
\hline Key Elements of Each & $\begin{array}{l}\text { Use their wisdom to educate students who } \\
\text { are disadvantaged by inspiring them to } \\
\text { make better life choices. Reinforces } \\
\text { individualism and colorblind race ideology. }\end{array}$ & $\begin{array}{l}\text { Use their life experiences to } \\
\text { educate/advise their sons on how } \\
\text { to make better life choices by } \\
\text { reinforcing notions of } \\
\text { masculinity. Reinforces } \\
\text { individualism and colorblind race } \\
\text { ideology. }\end{array}$ & $\begin{array}{l}\text { Use their life experiences to educate/advise children, } \\
\text { young adults, families to make better choices in life. } \\
\text { Reinforces individualism and colorblind race ideology. }\end{array}$ \\
\hline Hegemonic Characteristics? & $\begin{array}{l}\text { Yes. Male teachers are mean, intimidating, } \\
\text { and aggressive; traits found primarily in } \\
\text { men in the media }\end{array}$ & $\begin{array}{l}\text { Yes. Fathers teach their sons to be } \\
\text { hegemonically masculine. }\end{array}$ & $\begin{array}{l}\text { Yes. Mothers tend to be "mammies" or "sapphires" who } \\
\text { teach others to make better choices (like teachers). }\end{array}$ \\
\hline What Problems are Being "Solved"? & $\begin{array}{l}\text { Student failures and their implied lack of } \\
\text { proper values. }\end{array}$ & $\begin{array}{c}\text { Sons want to achieve some goal } \\
\text { but they are not "man enough" to } \\
\text { do so. }\end{array}$ & $\begin{array}{l}\text { Families (typically white) are dysfunctional and need } \\
\text { guidance. }\end{array}$ \\
\hline $\begin{array}{l}\text { Is the Problem Being Solved Individual; } \\
\text { Institutional; Systemic? }\end{array}$ & $\begin{array}{c}\text { Individual - teachers teach students to } \\
\text { make better life choices }\end{array}$ & $\begin{array}{c}\text { Individual - fathers teach sons to } \\
\text { be more masculine }\end{array}$ & $\begin{array}{l}\text { Individual - mothers teach children, young adults, } \\
\text { families to make better life choices }\end{array}$ \\
\hline Character Motivation for Altruism? & $\begin{array}{l}\text { Teachers often see "potential" in their } \\
\text { students and/or pity them }\end{array}$ & $\begin{array}{l}\text { Fathers want to create the best } \\
\text { future for their children/subjects }\end{array}$ & $\begin{array}{l}\text { Mothers want to create the best future for their } \\
\text { children/subjects }\end{array}$ \\
\hline Consequences of Altruist's Actions? & $\begin{array}{l}\text { Student succeeds and becomes the person } \\
\text { they want to be and/or they integrate into } \\
\text { mainstream society }\end{array}$ & $\begin{array}{c}\text { Son becomes less emotional or } \\
\text { moves closer to masculinity to } \\
\text { become a better version of } \\
\text { him/herself }\end{array}$ & $\begin{array}{l}\text { Child, family, young adult becomes a better version of } \\
\text { him/herself that is more confident or resilient emotionally } \\
\text { and socially. }\end{array}$ \\
\hline Associated Controlling Images? & Violent/angry black male & Violent/angry black male & mammy or sapphire \\
\hline Movies Associated with each category & $\begin{array}{l}\text { Akeelah and the Bee; Precious; Night } \\
\text { School (Total: 3) }\end{array}$ & $\begin{array}{c}\text { After Earth; Fences } \\
\text { 2) }\end{array}$ & $\begin{array}{l}\text { Big Momma's House 2; The Help; Madea Goes to Jail } \\
\text { (Total: 3) }\end{array}$ \\
\hline
\end{tabular}




\section{CURRICULUM VITAE}

Eric Jordan

ADDRESS: University of Louisville

Department of Sociology

E-MAIL: eric.jordan@louisville.edu

103 Lutz Hall

PHONE: (502) 852-8045

Louisville, KY, 40292

\section{EDUCATION}

2020 University of Louisville, Louisville, KY, Race and Ethnicity, Applied Sociology, Ph.D.

Dissertation: "Exploring Black "Saviors": A Content Analysis of Black Characters and Racial Discourses in Obama-Era Films"

2016 University of Louisville, Louisville, KY, Race and Ethnicity, Sociology, M.A.

Thesis: "Reel Racism, Real Consequences: A Multiple Case Analysis of Savior Films as Racial Projects"

2014 University of Louisville, Louisville, KY, Psychological and Brain Sciences, B.A.

\section{RESEARCH}

\section{Publications}

Book Chapters

Jordan, Eric. Scheduled for 2021. "Gentrify This!" A Critical Analysis of Gentrification in Season 5 of Shameless" in, Shameless Sociology: Critical Perspectives on a Popular Television Series (University of West Georgia)

Jordan, Eric, Derrick Brooms. 2018. "Black and Blue: Analyzing and Queering Black Masculinity in Moonlight" in, Living Racism: Through the Barrel of a Book (Lexington Books)

Encyclopedia Entries

Jordan, Eric, Derrick Brooms. 2019. "White Savior Tropes (films)" in, The

Encyclopedia of Racism in American Cinema (Rowman \& Littlefield Publishers)

\section{TEACHING}

2017 - PresentGraduate Teaching Assistant, SOC 210 (Race in the U.S.), University of Louisville

Instructor: Dr. Melanie Gast

- Taught students to think critically about race and racism 
- Met with instructor to plan and discuss the course

- Facilitated discussions sessions where I lectured and discussed race and racism with students

- Planned discussion sessions

- Answered student emails

- Maintained student grades

- Held office hours and met students during that time

2014 - 2016 Graduate Teaching Assistant, SOC 210 (Intro to Sociology), University of Louisville

Instructor: Dr. Ryan Schroeder (Fall 2014 - Spring 2015)

Dr. Mark Austin (Fall 2015 - Spring 2016)

- Taught students the theories, methods, history, and concepts integral to Sociology

- Attended lecture with instructor

- Met with instructor to plan and discuss the course

- Facilitated discussions sessions where I lectured and discussed relevant class topics with students

- Planned discussion sessions

- Answered student emails

- Maintained student grades

- Held office hours and met students during that time

\section{RESEARCH AND TEACHING INTERESTS}

- Race and Ethnicity in the United States

- Race and Racism

- Race and the Media

- Social Theory

- Social Stratification

- Diversity and Inequalities

- Qualitative Methods

- Cultural Sociology

- Social Psychology

\section{PROFESSIONAL TRAINING}

Blackboard

- Learned how to maintain student records in this course management system

GTA Academy

- Learned how to teach effectively

- Learned to use a variety of teaching strategies to facilitate learning Inclusive Teaching Circle

- Learned how to discuss and understand race, racism, and racial domination in the classroom 